\title{
SPÄTGOTISCHE ÖFEN AUS ÖSTERREICH
}

\author{
MITTELALTERLICHE OFENKACHELN IN UNGARN IX.
}

Im Zuge der fortlaufenden Aufarbeitung der bei den Grabungen im Budaer Königspalast zum Vorschein gelangten Ofenkacheln kam 1983 das Material aus dem letzten Drittel des 15. Jahrhunderts an die Reihe. Bei dieser Gelegenheit ordnete ich auch die buntglasierten Kacheln erstklassiger Ausführung (mit gemischter Blei- und Zinnglasurtechnik) zu Gruppen. Eines der Ergebnisse dessen war, dass ich im Laufe der detaillierteren Untersuchung eine frühere Meinung revidierte ${ }^{1}$ (der zufolge das ganze Material auf unmittelbaren Einfluss der hier italische Majolika-Fußbodenfliesen herstellenden italienischen Meister entstand; ihre verschiedenen Kacheln die Phasen der lokalen Entwicklung auf immer höherer Stufe zeigen; die Meister ihre Tätigkeit nach 1490 in Österreich fortsetzten²). Aus meiner Sicht kann man mindestens drei bis vier separate Gruppen mit gemischter Glasierung absondern, deren Öfen verschiedenen Zeiträumen angehören, und von diesen ist nur einer als Ergebnis der lokalen Entwicklung zu betrachten. ${ }^{3}$ Die übrigen wurden von ausländischen Meistern verfertigt, und zwar mit großer Wahrscheinlichkeit nicht einmal hier, sondern - wie darauf auch die Bestimmung eines anderen Ofens vom Ende des Jahrhunderts hindeutete $^{4}$ - für den Budaer Palast aus dem Ausland geliefert.

Das mengenmäßig bedeutendste Fundmaterial sonderte ich nach dem Ankaufsort der Kacheln der ehemaligen Figdor-Sammlung unter dem Namen „Rauriser Gruppe“ ab (eine offene Frage ist, wo ihr Meister eigentlich tätig war: in Hallein oder Salzburg?), verbunden mit der Feststellung, dass diese Öfen schon entstanden, bevor der berühmte Salzburger Ofen in Auftrag gegeben wurde. Allerdings lieferte man von hier auch später noch Öfen in den Budaer Palast. ${ }^{5}$

\section{RAURISER GRUPPE (HALLEIN?, ERZBISTUM SALZBURG)}

Zur Absonderung dieser Gruppe (bzw. Öfen) von den übrigen bieten archäologische Angaben keine Möglichkeit. Überall gingen sie zusammen mit den anderen, im Zeitraum zweite Hälfte bis Ende 15. Jahrhundert gesetzten Öfen unter. Zu ihrer endgültigen Vernichtung kam es während der Türkenherr-

\footnotetext{
${ }^{1}$ HOLL 1983; I. Holl: Neutronenaktivierungsanalyse mittelalterlicher Ofenkacheln II. ActaArchHung 47 (1995) 291-293.

${ }^{2}$ P. VOIT: Hunyadi Mátyás budavári majolikagyártó múhelye [Die Majolikawerkstatt Matthias Hunyadis in der Budaer Burg]. BudRég 17 (1956) 83-150, mit Auszug in italienischer Sprache. Kurz: P. VorT-I. HolL: Alte ungarische Ofenkacheln. Budapest 1963, 27-61. - Irrtümlich war hier, das ganze Fundmaterial von Buda einer lokalen Werkstatt zuzuweisen. Das bunte Dach des Stephansdoms entstand nicht in Matthias' Auftrag, wie der Verfasser auf Grund einer irrtümlichen Angabe von Tietze vermutete, sondern früher. Die österreichischen buntglasierten Keramiken sind keine Arbeiten des weiterwandernden Budaer Meisters, sondern stammen aus verschiedenen dortigen Werkstätten. (Den
}

größten Teil seiner Meinung hat leider auch die österreichische Forschung übernommen.)

${ }^{3}$ I. HOLL: Neutronenaktivierungsanalyse mittelalterlicher Ofenkacheln I. ActaArchHung 46 (1994) Abb. 2-3. (König Matthias darstellende Kacheln und andere Fragmente.) Diese werde ich in einer in Vorbereitung befindlichen Studie behandeln.

${ }^{4}$ I. Holl: Regensburgi késő középkori kályhacsempék (Spätmittelalterliche Kachelöfen aus Regensburg in Ungarn). ArchÉrt 107 (1980) 20-43. Zwischen 1487 und 1490, Geschenk des Pfalz-grafen Rupert II., Koadjutor (in den Palästen Buda, Visegrád, Tata).

${ }^{5}$ Holl 1983, 225. 
schaft, in der zweiten Hälfte des 16. Jahrhunderts; beim Hinaustragen von Abfällen oder bei Planierungen wurden sie in wahllosem Durcheinander über das ganze Palastgelände verstreut. Einige Stücke (bezeichnenderweise gerade die größeren Fragmente) gelangten in die Abfallgruben des Palastes; diese dürften im Zeitraum eines der Ereignisse zwischen 1526 und 1544 beschädigt worden sein. ${ }^{6}$

Eine Stütze zur Bestimmung der einzelnen Stücke der Gruppe sind ihre herstellungstechnischen und Stilmerkmale. Bei einem Teil der Kacheln ist das die Behandlung des Hintergrundes der plastischen Verzierung: Mit einem fünfzinkigen Kammwerkzeug eingeritzte geschwungene Linien, womit man offenbar die Lösung des ein Brokatmuster zeigenden Goldhintergrundes der gotischen Tafelbilder imitierte. ${ }^{7}$ Den Rand eines Teils der Kacheln bildet eine Reihe von stilisierten Blättern, die sich um einen Ast ranken (bei den buntglasierten Exemplaren Grün auf gelbem Grund oder Gelb auf grünem Grund); von dieser Blattverzierung gibt es verschiedene Detaillösungen (Abb. 18-19). - Im Falle vieler Kacheln kann man die Behandlung der plastischen Oberfläche (Wappen, Blume, Gewand) mit winzigen eingedrückten Kreisen beobachten $(A b b$. 1-6, 10-11). - Was ihren Stil anbelangt: Häufig sind die bewegte Einstellung der Gestalten oder auch das Gegenteil, deren steife Frontalansicht; oberflächlich gearbeitete, aber ausdrucksvolle Gesichter; Hände schematischer Plastik; der tiefe, eckig kannelierte Faltenwurf des Gewandes (und der Stiefel).

Ihre technologischen Merkmale: Aus sehr gut geschlämmtem Material gebrannte, gelbe bzw. gelblichweiße Scherbe; ihren Magerungsstoff kann man mit bloßem Auge nicht erkennen (in selteneren Fällen sehr wenig Quarzkiesel). Gleichzeitig haben die Kacheln (bei der 2. Untergruppe) einen angeklebten Rumpf aus bräunlichrot gebrannter Scherbe. Der stark plastische, blattverzierte Rahmen wurde gesondert auf das verzierte Kachelblatt geklebt, was die räumliche Wirkung der sich flach wölbenden, vertieften Kachel verstärkt. Die Farben der verwendeten Glasur: Goldgelb, Ockergelb oder ein lebhaftes Grün (der Hintergrund); an den plastischen Details gelbe, braune, dunkelbraune, schwarze, grüne Bleiglasur; weiße, blassblaue, lilablaue Zinnglasur (Gesicht, Hände: weiß). Neben den buntglasierten Kacheln entstanden aber auch sehr viele einfarbig grünglasierte Kacheln (Abb. 5, 8-11, 23-24). Im Falle eines kleineren Teils ist nachweisbar, dass es davon eine buntglasierte Variante gab (wappentragender Ritter, reitendes Paar, Lebensbaum usw.). - Die Form der Kacheln: reliefierte Nischenkachel, Blattkachel mit rückseitigem Halbzylinder, Blattkachel mit Rumpf (auf der Scheibe gedreht, Mündung rund). Diese Kachelformen erscheinen in der zweiten Hälfte des 15. Jahrhunderts (mit Ausnahme der letzten Form, die eine alte Lösung darstellt) und verdrängen die seit einhundert Jahren allgemein gebräuchlichen Lösungen, um den Öfen eine stärkere räumliche Wirkung zu verleihen. (Interessanterweise übernehmen ihre Rolle vom Anfang des 16. Jahrhunderts an erneut die flachen Blattkacheln, vielleicht um die Herstellung zu vereinfachen.) - Für ebenfalls charakteristisch halte ich im Falle unserer Gruppe, dass man im Gegensatz zu den älteren Öfen oftmals größere Ofenkacheln als früher anfertigte. Das fällt hauptsächlich bei den zum Oberbau des Ofenkörpers gehörenden Stücken auf ( $30 \times 40 \mathrm{~cm}$ : Buda; $30 \times 45 \mathrm{~cm}$ : Figdor-Sammlung, Rauris), aber auch im Falle des unteren Körpers ist das größere Format häufig (H: $28 \mathrm{~cm}$, Buda; $29 \mathrm{~cm}$, Esztergom), obwohl man hier auch kleinere verwendete (H: $25 \mathrm{~cm}$, Buda). Diese Abweichung ist vielleicht damit zu erklären, dass sie für Öfen mit massigerem und vor allem breiteren Körper hergestellt wurden, die auch in größeren Sälen ausreichend Wärme spenden konnten. ${ }^{8}$

Im Weiteren möchte ich versuchen, unsere Funde nach Untergruppen getrennt zu besprechen, um ihren Zusammenhang (identischer Ofen?) besser herauszustellen (im Falle der stark fragmentierten Stücke konnte das leider nicht immer gelingen).

\footnotetext{
${ }^{6}$ Ostfassade, Grube I; Grabung des Jahres 1948, z. B. die hier gezeigten Stücke: Abb. 1-2, 17, 21, 38-39, 45. - Auf eine vielleicht um 1500 erfolgte Beschädigung deuten zwei in der unteren Abfallschicht des Felsgrabens gefundene Fragmente hin: Abb. 34 und 46.

${ }^{7}$ Ein solcher Hintergrund in viel genauerer Ausführung, plastisch und mit blauweißer Farbe, ist schon am "Schweizer"
}

Ofen zu sehen, wird aber später auch an einem norddeutschen Ofen verwendet: Holl 1983, 12 und Abb. 46-47. (Der erste dürfte 1469/73, der zweite um 1470/80 entstanden sein.)

${ }^{8} \mathrm{Im}$ Falle der älteren Öfen konnte der Umfang nur vergrößert werden, indem man viele Kacheln nebeneinander setzte, was ihren Aufbau erschwerte. 


\section{Untergruppe}

1. David und Goliath. Polychrom glasierte Kachel mit Halbzylinder. Der goldgelbe Hintergrund mit eingeritztem Kammstrichmuster. Auf der rechten Seite David mit der Schleuder, in grasgrünem Gewand, am lilabraunen Aufschlag ein Saum, Haar und Krone gelb. Goliath in weißer Rüstung und bräunlichschwarzen Stiefeln mit Faltenwurf. Der Schwertknauf blauer, die Augen bläulichgrüner Farbe. Ein typischer Kunstgriff sind die winzigen eingedrückten Kreise, die einzelne Details (den Aufschlag von Davids Gewand, Goliaths Oberschenkel und seinen - das Bein verbergenden - grünen Schild) bedecken. Im breiten, gekehlten Rahmen winden sich, von rechts nach links oben, stilisierte Akanthusblätter um einen Stab. Eine Ecke der Kachel wurde schräg abgeschnitten, der hierher applizierte Teil (Wappen?) brach ab. Die Ecke ziert ein aus zwei Schnurbändern gedrehter, weißlila- und grünfarbiger Stab (Abb. 1). Rekonstruierte Abmessung: ca. $30 \times 30 \mathrm{~cm}$.

2. Wilder Mann. Fragment des an die Ecke des vorherigen Stückes angepassten Exemplars. Auf gelbem, geritzt gemustertem Grund die Gestalt eines wilden Mannes mit behaartem Körper (blassblau), nach rechts schreitend. In seiner linken Hand ein grüner Schild, wie bei Goliath. Auch hier hat man die gepunzte Oberflächenverzierung verwendet. Maße: $18 \times 19,5 \mathrm{~cm}$ (Abb. 2). Die Kacheln waren in der obersten Reihe des unteren Ofenkörpers, an einer der äußeren Ecken, platziert.

3. Gestalt in Rüstung. Fragmente einer buntglasierten Kachel in Halbzylinderausführung. Vor dem bräunlichgelben, geritzten Hintergrund Gestalt in voller Rüstung, die Beine gespreizt. Seine rechte, in einem Panzerhandschuh steckende Hand umfasst den Schwertgriff. Mit der linken Hand hielt er wahrscheinlich den am rechten Kachelrand sichtbaren Wappenschild (das Fragment ist vermutlich ein Stück des österreichischen Bindeschildes: weißer Balken in braunem Feld). Die Rüstung ist weiß, das Schwert schokoladebraun. Auch hier ziert den Rand eine grüne, gewundene Blattranke. Die Kachel war mindestens $28-30 \mathrm{~cm}$ breit (mit der folgenden übereinstimmend) ( $A b b .3-4)$.

4. Gestalt in Rüstung, mit Adlerwappen in der linken Hand. Auch dies eine flache Halbzylinderkachel; grasgrüne Glasur. Nach links schreitende Gestalt, von der Hüfte aufwärts dem Betrachter zugewandt. Armschiene und Kniekachel der Rüstung sind im Vergleich zur vorigen abweichend; vielleicht soll das Punzmuster eine andere Materialart (Leder?) andeuten. Auch das Achselstück zeigt eine von den spätgotischen Harnischen abweichende Lösung. Die fehlende rechte Hand hält das Schwert, die linke den Wappenschild mit doppelköpfigem Adler. Die Blattverzierung am Rahmen wurde anders ausgearbeitet als bei den vorigen Stücken; hier bedecken eingestoßene Punkte die kleineren Blätter. Am oberen Abschluss der Kachel befand sich ein Spruchband, doch infolge der stark fragmentierten Zustandes ist die Reihenfolge der Minuskelbuchstaben ungewiss: $m l . . . e r s t . . . m s d . . . a c i e$ (zum Vorschein kamen Bruchstücke von zwei Exemplaren. B: $30 \mathrm{~cm}$, Höhe des Fragments: $39,5 \mathrm{~cm} ; A b b .5)$.

5. Quadratische Kachel mit flachem Vorderblatt; verziert mit verschlungenen Ranken, die in Blattköpfen enden. Schmuck der beiden symmetrisch anschließenden, gewundenen Ranken sind stilisierte Blätter und zwei Gesichtsblätter. Mit gelber, grüner und blauer Glasur. H: 24,5 cm (Abb. 6) - Der Lebensbaum oder sprechende Baum des Paradieses ging als Überlieferung der orientalischen Literatur in die Literatur und Darstellungen ${ }^{9}$ des Westens ein. Es handelt sich also nicht einfach um Dekoration, sondern um ein symbolisches Bild. - Derselbe Typ kommt fragmentiert auch als grünglasierte Halbzylinderkachel vor, deren Rand gedrehte Blattverzierung schmückt. In der Burg zu Tata fand man ein dieser ähnelndes Exemplar, dessen Ecke schräg abgeschnitten war (das Wappen fehlt jedoch). ${ }^{10}$ - Die Kopie der Kachel ist aus Österreich als unglasiertes, mit Graphit überzogenes Exemplar bekannt ${ }^{11}(A b b .7)$.

9 J. BAltrusaitis: Le Moyen Age Fantastique. Paris 1955, 118-127. - Ein frühes Beispiel: Hortus Deliciarum, Paradiesbaum auf der Zeichnung von Evas Schöpfung. RDK Bd. 1, Stuttgart. 1937, 133, Abb. 7. - Doch hier ergänzt der Baum die Paradiesszene nur, während er in dem Buch von Jean de Mandeville: Livre des Merveilles als indischer Baum - s. die Holzschnittillustration von 1499 - schon mit stilisierter Komposition vorkommt.
${ }^{10} \mathrm{~S}$. B. SZATMÁRI: Elôzzetes jelentés a tatai vár ásatásáról (Vorläufige Mitteilung über die Ausgrabungen in der Burg von Tata). ArchÉrt 101 (1974) 50, Abb. 8 (nach der Belagerung des Jahres 1529 erfolgte Verfüllung). H: $30,7 \mathrm{~cm}$.

11 WALCHER 1909, Abb. 77, Höhe: $20 \mathrm{~cm}$. 


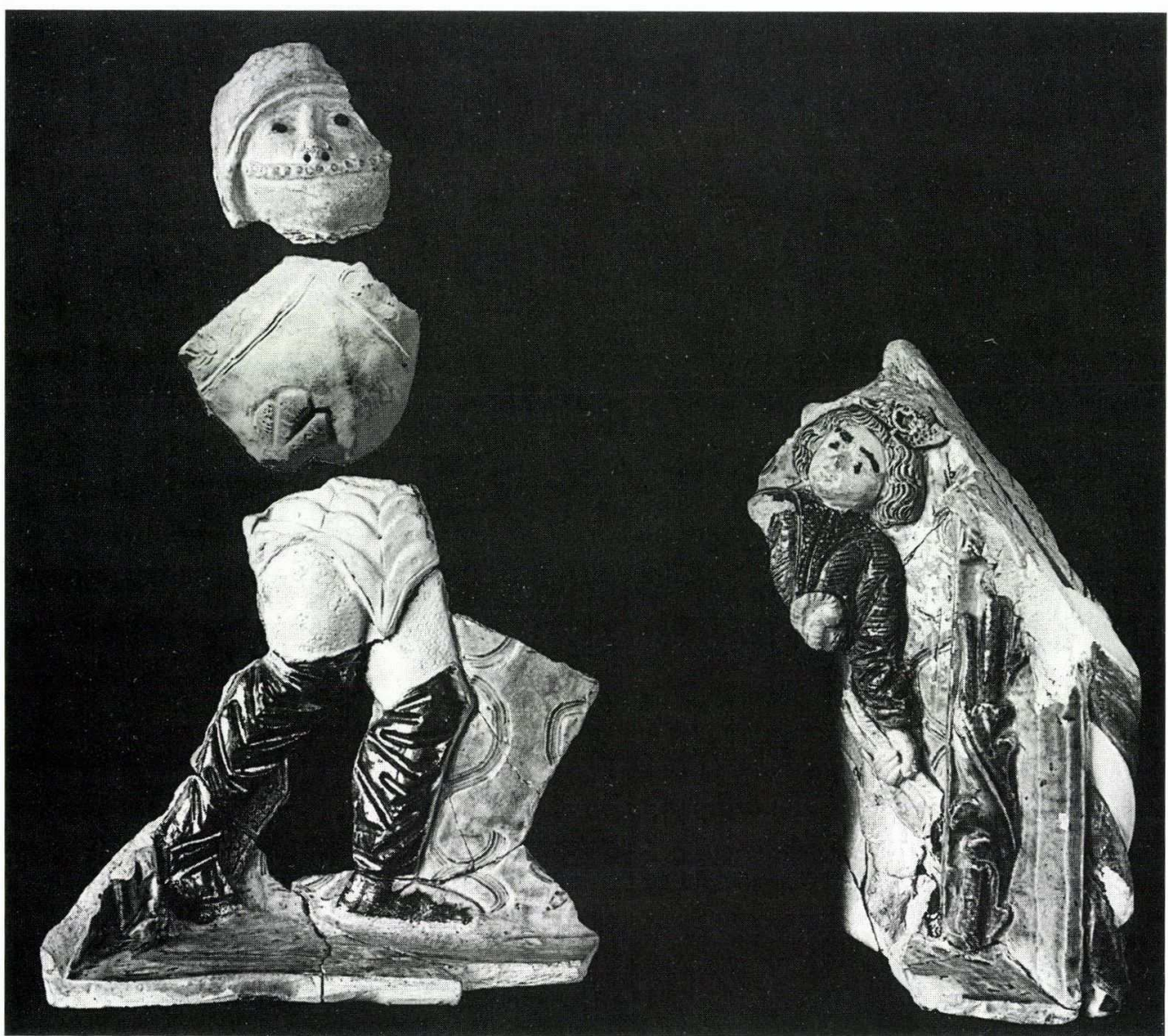

Abb. 1. David und Goliath, buntglasiert (Buda, königl. Palast)

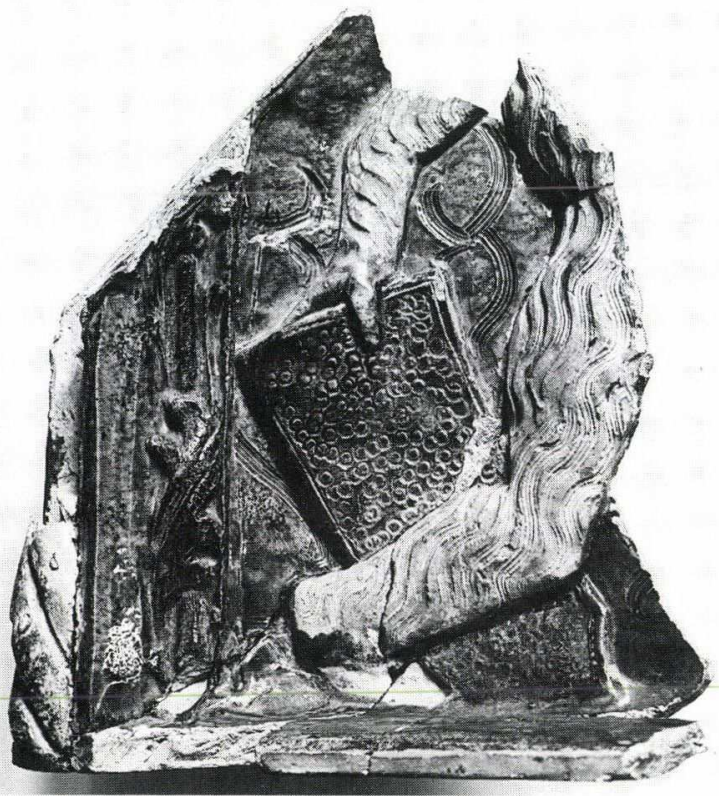

Abb. 2. Wilder Mann, andere Seite der auf Abb. 1 abgebildeten Eckkachel 
Die letzteren Kacheln bezeugen, dass man unter Verwendung von identischen Negativen auch Kacheln mit abweichender Form und Rahmung hergestellt hat; vermutlich begründete das ihre unterschiedliche Platzierung. In der oberen Reihe des unteren Ofenkörpers reihten sich die Halbzylinderkacheln mit reicher Rahmenverzierung aneinander, darunter kamen etwas kleinere Exemplare mit flachem Blatt und einfachem, gekehltem Rand. (Wie dazu schon früher ausgeführt, wurden einzelne leichter nachzufertigende Kacheltypen auch von anderen Werkstätten kopiert. ${ }^{12}$ )

6. Aristoteles und Phyllis. Flache Kachel mit rückseitigem Zylinder. Ihr Originalmotiv ist nur auf der in Rauris erworbenen (nach Walcher von der auch die Umgebung Halleins beherrschenden Töpferzunft hergestellten) Kachel der ehemaligen Sammlung Figdor zu sehen $(A b b .8) .{ }^{13}$ Von der auf dem Rücken des knienden, bärtigen Mannes sitzenden Frau blieben nur Bruchstücke erhalten. Grün glasiert; hart gebrannte, weiße Scherbe. Das Gewand bedecken auch hier winzige Kreise (Abb. 10).

7. Samson und Delila. Grünglasierte Kachel, von der ebenfalls nur Fragmente erhalten sind (von zwei Exemplaren jeweils die obere bzw. untere Gestalt; $A b b$. 11). Hinter dem sitzenden Samson erkennt man die eine Schere haltende Hand Delilas, den Saum ihres pelzbesetzten Gewandärmels und das um ihren Hals geschlungene Tuch. Die Komposition mag, ebenso wie bei der vorigen Kachel, auf ein uns unbekanntes Vorbild (Stich, Holzschnitt) zurückgehen ( $A b b .11)$.

Beide Kacheln dürften Teile einer größeren Serie sein. Sie sind bildliche Darstellungen der Macht der Liebe bzw. der Weiberlist (die übrigen: David, Geschichten Salamons, Vergilius), die auch in die mittelalterlichen Fastnachtsspiele eingingen und allgemein bekannt waren.

8. Zu einer Eckkachel gehörende Halbkachel. In einem glatten, gekehlten Rahmen Fragmente eines Ritters in Rüstung. Dieselbe frontale Darstellungsweise wie auf der großen Kachel Typ 3. Dieser trägt jedoch eine Lanze (oder Fahne) in seiner rechten Hand und in der linken Hand hält er das Schwert. Der Hintergrund hellgrün, die Rüstung blassblau, das darunter hervorschauende Kettenhemd, die Kniekacheln sowie die Handschuhe gelb, das Schwert schwarz und die Lanze lilafarben glasiert. Ihre Maße sind nicht bekannt, vielleicht gehörte sie zu einer $24 \mathrm{~cm}$ hohen Kachel. In der rechten Ecke imitierte Schnurverzierung (Abb. 12).

9. Fragment des Paarstückes der vorigen Eckkachel, hier aber die Schnurverzierung am linken Rand. Lilafarbig, geritzter Hintergrund. - Vermutlich ein Fragment dieser Kachel ist eine (vor ebensolchem Hintergrund) stehende nackte Frau, die mit ihren Händen auf den Schultern einen vor ihrem Körper herabhängenden grünen Schal hält ( $A b b .13)$. Die Haltung der Frauengestalt folgt dem in der Kunst der zweiten Hälfte des 15. Jahrhunderts bei profanen und sakralen Darstellungen angewandten Schema.

10. Sein Geschlechtsteil zeigender Mann. Fragment einer zylindrisch gestalteten Kachel. Vor grünem Hintergrund Detail einer mit weißer Glasur überzogenen, sehr plastisch geformten Gestalt: linkes Bein, mit der rechten Hand hebt er den unteren Teil des gelben Gewandes hoch. Der Gewandsaum trägt ein Muster aus kleinen eingestempelten Kreisen. (Die auf der Rückseite sichtbaren Reste von roter angeklebter Scherbe deuten darauf hin, dass es sich um ein auf eine andere Kachel appliziertes Eckstück handeln dürfte.) H: $17 \mathrm{~cm}$. Vielleicht war es das in der Reihe der $31 \mathrm{~cm}$ hohen Kacheln die quadratische 6.-7. Nummern ausfüllende Eckteil. - Die Anwendung von Gestalten solcher Auffassung in der Darstellung hat nach meiner Meinung mit ihrer Rolle als „Abwehrzauber" (wie bei den Beispielen der romanischen Plastik in Kirchen) zu tun (Abb. 14).

11. Musikant mit Fidel. Horizontale Fußgesimskachel. Auf dem Erdboden liegende Gestalt mit angewinkeltem Knie in einem grünen Gewand mit (innen hellilafarbiger) Kapuze. Das Instrument braun, Gesicht und Beine weiß, Haar und Stiefel schwarz, der Hintergrund grünlichgelb glasiert. Länge 30,5 cm; oben und unten durch ein dickes (grünes) Stabglied abgeschlossen; beide Enden randlos, gerade abgeschnitten. Der starke plastische Eindruck resultiert aus ihrer Lage: Vermutlich bildete sie (wie auch bei dem Ochsenfurter Ofen) zusammen mit anderen Darstellungen in einer Reihe das untere Ofengesims (Abb. 17).

${ }^{12}$ I. HoLl: Középkori kályhacsempék Magyarországon [Mittelalterliche Ofenkacheln in Ungarn] VI. BudRég 33 (1998) 292-297, Abb. 6:3-4, Abb. 7-8.
${ }^{13}$ WALCHER 1909, Abb. 94, Höhe: $31 \mathrm{~cm}$. 


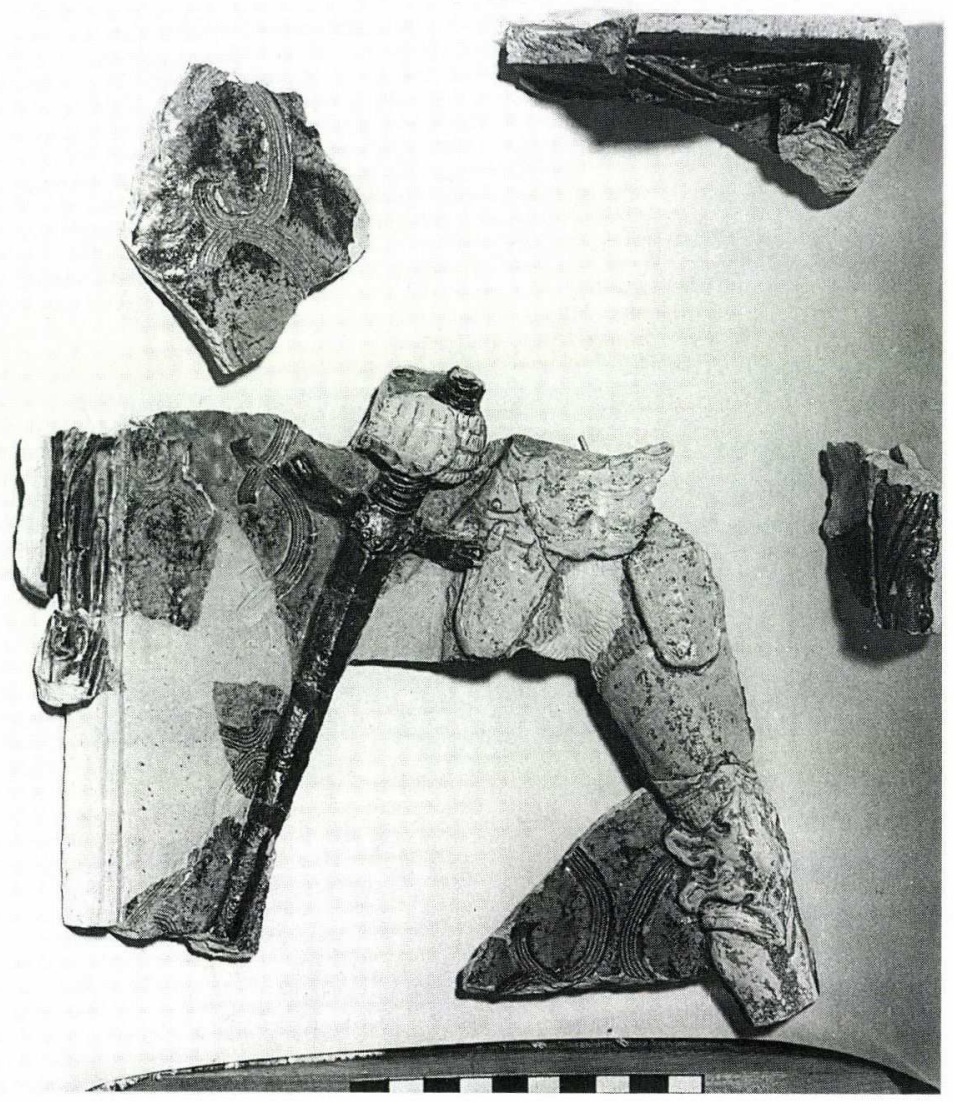

Abb. 3. Gestalt in Rüstung mit österreichischem Wappen (Buda, königl. Palast)

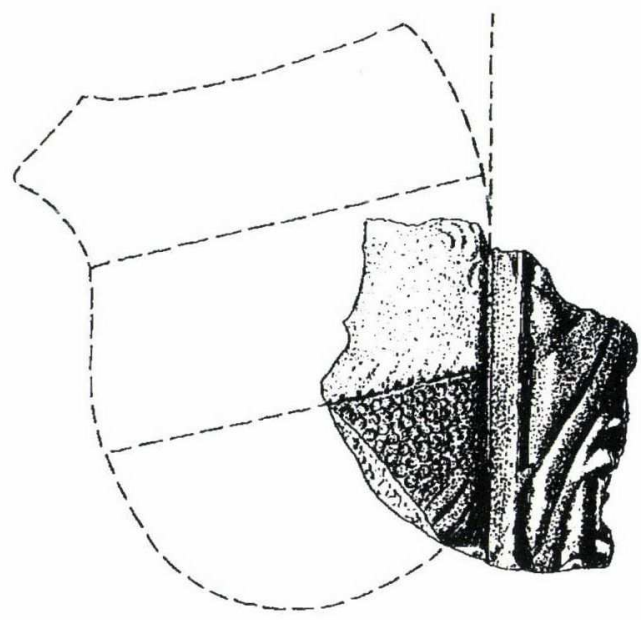

Abb. 4. Das österreichische Wappen, Fragment 

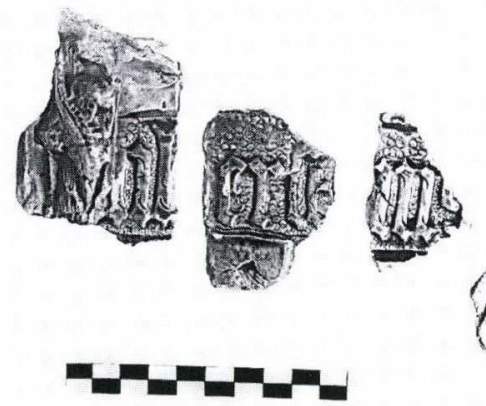
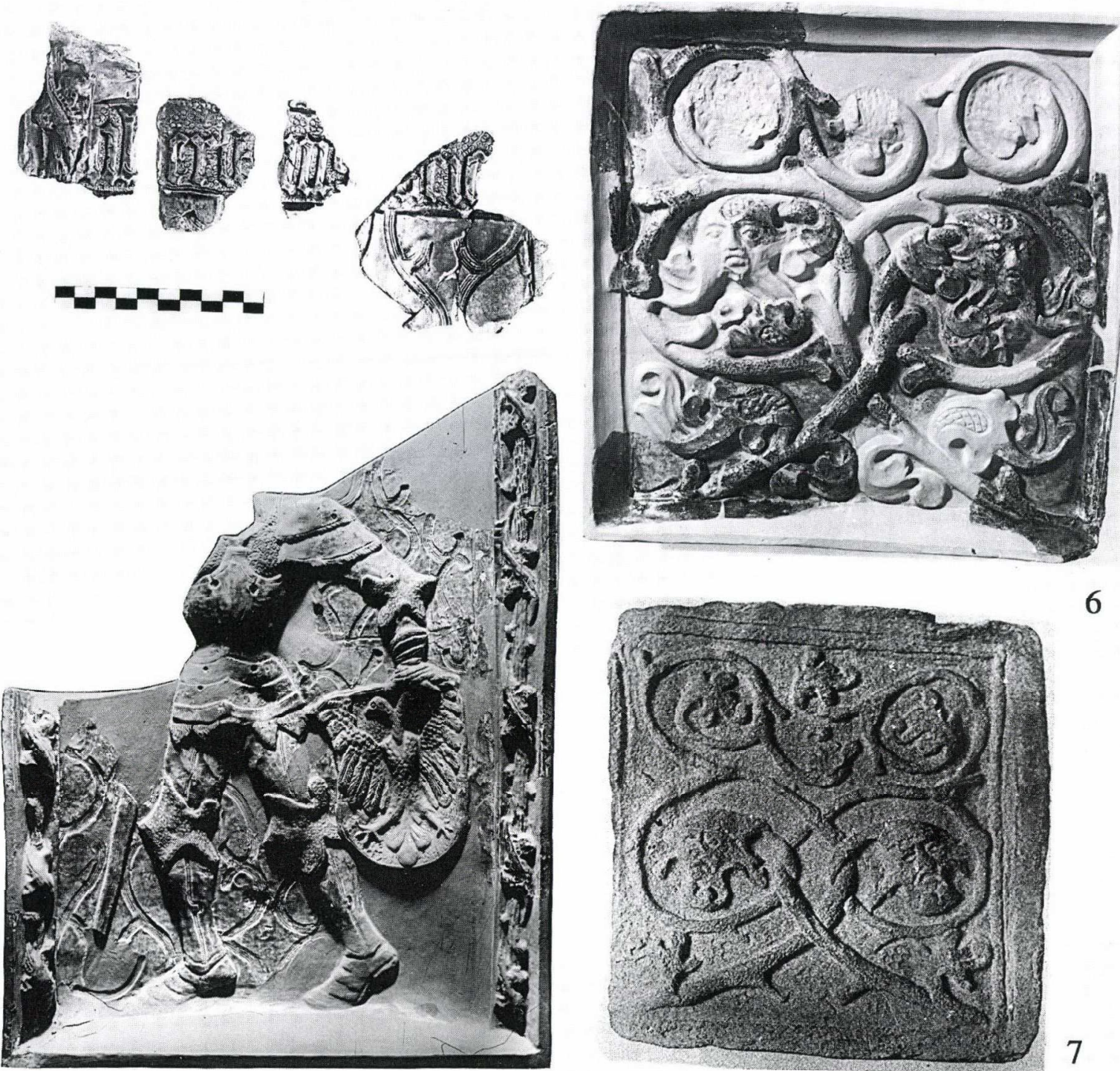

5

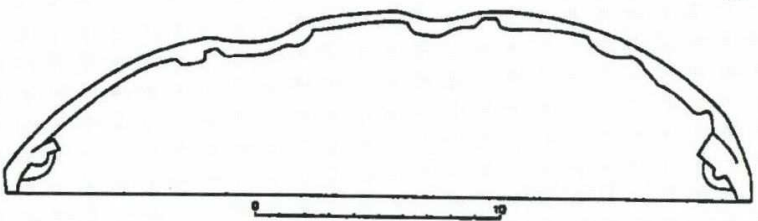

Abb. 5. Geharnischte Gestalt - Julius Caesar?, grünglasiert (Buda, königl. Palast) Abb. 6. Rankenverzierte Kachel - der Paradiesbaum, buntglasiert (Buda, königl. Palast) Abb. 7. Unglasierte Kopie der vorangehenden Kachel (Österreich) 

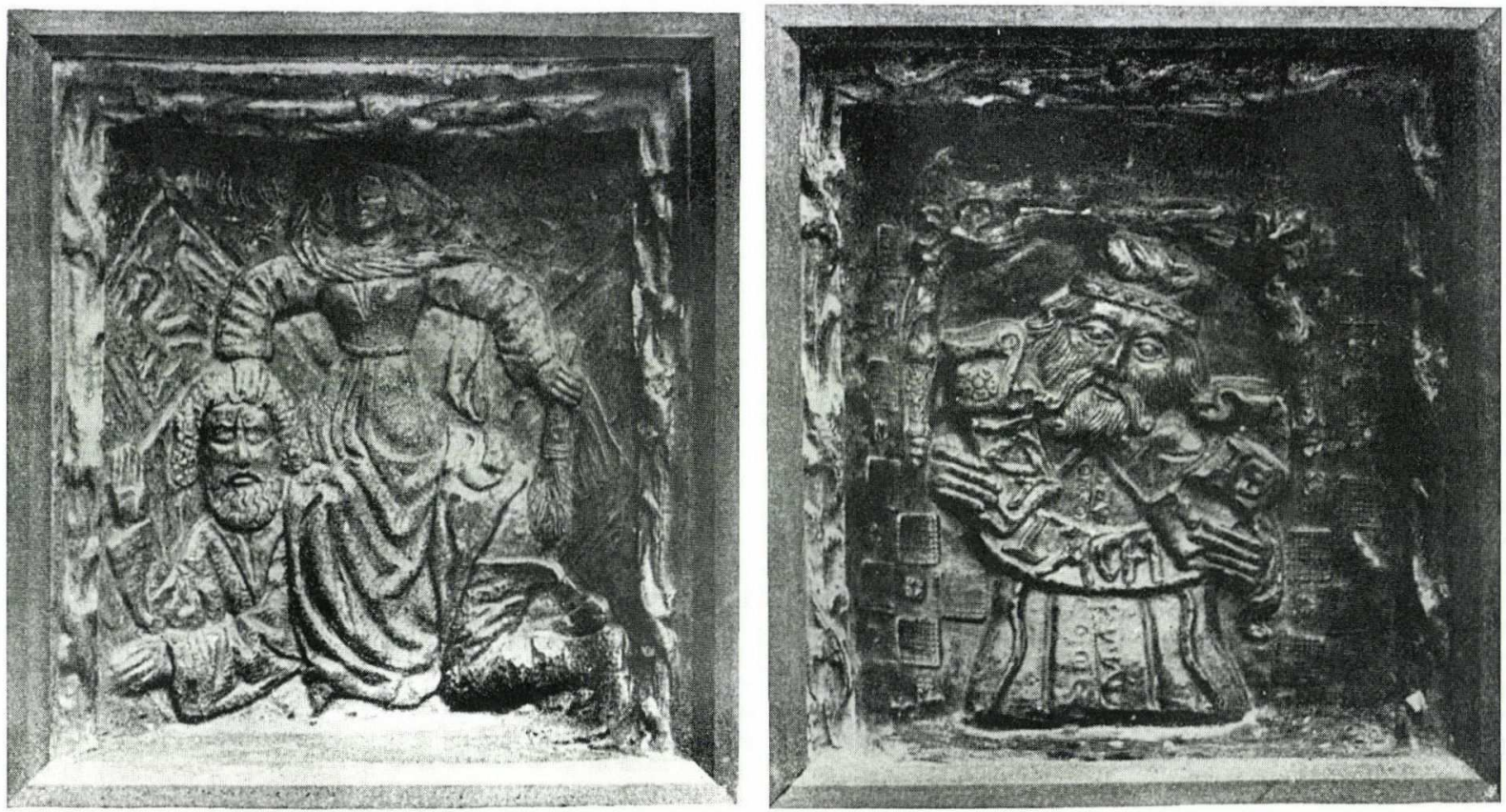

Abb. 8-9. Aristoteles und Phyllis - Malachias, in Rauris erworbene Ofenkacheln, grünglasiert (Österr. Museum f. Angewandte Kunst, Wien)

12. Flötenbläser. Von der Kachel wurde nur ein Fragment gefunden. Die Dicke der Scherbe gestattet jedoch den Schluss, dass es, ähnlich wie die Vorangehende, eine Gesimskachel war. Detail einer ein grünes Gewand mit starkem Faltenwurf tragenden Gestalt, die auf einem mit den Händen gehaltenen (gelbglasierten) Blasinstrument spielt. Maße: $8 \times 6,4 \mathrm{~cm}(A b b .15)$.

Auf weitere Gesimskacheln deutet ein Fragment hin, an dem das Detail eines rechten Arms mit blassblauem Kleiderärmel erhalten blieb; hier ist der obere Stababschluss gelbglasiert ( $A b b .15)$. - Eine ähnliche Lösung für das untere Ofengesims wandte man um 1500 auch bei dem bekannten Ochsenfurter Ofen an (Germanisches Nationalmuseum, Nürnberg). Dort sind liegende Landsknechte abgebildet, mit einer ähnlich überkreuzten Beinhaltung wie im Falle des Fiedlers von Buda.

Während bei den oben vorgestellten Kacheln vermutet werden darf, dass der die Originalmatrize anfertigende Meister zu seinen Kompositionen verschiedene bekannte Vorbilder verwendet hat (indes die Oberflächenausarbeitung der Details sein eigener Geschmack beeinflusste, wodurch die ganze Serie einheitlicher wirkte), stellt das folgende Stück bereits eine Einzelschöpfung dar. Von dieser ganz neuartigen Lösung ist nur eine einzige Parallele bekannt. (In beiden Fällen handelt es sich nicht um vervielfältigte Kacheln, sondern um einzeln angefertigte Tonplastiken.)

13. Bruchstück vom Kopf einer Eckfigur. Auf die Skulptur, die ehemals (ebenso wie am Salzburger Ofen) im unteren Teil des Ofens an der rückseitigen Ecke stand, deutet lediglich ein größeres Gesichtsfragment hin. Handgeformt; Gesicht grünlich weiß, Bart schwarz, Augen und Lider blau bemalt, Mütze (?) hellgrün. H: $14 \mathrm{~cm}, \mathrm{D}:$ 1,3-2,5 cm (Abb. 16). (Man fand es 1951 in der um 1579 verfüllten Abfallschicht zusammen mit anderen Funden vom Ende des 15. Jahrhunderts.)

Neben den beschriebenen Kacheltypen lassen sich dieser charakteristischen Untergruppe noch zahlreiche Fragmente zuweisen. Von den meisten kann man heute leider nicht mehr feststellen, Details welcher Darstellung oder Dekoration sie waren. Nur einige wenige sind als andersfarbige Variationen schon bekannter Kacheln erkennbar, was darauf aufmerksam macht, dass man selbst im Falle identischer Motive auch auf diese Weise nach Mannigfaltigkeit strebte. So gab es zum Beispiel auch von der Kachel mit David und Goliath andere, aber mit grünem Hintergrund $(A b b .18)$. Oder von der Kachel mit der das 

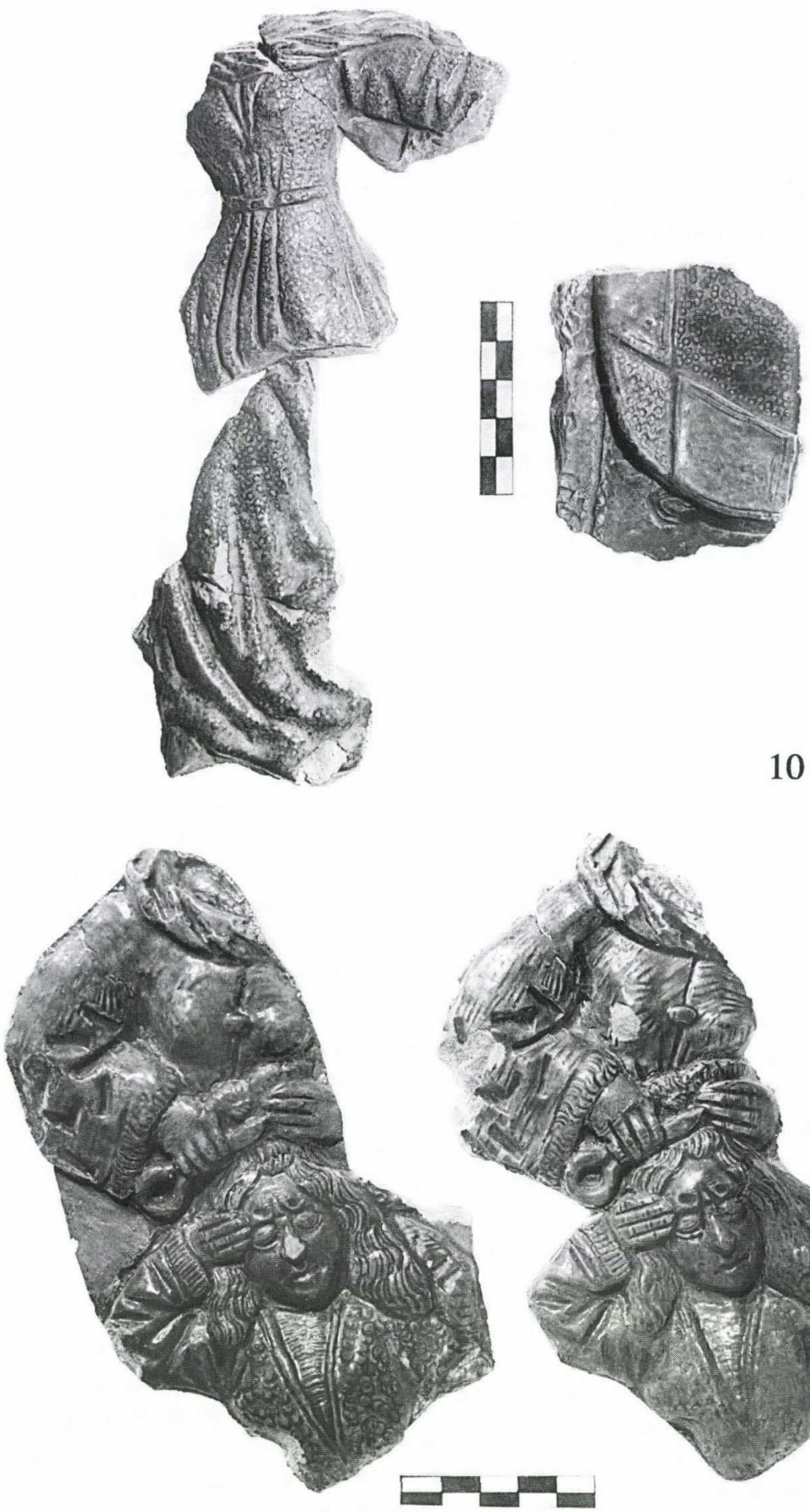

Abb. 10-11. Aristoteles und Phyllis, bairisches Wappen - Samson und Delila, grünglasierte Fragmente aus dem Burgpalast Buda 


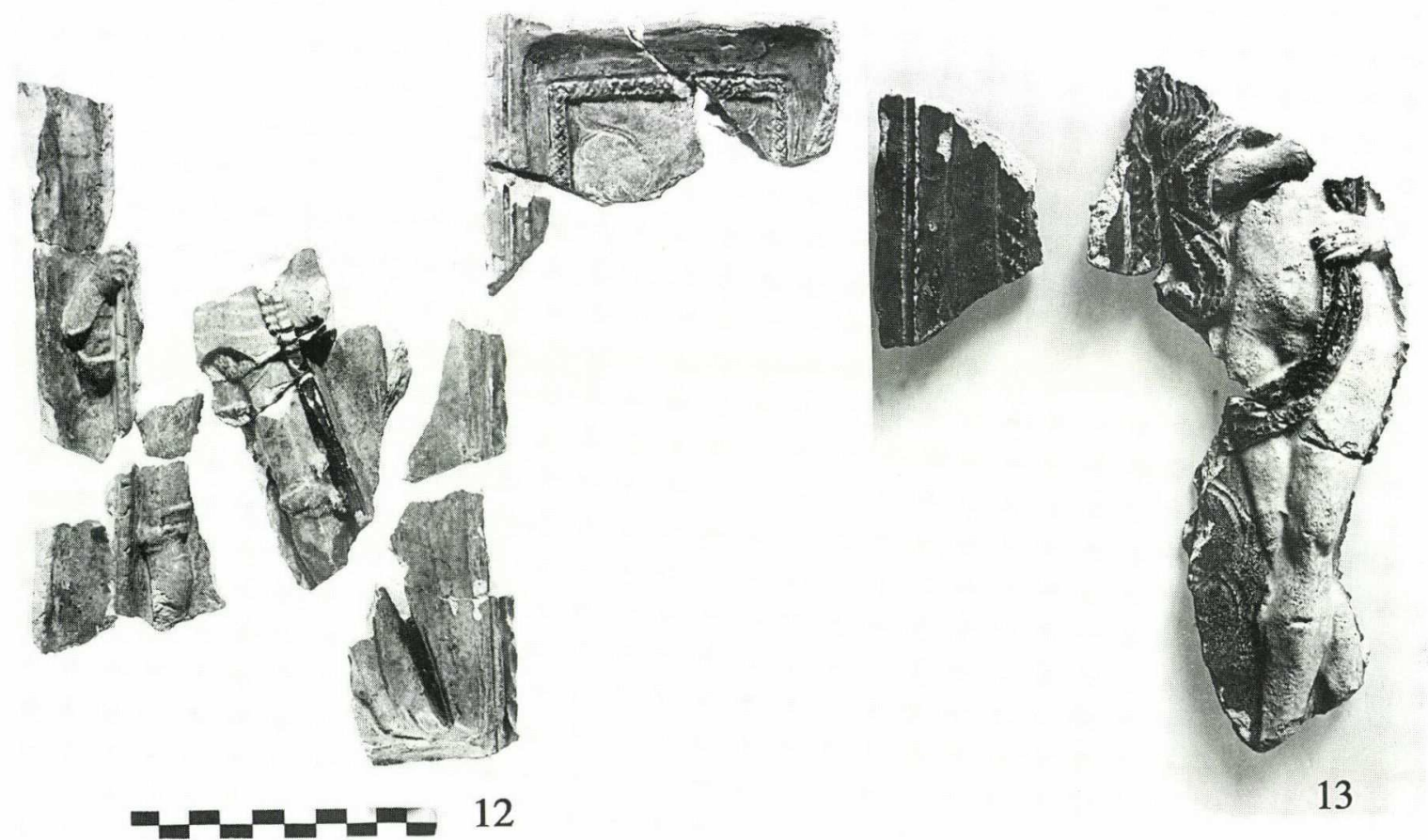

Abb. 12-13. Fragmente buntglasierter Eckkacheln: Gestalt in Rüstung, nackte Frau (Buda, königl. Palast)
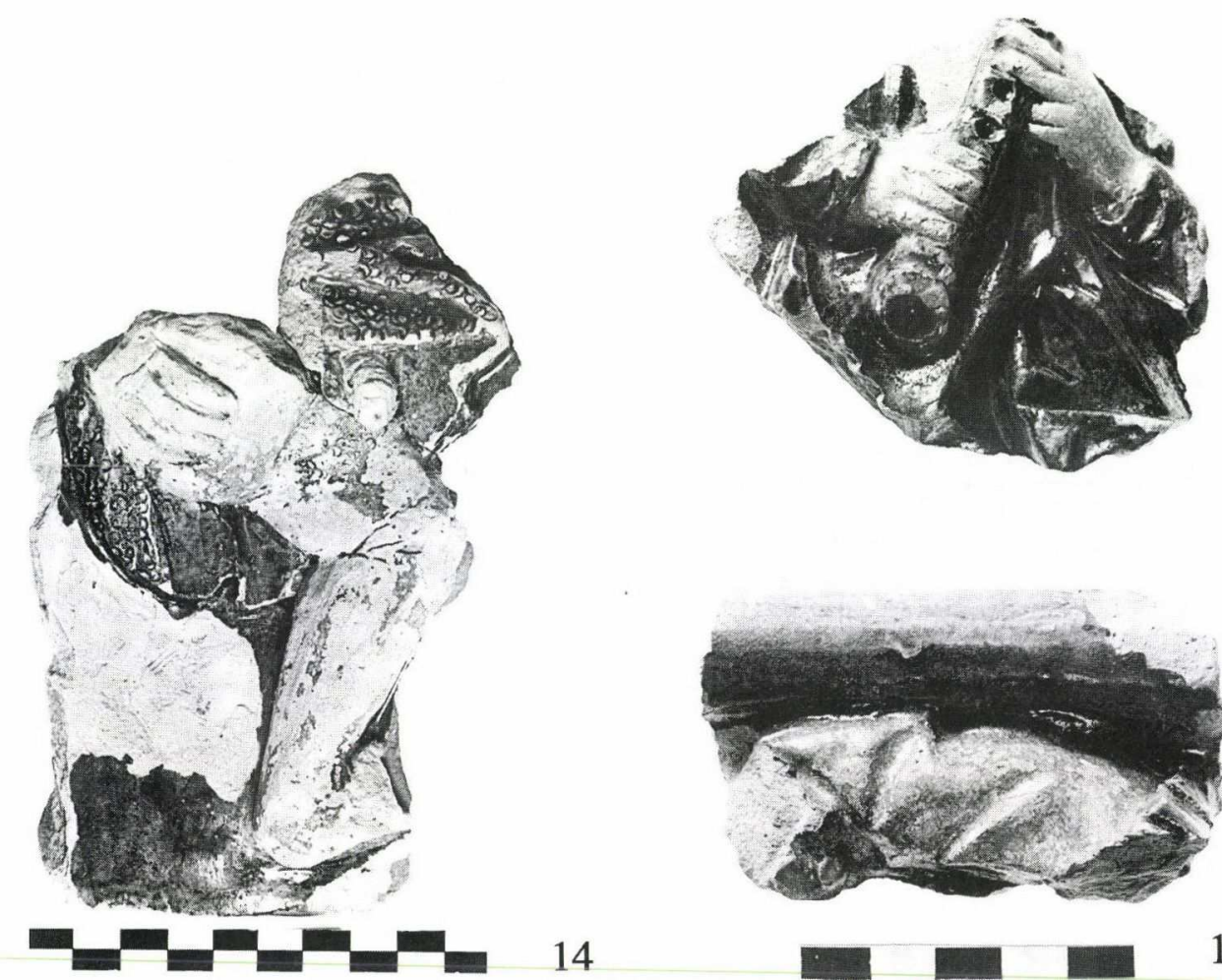

Abb. 14. Sein Geschlechtsteil zeigender Mann

Abb. 15. Flötenbläser, Fragment: Rand einer Gesimskachel mit einem Arm in blassblauer Kleidung 


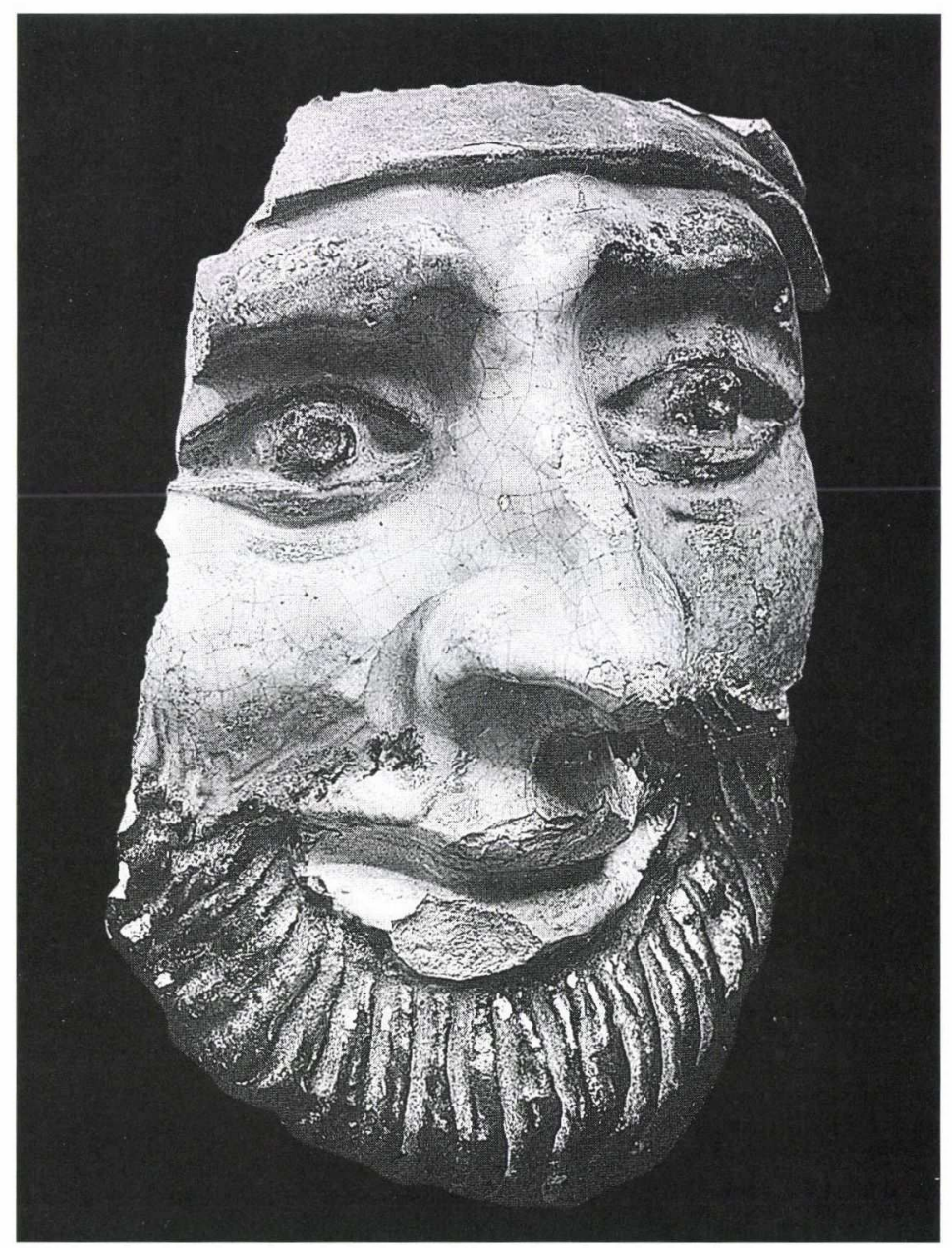

Abb. 16. Bruchstück vom Gesicht einer Eckfigur (H: $14 \mathrm{~cm}$ ) (Buda, königl. Palast)

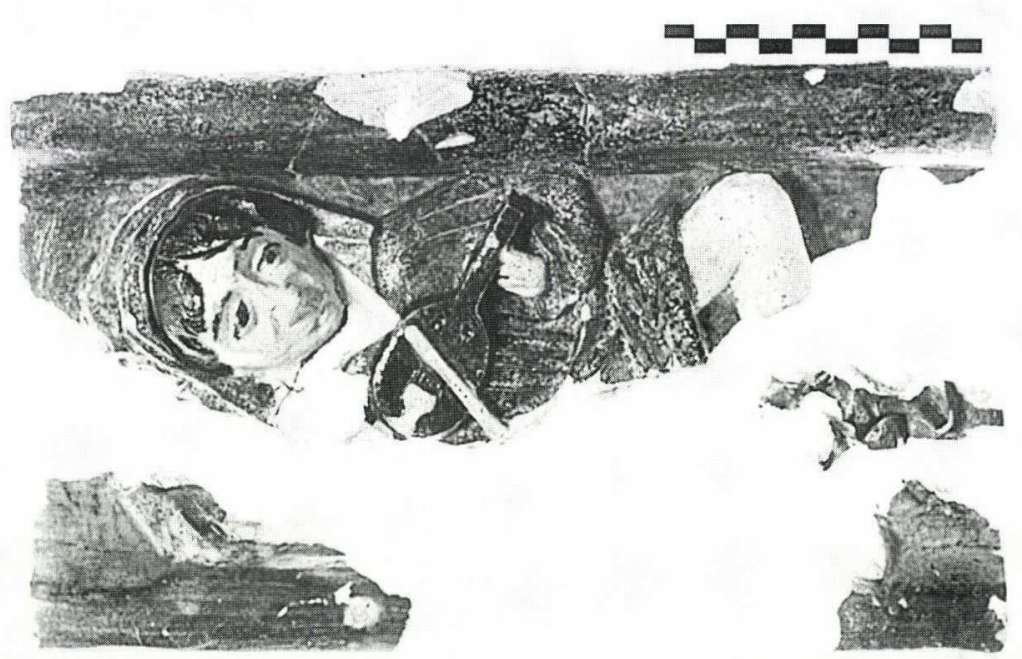

Abb. 17. Musikant mit Fidel, Fußgesimse, buntglasiert (Buda, königl. Palast) 

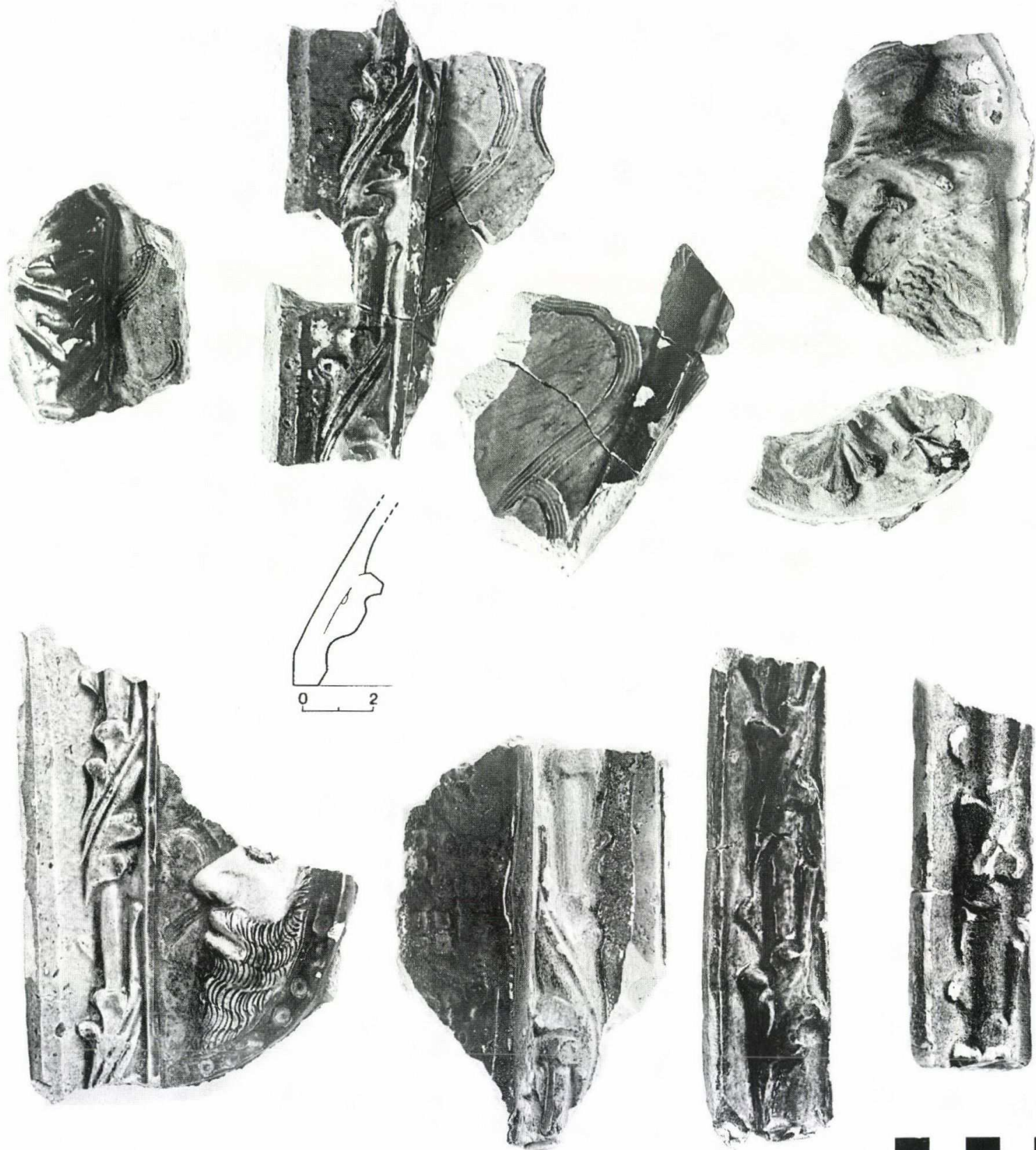

Abb. 18. Fragmente von buntglasierten Kacheln und Randverzierungen

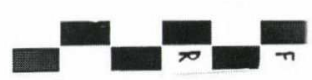



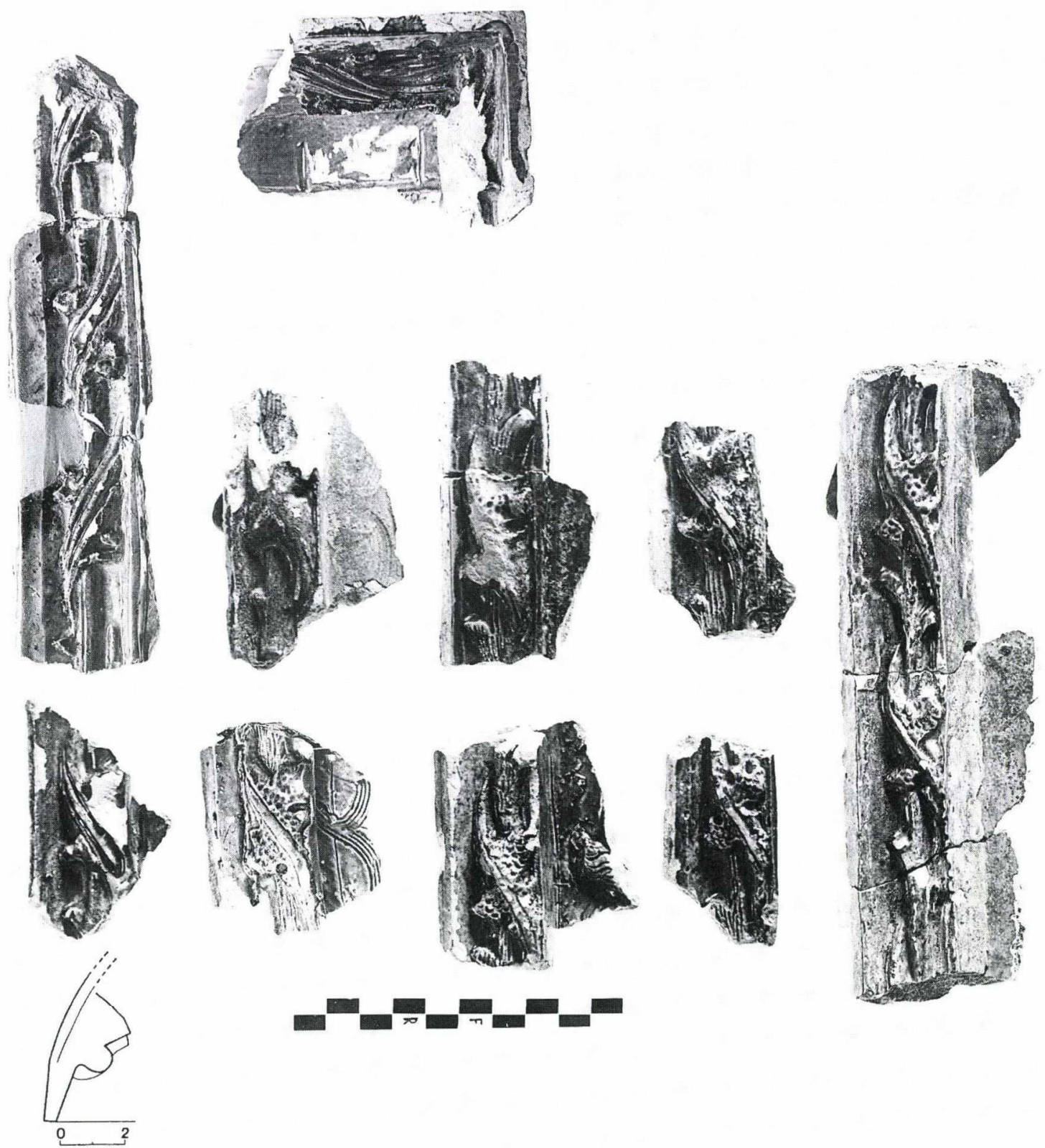

Abb. 19. Buntglasierte (in den beiden unteren Reihen grünglasierte) Rahmendekoration - Variationen (Buda, königl. Palast) 

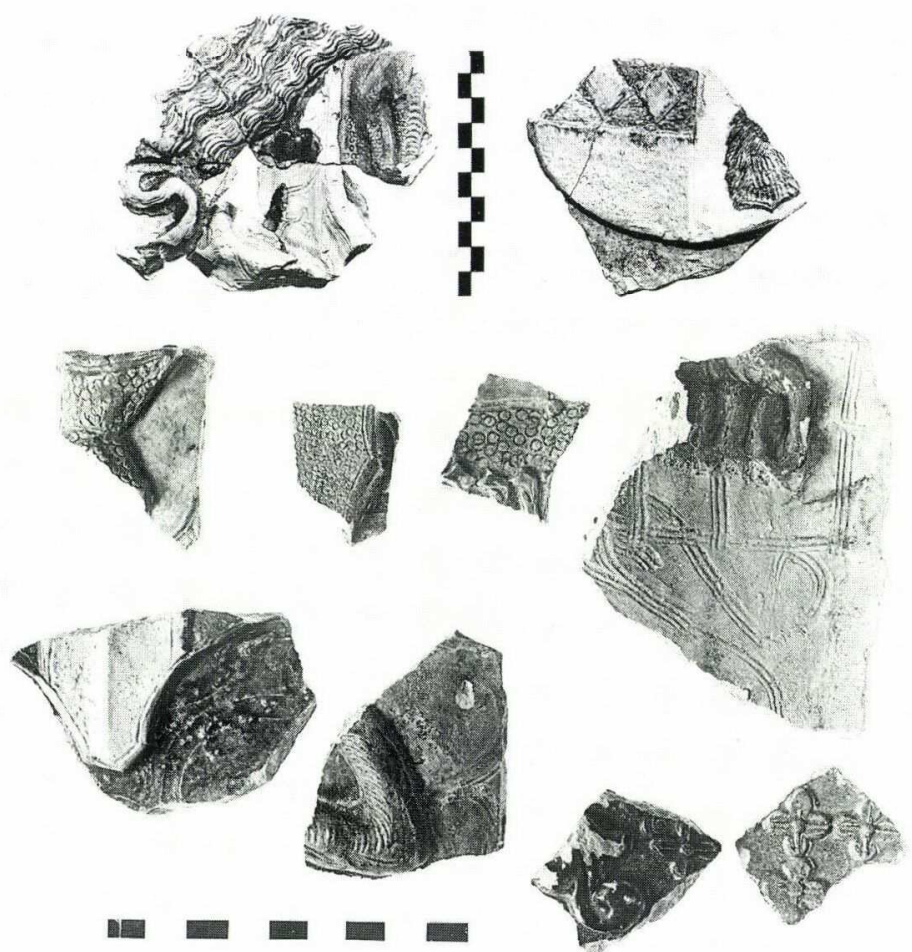

Abb. 20. Buntglasierte Kachelbruchstücke: Haar und Gewandfalte, Wappendetails, Inschriften, Arm eines wilden Mannes (Buda, königl. Palast)

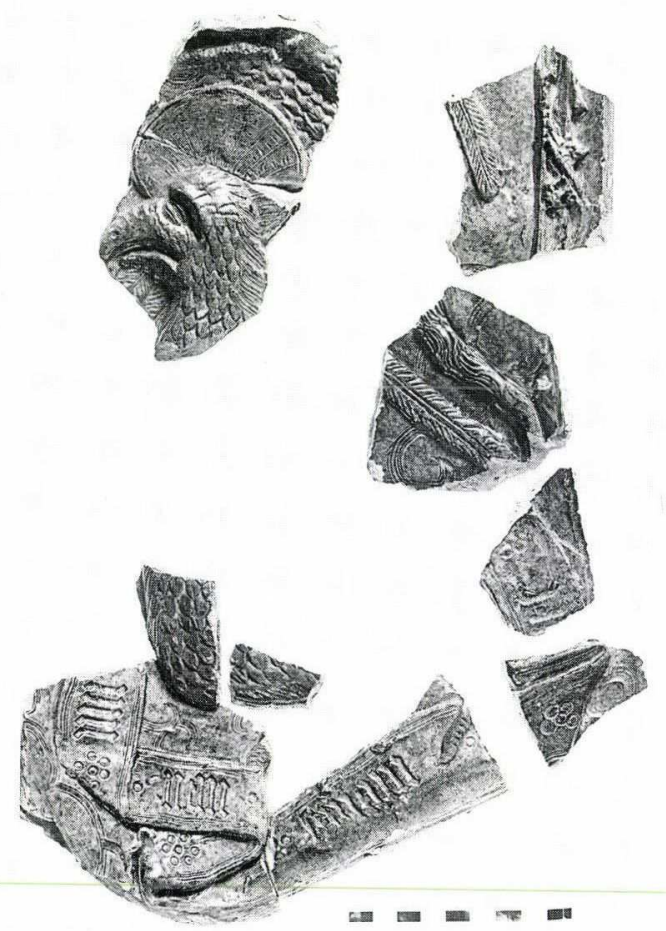

Abb. 21. Symbol des Evangelisten St. Johannes, grünglasiertes Fragment (Buda, königl. Palast) 
Wappen mit Doppeladler haltenden Gestalt buntglasierte Exemplare; bei einer das Wappenfragment (schwarzer Adler auf weißem Grund), bei einer anderen braunes Schwert vor gelbem Hintergrund ( $A b b$. 18). An der Letzteren fällt auf, dass eine andere Rahmenverzierung verwendet wurde (im Falle der buntglasierten Stücke häufiger mit größeren Blättern).

An dieser Stelle möchte ich auf einen weiteren, die Werkstatt charakterisierenden Umstand eingehen: auf den schon mehrfach erwähnten Randdekor, d. h. die Lösungen der einen Ast umrankenden Blätter. Während diese auf den fünferlei hierzu attribuierbaren Kacheln der ehemaligen Figdor-Sammlung immer mit identischer Zeichnung vorkommen, sind an den Kacheln von Buda verschiedene Variationen zu beobachten. An den Rauriser Kacheln ranken sich die sehr plastisch geformten Blätter nämlich immer von unten nach oben und von rechts nach links - mit diesen übereinstimmende findet man an den Randfragmenten buntglasierter (bräunlichgelb auf grünem Grund oder grün auf gelbem Grund) Kacheln aus Buda. Dieselben tauchen aber auch an den einfarbig grünglasierten Exemplaren von Buda auf (Abb. 19, dritte Reihe). Darüber hinaus kommen in Buda verschiedene Varianten dieses Blättertyps vor. Das bedeutet, dass von dem an sich schon aus einem gesonderten Negativ gepressten und auf die Kachel applizierten Rand ebenfalls mehrere verwendet wurden. - Eine mit ganz anders geformten Blättern gebildete Randverzierung (schlankere Blätter, unten und oben in je zwei Bögen von links nach rechts bzw. entgegengesetzt rankend) erscheint in der anderen Serie buntglasierter Kacheln aus Buda (David, wilder Mann, Wappen mit Doppeladler haltende Gestalt vor gelbem Hintergrund - Abb. 18). Von diesen fanden sich bislang noch keine an einfarbigen Kacheln; lediglich abweichende, kleinere Exemplare, aber auch davon nur wenige ( $A b b .18$, unten). Die Dekoration der Kacheln ist unbekannt.

Unter den schwer zu deutenden buntglasierten Fragmenten gibt es Stücke, die zur Gestalt eines Menschen gehören (mit goldgelbem Haar, braunem und blauem Umhang und Manteldetail) oder vielleicht Fragmente der zu den verschiedenen Gestalten gehörenden Wappen bzw. Wappenschilde sind ( $A b b$. 20). Eines zeigt den in der zweiten Hälfte des 15. Jahrhunderts in Mitteleuropa häufigen Schild des Fußvolkes (Pavese), mit weißem Balken auf schwarzem Grund und ein anderes ist mit Menschenkopf verziert (Abb. 18-19). Hierzu kann unter den einfarbig grünglasierten Kacheln auch ein bayerisches Wappenfragment ( $A b b .10$, rechts) attribuiert werden, dessen abweichende Grundfarbe man mit kleinen ein-gedrückten Kreisen angedeutet hat.

Als Typ 14 sind bei den grünglasierten Kacheln die Fragmente eines Adlers mit Aureole, Symbol des Evangelisten St. Johannes, zu erwähnen. Obwohl nicht rekonstruierbar, konnte dennoch festgestellt werden, dass es eine große, halbzylindrisch gestaltete Kachel mit der schon bekannten eingeritzten Hintergrundverzierung und sehr sorgfältig ausgearbeiteter, schön gezeichneter Plastik war. Am Boden der Kachel ist in voller Breite das von den Krallen gehaltene Spruchband mit eingerollten Enden und scharf eingedrückten Minuskelbuchstaben zu erkennen. (Wie es scheint, entstand die Inschrift durch Einstempeln einiger scharf geschnitzter Buchstaben in das originale Tonpositiv.) Nach der Anordnung der Fragmente, auf die man folgern kann, muss die Kachel mindenstens $30 \mathrm{~cm}$ breit gewesen sein und daher, übereinstimmend mit den Nr. 3-4, zum oberen Ofenkörper gehört haben (Abb. 21).

Auf eine große Kachel deutet angesichts seiner Maße (H: 13,5 cm) auch ein bärtiger Königskopf mit eigenartiger Krone hin; ${ }^{13 a}$ Bart und Haare ziert ein aus winzigen Kreisen bestehendes Muster. Grünglasierte, aber weiche, weiße Scherbe (auch aus solcher Scherbe finden sich zahlreiche Stücke). (Abb. 22.1)

Einige handgeformte, dicke $(1,2-2,2 \mathrm{~cm})$ Bruchstücke aus gelblich weißer Scherbe und mit glänzender goldgelber (in Spuren grüner) Glasur sind gewiss Fragmente von einer der den Ofen tragenden Tierfiguren. Auf einem größeren, erhabenen Stück sieht man den Ansatz des Vorderbeins, auf einem kleineren das Fell, die Mähne und die Spitze des Ohres (Abb. 26.2). (Auf diese Frage werde ich im Zusammenhang mit dem Esztergomer Ofen noch zurückkommen.)

Zur behandelten Untergruppe gehören weiters Kacheln mit anders gestaltetem Rand. Bei einem Teil wandte man das bereits bekannte, mit einem Kammwerkzeug eingeritzte Hintergrundmuster an, bei

13a Mit solchen Turbankronen bildete man Mitte des Jahrhunderts die Könige auf Kupferstich-Spielkarten ab (Meister der
Spielkarten: Löwen-König; Meister der Weibermacht: BlumenKönig). 

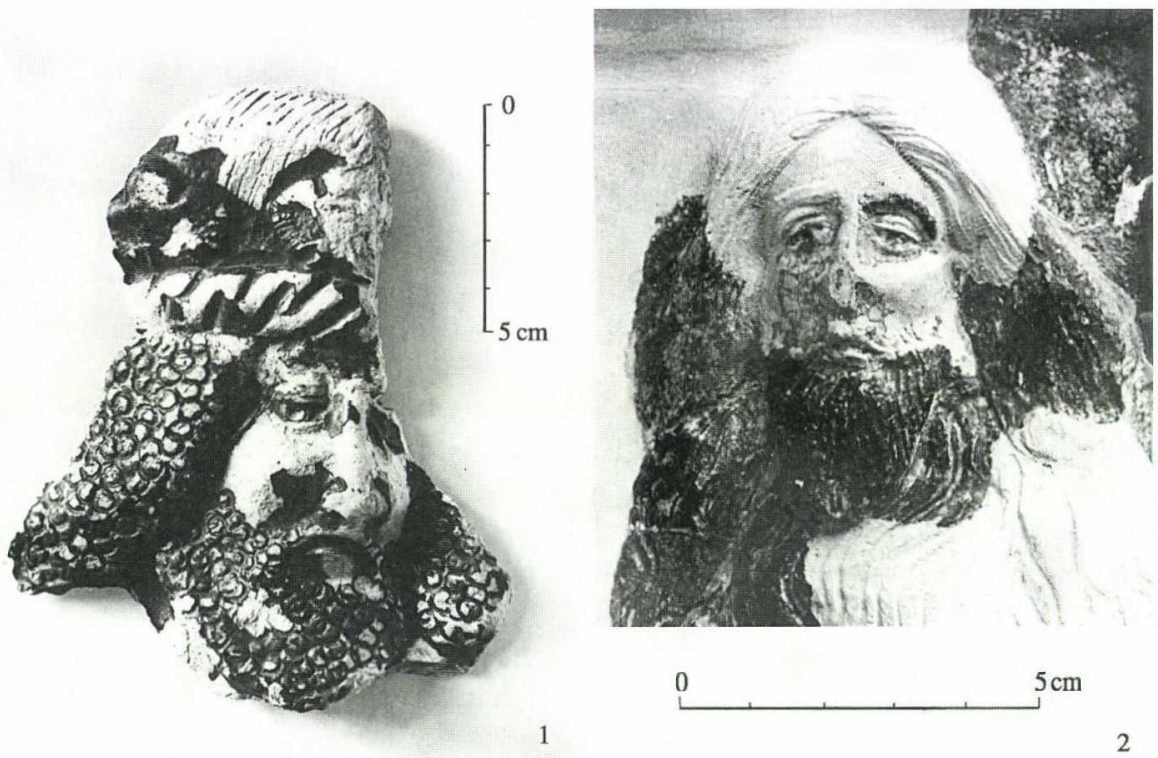

Abb. 22. 1: grünglasierter Königskopf; 2: Kopf eines wilden Mannes (Buda, königl. Palast)

anderen ein komplizierteres und schöner eingetieftes Muster, welches das Brokatmuster genauer wiedergibt. Der vertiefte Grund wurde durch kleine eingedrückte Kreise betont. Den gekehlten Rahmen dieser Kacheln hat man nicht als Extrastück angeklebt, die Verzierung des Randes (fünfblättrige Rosette - aus fünf eingedrückten Kreisen gebildete Rosette, abwechselnd) sowie dessen innere Kante (dünner, kreuzweise eingeschnittener Stab) befanden sich auch auf dem Originalnegativ (Abb. 23). Von den Exemplaren dieses Kachelkreises kennen wir überwiegend grünglasierte Fragmente. Dem Anschein nach waren es sämtlichst vermutlich viereckige Kacheln mit flachem Vorderblatt und rückseitigem Zylinder, welche die verschiedensten Tiergestalten zierten. Neben einem nach rechts blickenden Greif, einem nach links gewandten Einhorn, einer Vogelgestalt und anderen schwer zu deutenden Tierfragmenten kam auch die Darstellung eines behaarten wilden Mannes vor. Einige Fragmente bezeugen, dass es auch von diesen buntglasierte Exemplare gegeben haben muss; z. B. ein als Flosse auslaufendes behaartes Tierbein (weiß auf grünem Grund) oder ein Löwenkopf (der Kopf lilafarben, die Mähne gelb, das Auge weiß - bzw. einfarbig grün glasiert). (Abb. 25-26)

Von dem rosettenverzierten Rahmen kam ebenfalls ein gelbglasiertes Fragment zum Vorschein, was zeigt, dass die einfarbigen grünen Kacheln keine von den übrigen altersmäßig abweichende Gruppe bilden.

Einige Fragmente unter den grünglasierten Kacheln lassen erkennen, dass sich ein weiterer Meister mit höheren Kenntnissen der Plastik eingeschaltet hat: Dazu gehören die Stücke einer Frauenbzw. Männergestalt mit erhobenen Händen $(A b b .27)$ sowie eine schön ausgearbeitete, eine Gewandfalte haltende Hand ( $A b b .78$, Probe Nr. 92). Die einzige interpretierbare Szene ist ein Detail der Komposition Anbetung des Kindes: Auf der linken Seite Maria, kniend und mit gefalteten Händen betend, vor ihr auf dem Boden liegend (die Liniierung soll vielleicht Stroh andeuten), ein Knie angewinkelt, das Kind ( $A b b$. 28). Leider kennen wir weder die übrigen Details, noch die Maße der mindestens $28 \mathrm{~cm}$ hohen Blattkachel. - Ihre Komposition ist der Einstellung verwandt, die man auf den Tafelbildern von Robert Campin (um 1425) oder Stephan Lochner (1445, München) sehen kann, auch wenn sie in ihren Details davon abweicht. ${ }^{14}$ - Die Einordnung der Kachel in diesen Kreis geschah deshalb, weil sie aus der gleichen weichen,

${ }^{14}$ Die Szene mit der Geburt Christi am Salzburger Ofen (FrANZ 1969, Abb. 131) weicht davon gänzlich ab, sie wurde nach einem Stich des Meister E. S gestaltet: ebenda, 59. 


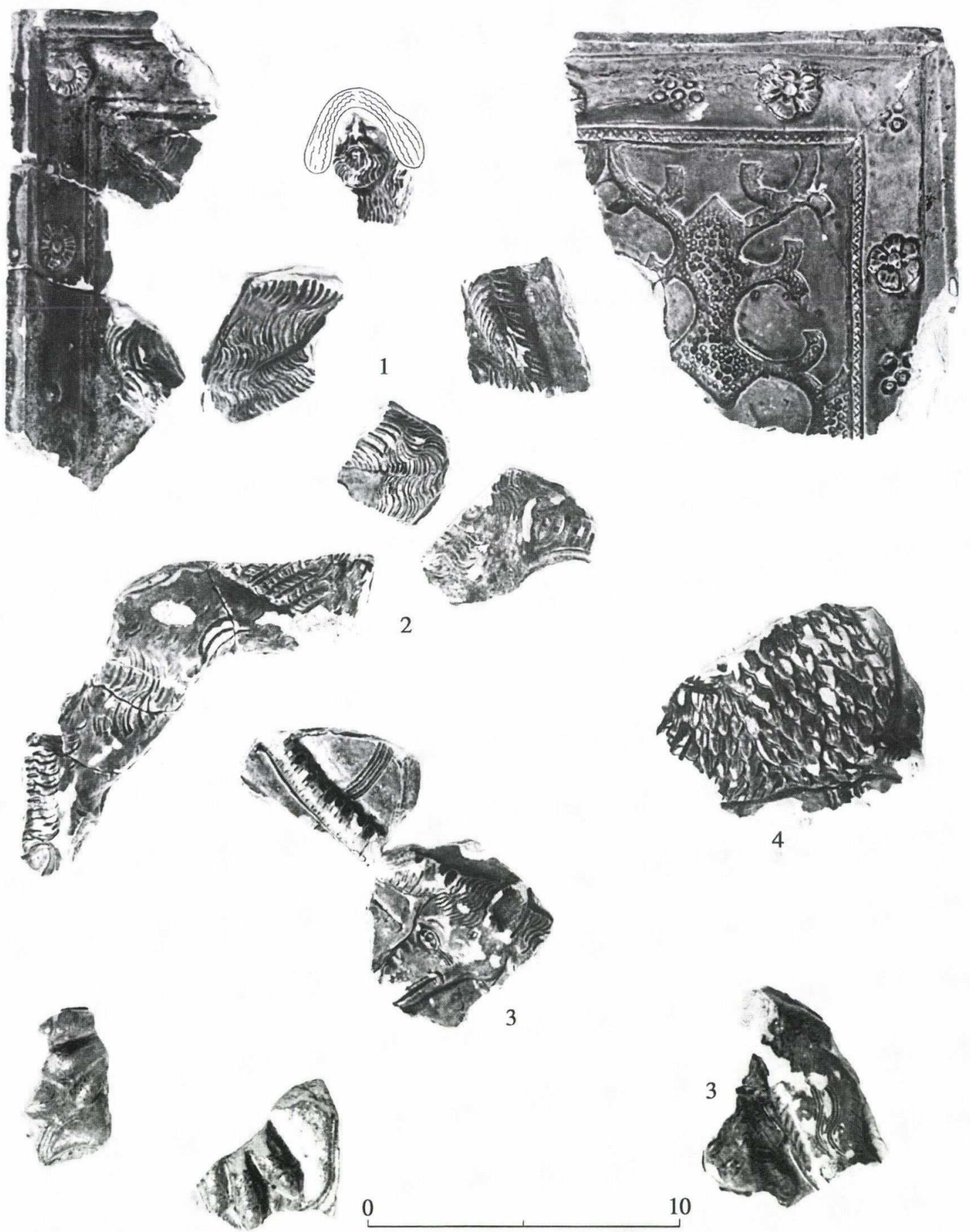

Abb. 23. Grünglasierte Ofenkacheln mit verziertem Hintergrund. 1: wilder Mann; 2: Greif; 3: Einhorn; 4: Vogel (Buda, königl. Palast) 


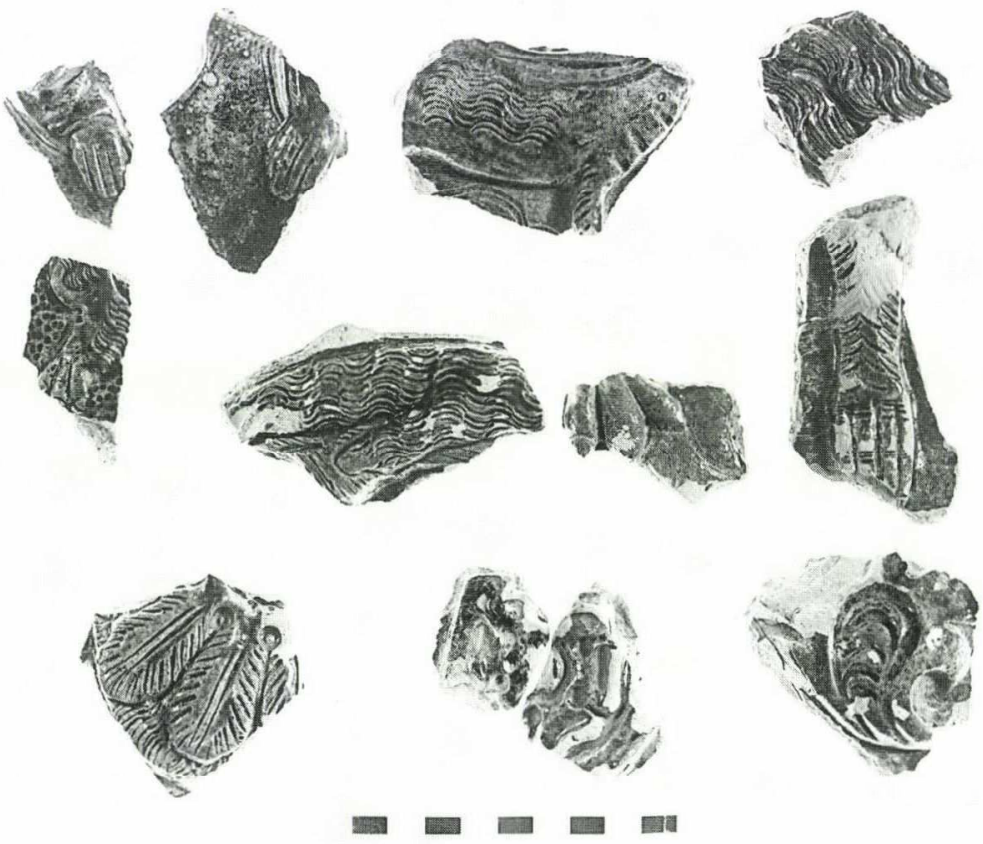

Abb. 24. Grünglasierte Kachelfragmente - Wappen haltende Hände, Tiergestalten, Pflanzenschmuck (Buda, königl. Palast)
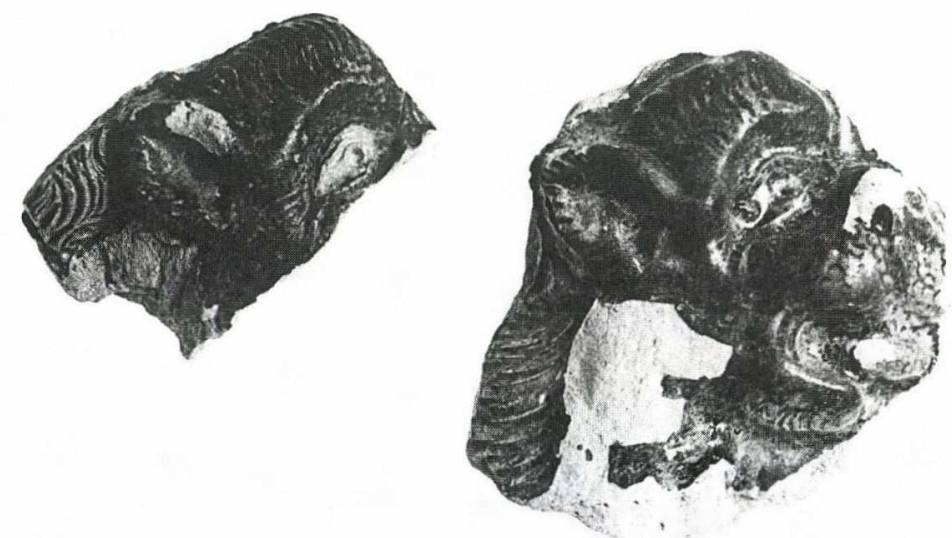

Abb. 25. Bunt- und grünglasierter Löwenkopf (Buda, königl. Palast)

weißen Scherbe verfertigt wurde (daher auch die abplatzende Glasur) wie zahlreiche andere, die typische Dekorationstechnik aufweisende Fragmente der $A b b$. 23. (Ob die zweierlei Scherbenqualität - hart oder weich gebrannt - lediglich auf unterschiedliches Brennen oder auf abweichende Tonarten zurückzuführen ist, weiß man nicht. ${ }^{15}$ )

${ }^{15}$ Die vor längerer Zeit begonnenen Keramikanalysen wurden leider abgebrochen, so dass von den Kacheln vom Ende des Jahrhunderts nur einige untersucht werden konnten. - Solche technologischen Fehler, derentwegen die Glasur später abblät- tert, sind bei Ofenkacheln relativ selten. Ihr häufiges Vorkommen in dieser Gruppe könnte daher eines der Kriterien zur Einordnung in die Unterguppe sein (s. noch im Anhang). 

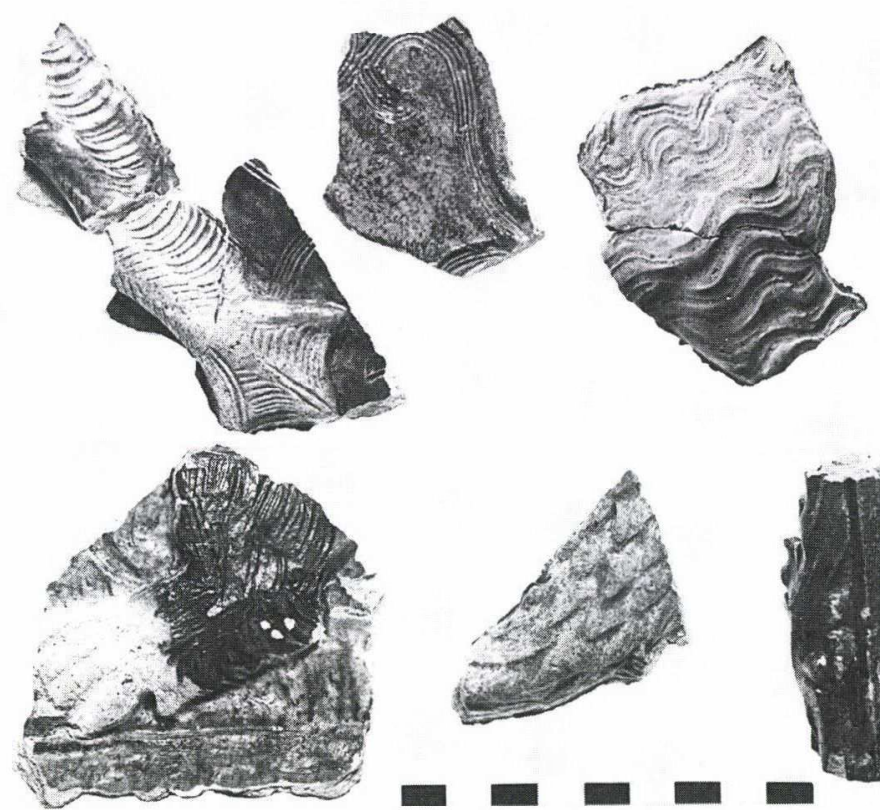

Abb. 26. 1: buntglasierte Fragmente; 2: gelbglasierte Bruchstücke von Ofenfüßen (Buda, königl. Palast)
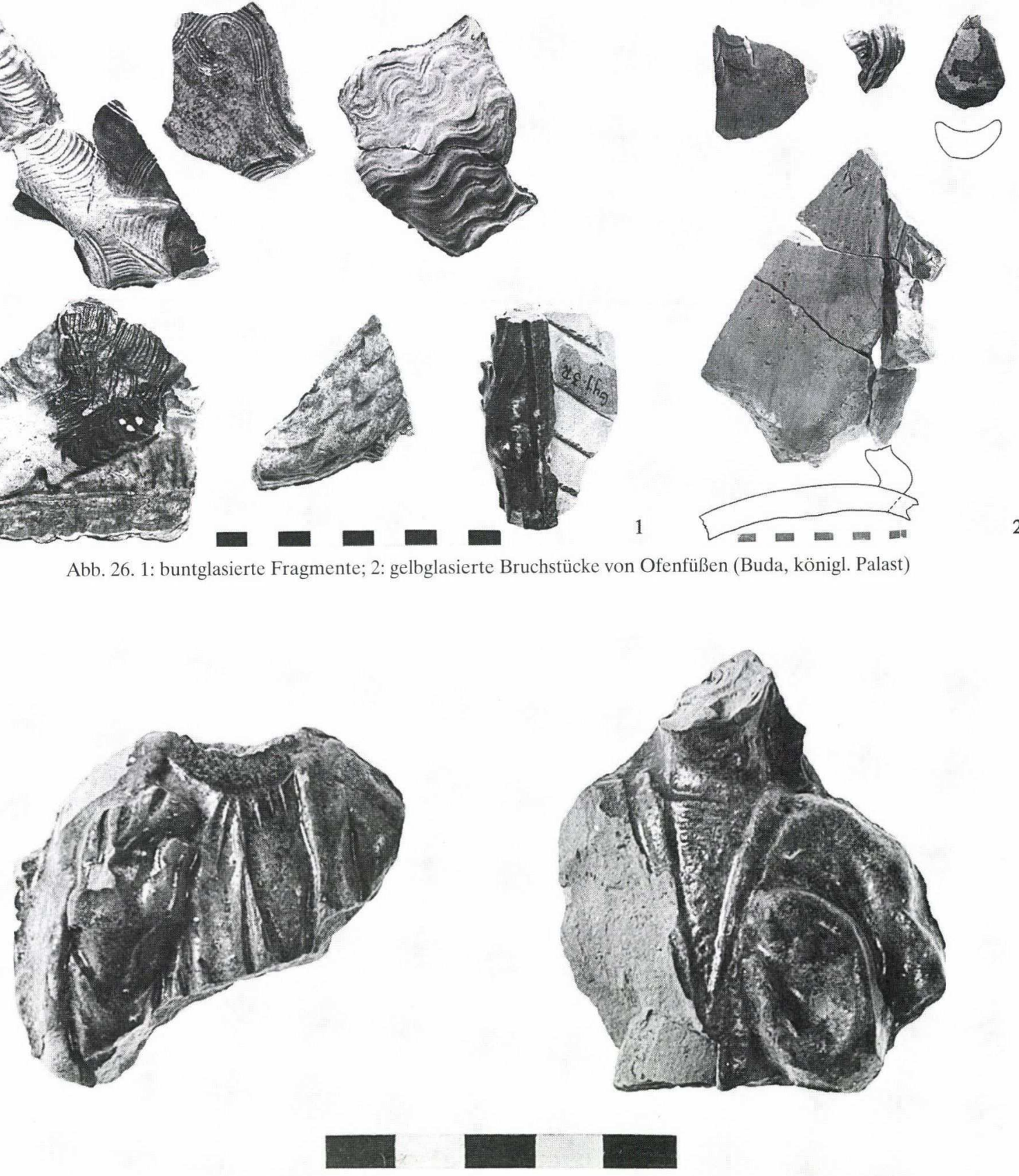

Abb. 27. Grünglasierte Bruchstücke (Buda, königl. Palast) 


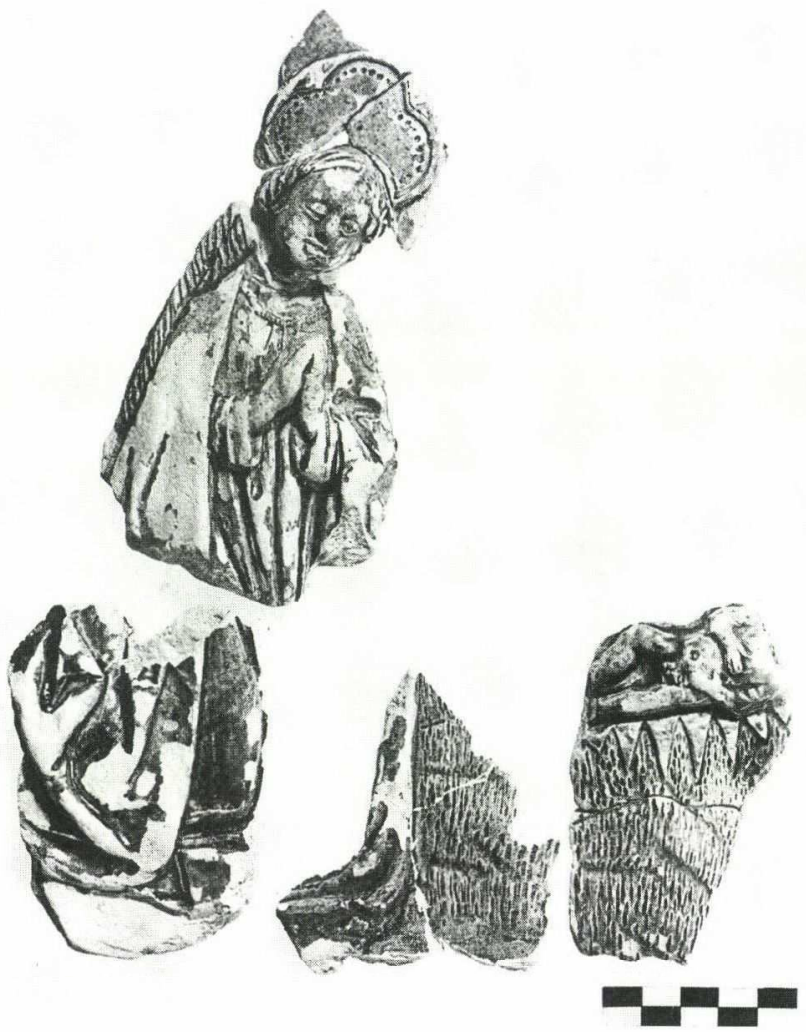

Abb. 28. Anbetung des Kindes - Szene von einer grünglasierten Kachel (Buda, königl. Palast)

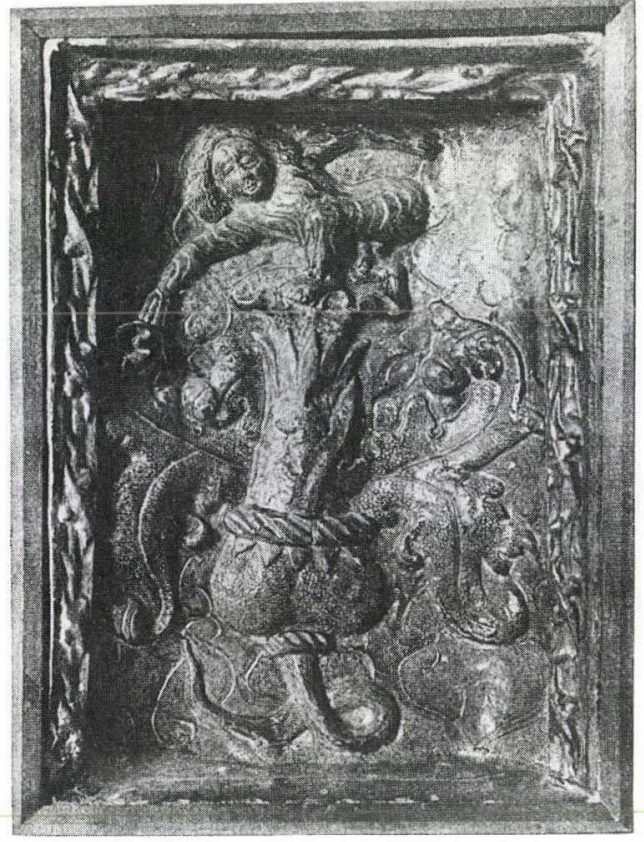

29

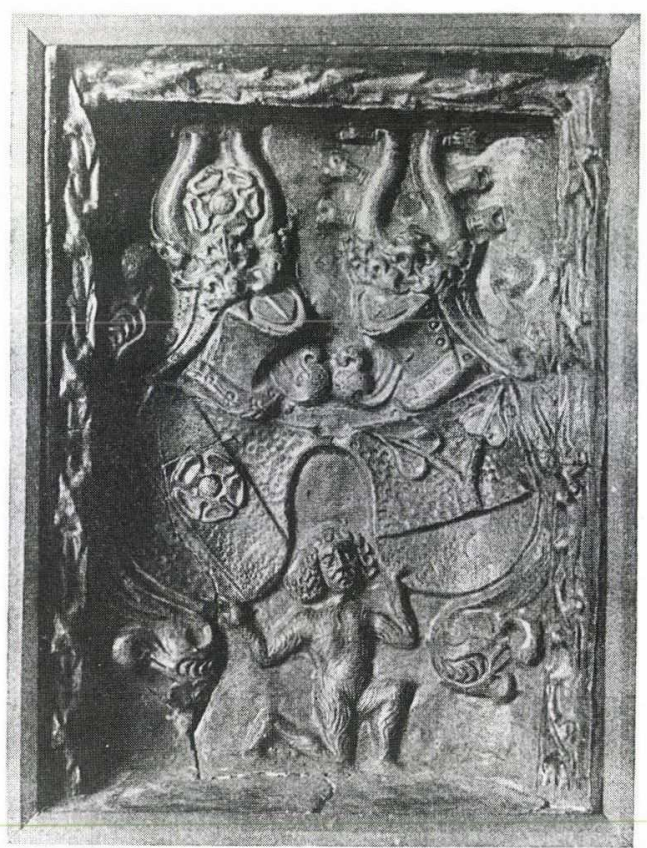

30

Abb. 29-30. Aus Rauris erworbene grünglasierte Kacheln: „Alraunwurzel - Waldschrat mit Wappenschilden“ (H: $45 \mathrm{~cm}$ - Österr. Museum f. Angewandte Kunst, Wien) 

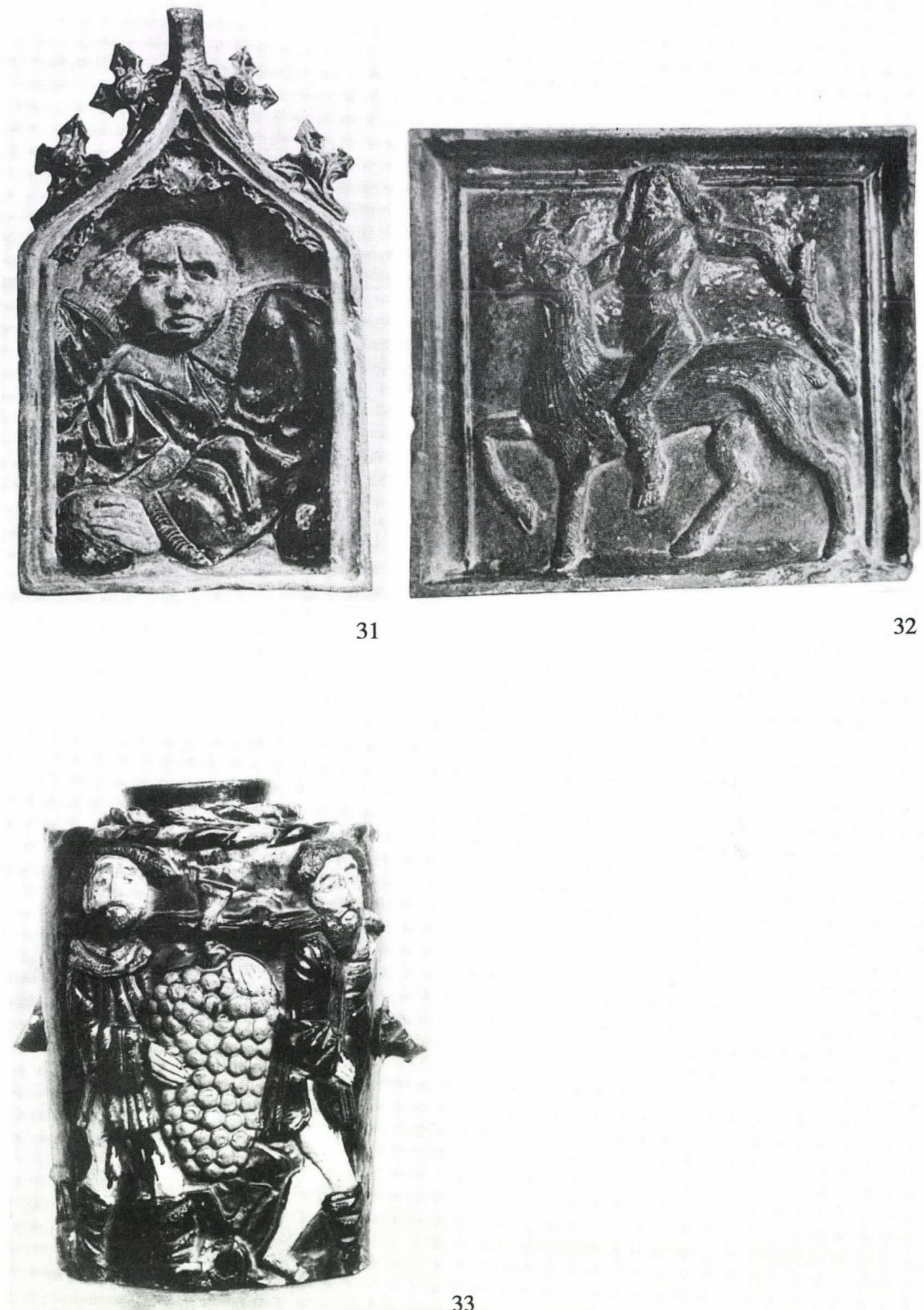

Abb. 31. Giebelkachel (lilafarbige, gelbe, grüne und weiße Glasur, H: $45 \mathrm{~cm}$ - Wien) Abb. 32. Wilder Mann auf Fabeltier reitend (grünglasiert, H: $24 \mathrm{~cm}$ - Wien), Kachel der 2. Untergruppe Abb. 33. Weinkühler, buntglasiert (H: 40,5 cm - Museum f. Kunst und Gewerbe, Hamburg) 
Das vorgestellte Material (sowie weitere, hier nicht genannte Fragmente) deutet auf eine sehr vielschichtige, abwechslungsreich ausgewählte Dekoration hin. Im Gegensatz zu früheren Öfen begegnet man hier keinen serienmäßig kopierten Kacheln eines identischen Motivs, was von bedeutenderen Vorbereitungen (Verwendung vieler verschiedener Positive-Negative) zeugt. Dazu dürfte, wie ich meine, auch der Umstand beigetragen haben, dass es in der zweiten Hälfte des 15. Jahrhunderts mit den Kupferstichen und dann den mit Holzschnitten illustrierten Büchern (z. B. die religiösen Szenen der Biblia pauperum, die in den siebziger Jahren in Ulm herausgegebenen Bücher usw.) einen reichen Fundus zur Darstellung sakraler und profaner Themen gab. Daneben mag die Auffassung des das Positiv formenden Meisters auch von der Tafelbildmalerei seiner Zeit und Umgebung beeinflusst worden sein (siehe die Beliebtheit der Hintergründe mit Brokatmuster, die in der zweiten Hälfte des Jahrhunderts noch bei einigen anderer Werkstätten spürbar ist). Dass man ein sakrales und profanes Thema vermischt, ist im Falle der repräsentativen Hofkünste - damals allerdings auch schon in bürgerlicher Umgebung - allgemein verbreitet. Vielleicht das Weiterleben einer klassischen Auffassung zeigt die häufige Verwendung von ursprünglich symbolischen, später jedoch eher dekorativen Zwecken dienenden Tieren und Mischwesen (Fabelwesen). Den Stil der dekorativen Pflanzenmotive haben die ab der Mitte des Jahrhunderts auf Kupferstichen verwendeten komplizierten Blatt- und Blumengebilde inspiriert. Was die aus einem Blütenkelch emporragenden menschlichen Halbfiguren anbelangt (siehe im Weiteren die Esztergomer Kacheln), kann man sich auf die ähnliche, nach 1480 im Missale des Erzbischofs Bernhard von Rohr dargestellte, aber schon um 1460 bekannte Auffassung berufen. ${ }^{16}$

Bislang gibt es nur einen brauchbaren Anhaltspunkt, um sich dem Herstellungsalter des Ofens (der Öfen?) zu nähern. Das Wappenfragment der Kachel vom Typ 3 bedeutet nach meinem Dafürhalten Niederösterreich (wobei anstelle der roten braune Farbe benutzt wurde). Bindet man das an die Eroberungen Königs Matthias', so wäre ein Zeitpunkt ab 1486 denkbar ${ }^{17}$ (Abb. 4). Es kann kein Zufall sein, dass das Paarstück der Kachel - mit dem sie in einer Reihe stand - die ebenfalls stehende Gestalt in Rüstung, in der Hand das Wappen mit Doppeladler, vom Typ 4 ist. Bei dem Wappen handelt es sich hier, wie ich meine, nicht um das Reichswappen. Denn die auffallend andere Rüstung der Gestalt zeigt nicht die Züge dieses Zeitalters, sondern absichtlich abweichende (fiktiv altertümliche?). Meiner Ansicht nach haben wir es hier mit einem Bild von Julius Caesar zu tun, noch dazu einem aus der bekannten allegorischen Serie der „neun guten Helden“ übernommenen. Das stellte ihn nämlich bereits vom Ende des 14. Jahrhunderts an in Rüstung dar, mit einem Wappenschild mit Doppeladler in der Hand und im 15. Jahrhundert dann mit dem auf ihn hinweisenden Spruchband. ${ }^{18}$ - Leider bleibt ohne entsprechende Anhaltspunkte unklar, ob die das österreichische Wappen haltende Gestalt nur ein symbolischer Hinweis oder eine bestimmte Person gewesen sein könnte. ${ }^{19}$ - Aus dem mehrfachen Vorkommen des bayerischen Wappens ergeben sich nur weit gesetzte Zeitgrenzen: das schon seit 1469 bestehende und wiederholt erneuerte Bündnis zwischen König Matthias und den bayerisch-pfälzischen Fürsten, ${ }^{20}$ zuletzt im Jahre 1488 mit Fürst Georg von Bayern.

Zur Bestimmung der Werkstatt dieser Kachelgruppe habe ich schon 1983 die für die ehemalige Sammlung Figdor in Rauris erworbenen Kacheln als Beweise herangezogen. ${ }^{21}$ Besonders der Stil und die in der Dekoration angewandten Kniffe der „Alraunwurzel mit Moosmännchen“ genannten Kachel sowie ihres „Waldschrat mit Wappenschild“ genannten Paarstückes (Abb. 29-30) sind charakteristisch: der mit

\footnotetext{
${ }^{16}$ B. von Rohr: Missale: Baum Jesse, nach $1480(† 1487)$. Bild in: Propyläen Kunstgeschichte Bd. 7. Berlin 1972, Abb. 86. - Der Meister der Berliner Passion, Kupferstich (Lehrs 115), um 1460.

${ }^{17}$ Auf dem Siegel Matthias' und in den Corvina Kodizes kommt ab 1486 das Balkenwappen Niederösterreichs vor.

${ }^{18}$ RDK Bd. 3. Stuttgart 1954, Sp. 363-366. S. z. B.: Einblattholzschnitt, Bern 1460/80, „Julius der erste keiser ...“.

${ }^{19}$ Eventuell Matthias Hunyadi?
}

${ }^{20}$ Ausführlich habe ich darauf im Zusammenhang mit der Schenkung des Regensburger Ofens hingewiesen, s. Anm. 4.

${ }^{21}$ WALCHER 1909, 325-327, Abb. 90-95. „Salzachtal, um 1500 “. Sie kamen in die Sammlung des Wiener Museums für Angewandte Kunst. - Rauris liegt etwa 65 km südlich von Salzburg. (In der Benennung folge ich hier der Erklärung Walchers, die Gestalten entsprechen eher dem Typ ,wilder Mann“.) 

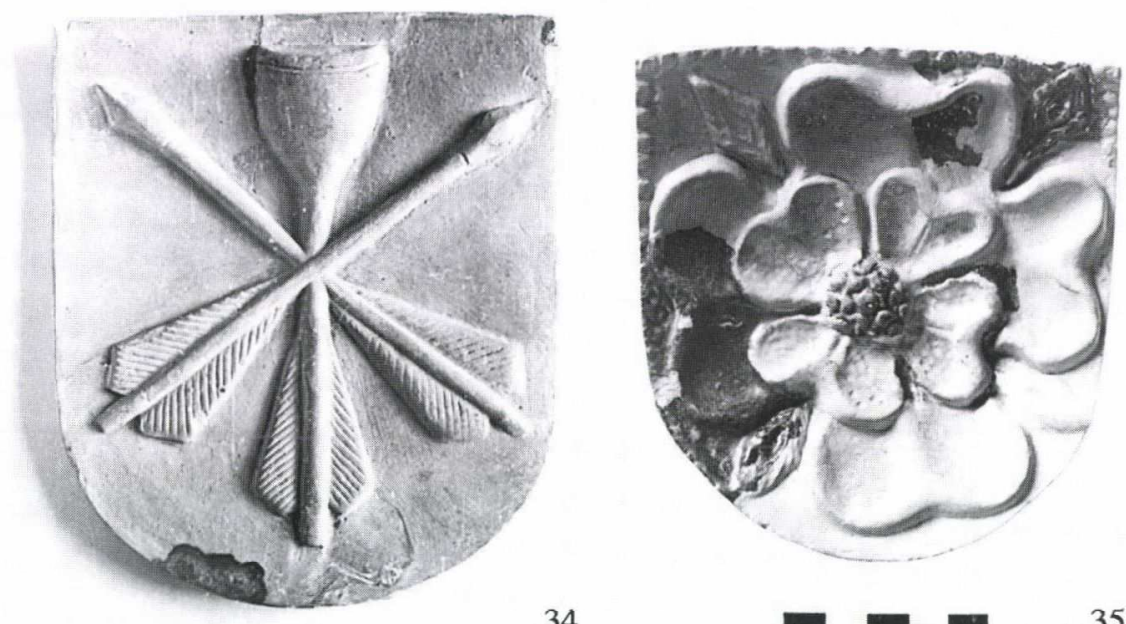

Abb. 34-35. Wappen an Eckkacheln. 34: Wappen des Bischofs und Kanzlers János Filipecz (1481-1489?); 35: buntglasiertes Wappen mit Rose (Buda, königl. Palast)

dem der Budaer Kacheln identische blattverzierte Rahmen, die Blattformen, der mit kleinen Kreisen gepunzte Hintergrund (bei der ersteren Kachel an der Blume, bei der zweiten an den Wappen), das wie Kammstrich liniierte Textilmuster des Kachelblattes, aber auch die Art, wie beispielsweise der Kopf des „Moosmännchens“ oder der behaarte Körper des kleinen wilden Mannes (bei Walcher „Waldschrat“) behandelt wurden. Darüber hinaus begegnet man hier einem vom Üblichen abweichenden, großen $(45 \mathrm{~cm}$ hohen) Kacheltyp mit Halbzylinder. Auch die weiteren Stücke der Sammlung (Kretin, Malachias, Aristoteles und Phyllis, Giebelkachel mit der Halbfigur eines Bäckers) sind für den Stil des Meisters und die Erzeugnisse der Werkstatt kennzeichnend. In einem Fall konnte bereits nachgewiesen werden, dass an dem Budaer Ofen ebenfalls ein Exemplar davon vorkam ( $A b b .8, A b b .10)$. Der Umstand, dass die Rauriser Stücke der ehemaligen Figdor-Sammlung alle einfarbig grünglasierter Ausführung sind (wie auch ein Teil der Funde von Buda), darf nicht irreführen; er deutet lediglich auf den Gebrauch einfacherer und offenbar billigerer Kacheln hin. Für teurere Öfen aber wurden solche Kacheln (wie bei manchem Budaer Exemplar) auch zum Teil mit buntglasierter Lösung hergestellt ${ }^{22}$ - bei diesen platzierte man die grünglasierten Stücke an der rückwärtigen Ofenseite.

Walcher dachte in Bezug auf ihren Herstellungsort an die südlich von Salzburg gelegene Stadt Hallein, wo der Großmeister der Töpferinnung der Vorsteher aller Zünfte dieser Gegend war. (Hallein liegt etwa $14 \mathrm{~km}$ südlich von Salzburg am Ufer der Salzach.) Dass für den 1501 fertiggestellten großen Salzburger Ofen auch Kacheln aus dieser Werkstatt verwendet wurden, steht außer Zweifel - nur eben schon an der rückwärtigen, dem Betrachter abgewandten Seite des Ofens. ${ }^{23}$ Darauf gründete Walchers Datierung der Gruppe „um 1500“. Ich dagegen denke, dass man im letzteren Fall lediglich aus Gründen der Sparsamkeit einige Stücke aus dem älteren Musterschatz dieser Werkstatt benutzte (von denen sich die übrigen Kacheln des Ofens, von der Hand eines späteren Meisters der Werkstatt, durch ihre entwickeltere und kunstvollere Plastik unterscheiden). Nach Molthein stammt übrigens auch der Salzburger Ofen aus Hallein.

22 Nach Prodinger 1972, 2 tritt die Malachias-Kachel am Salzburger Ofen grün-gelb-braun glasiert bzw. auch mit einfarbig grüner Glasur auf.

${ }^{23}$ WALCHER 1905, 232-243 deutet darauf bereits hin. PRODINGER erwähnt außer an der zuvor zitierten Stelle (1972) bei anderer Gelegenheit (Spätgotik in Salzburg, Ausstellung,
Salzburg 1976, Nr. 440) auch im Zusammenhang mit der Wiener Alraunwurzel-Kachel, dass sie in kleinerer Abmessung an der rückwärtigen Wandseite im oberen Teil des Ofens vorkommt $(29 \times 46 \mathrm{~cm})$. Die Datierungen sind hier bereits abweichend: Wiener Malachias-Kachel „Ende 15. Jh.“, letztgenannte Kachel „Salzburgisch, um 1500“. 

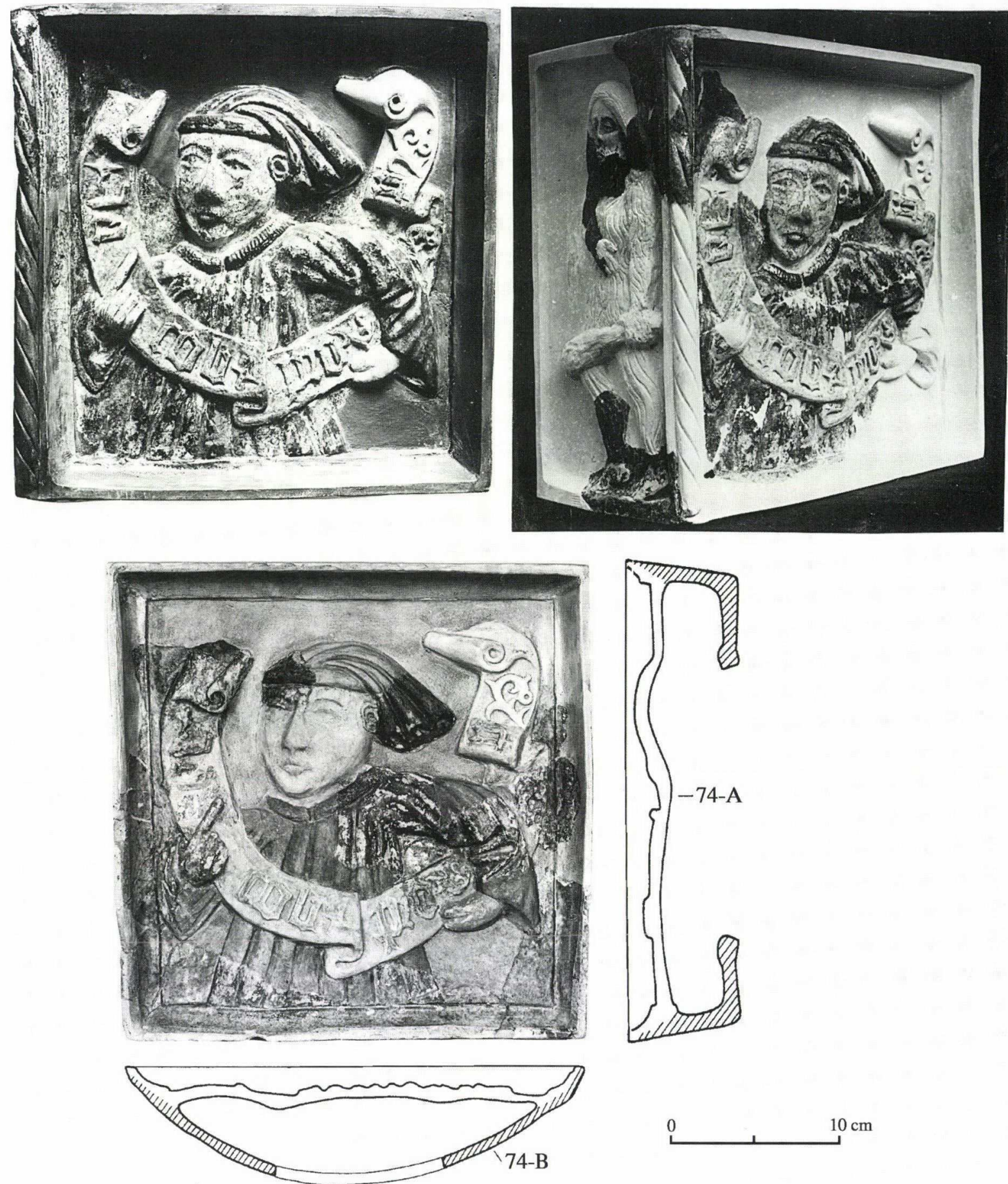

Abb. 36. Buntglasierte Ofenkacheln mit der Gestalt des „Jacob“ und eines wilden Mannes (Buda, königl. Palast) 

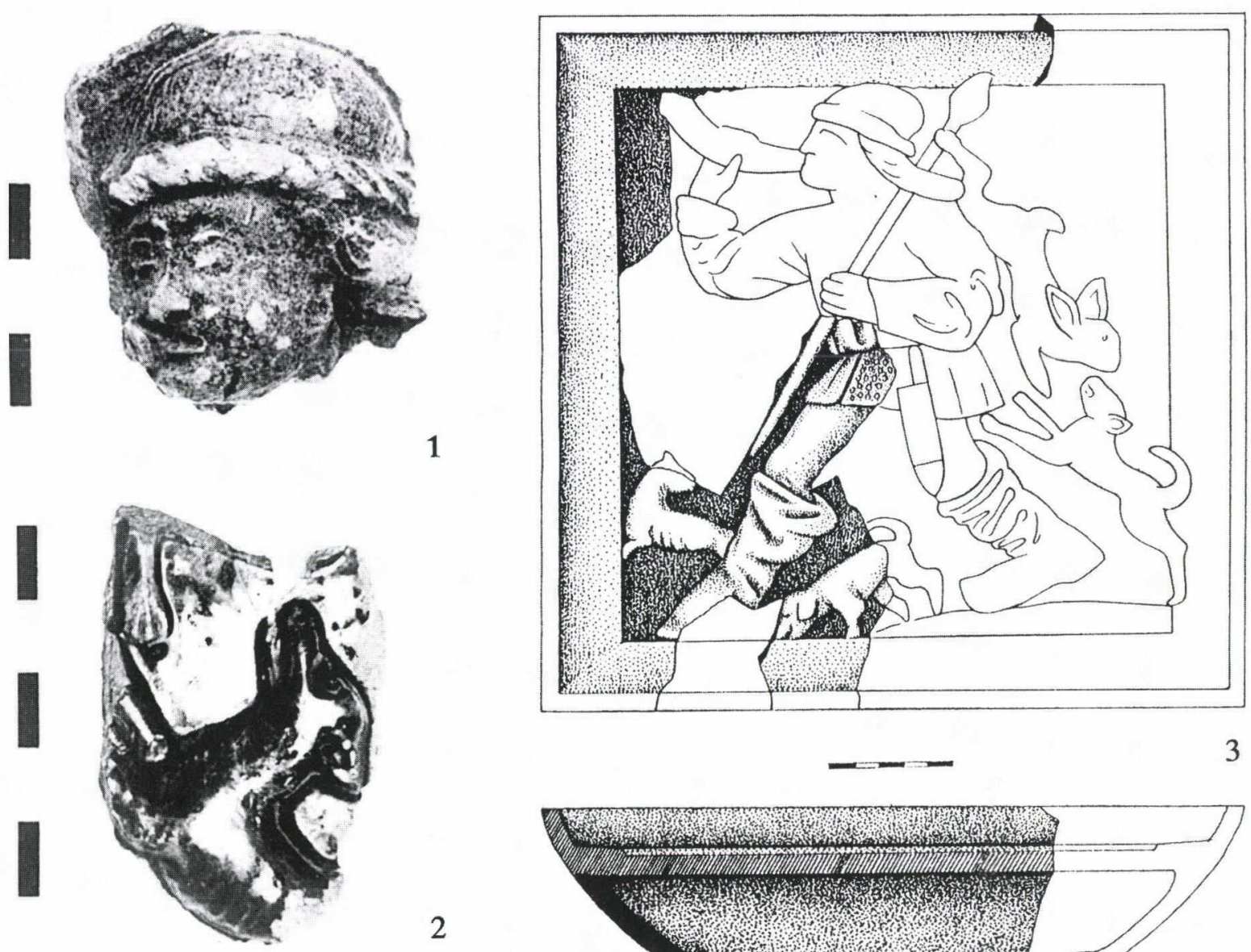

1
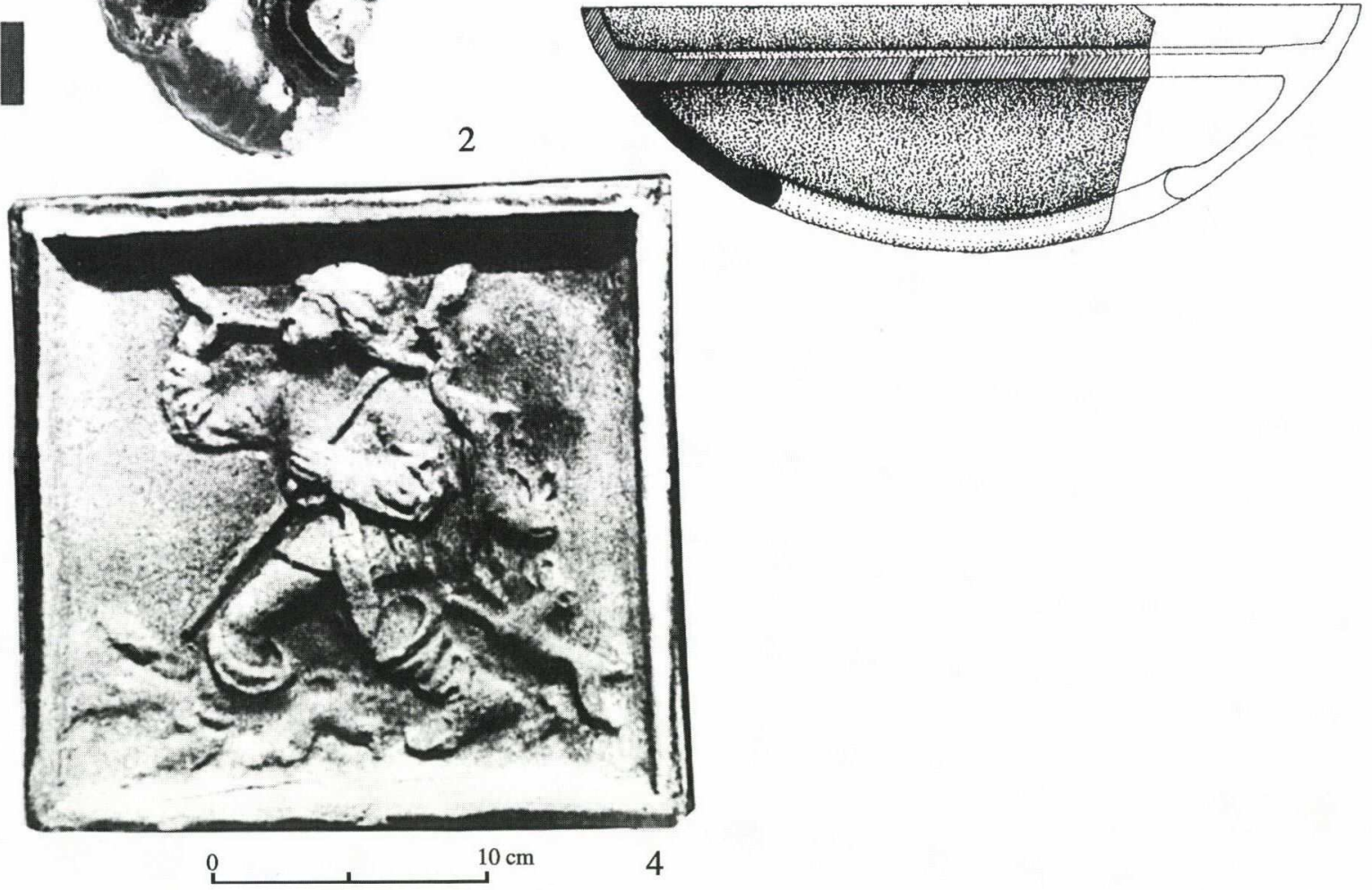

Abb. 37. Ofenkacheln mit Jägergestalt. 1-2: Palast Buda; 3: Palast Visegrád; 4: Ebendorf (N.Ö. - Stadtmuseum Melk) - unglasierte Kopie 

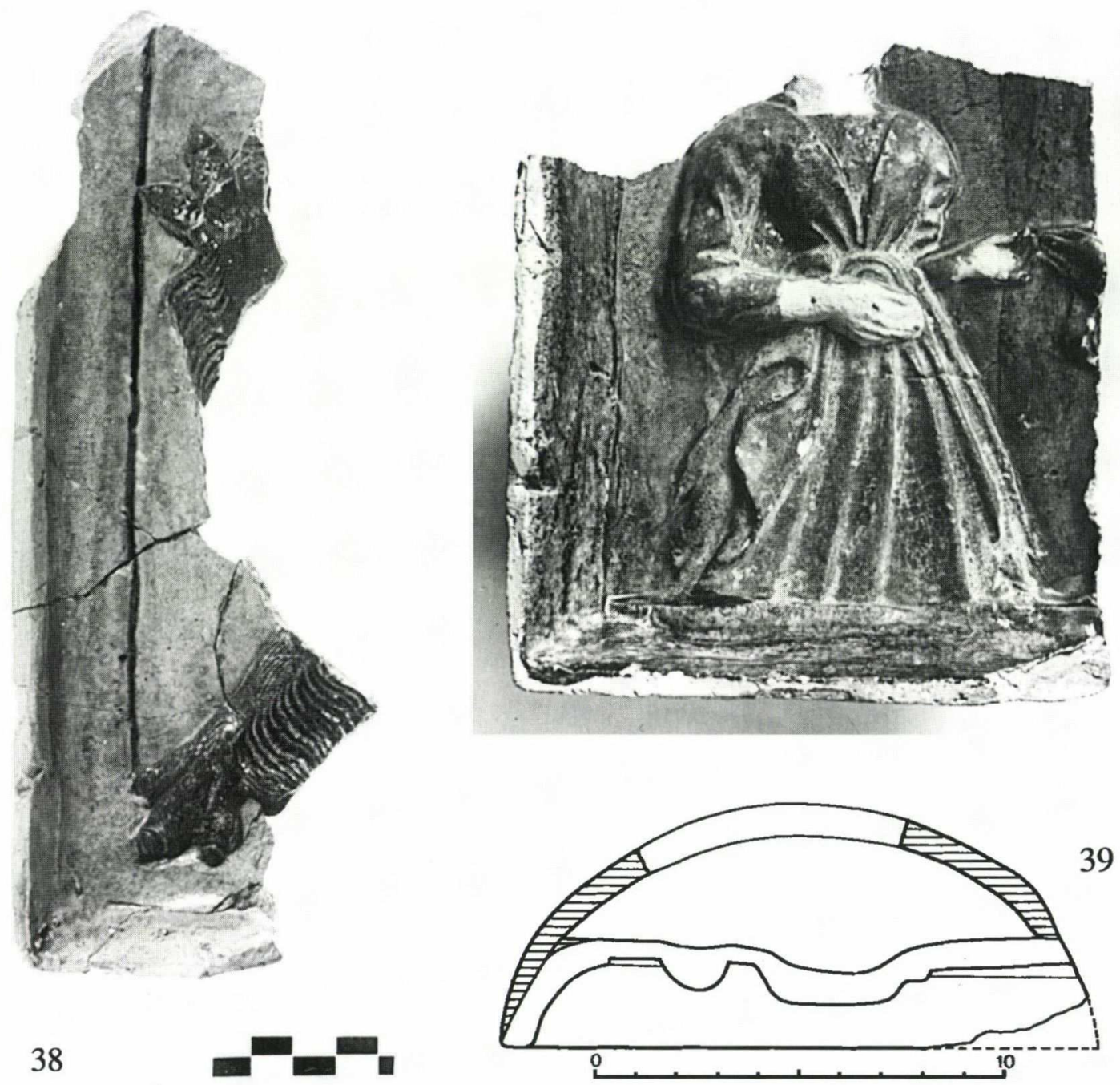

Abb. 38-39. Buntglasierte Kacheln: Fragmente von einem Löwen und einer Frau in lilafarbenem Gewand

Im Material der österreichischen Sammlung (bzw. unter den von hier in andere Museen und Sammlungen gewanderten Keramiken) findet man ebenfalls Stücke, die auf Grund ihres Stils und ihrer Technologie Erzeugnisse ein und derselben Werkstatt sind. Beispielsweise die in Neufelden (Mühlviertel) zum Vorschein gelangte grünglasierte Kachel mit reitendem Waldschrat der ehemaligen Figdor-Sammlung (Abb. 32). Von diesem Typ ist auch ein buntglasiertes Exemplar bekannt (Gelb auf grünem Grund; ehemals in der Sammlung Lanna). Im Unterschied zu den Vorgenannten hat die Kachel einen glatten gekehlten Rahmen und ebenso glatten Hintergrund - vielleicht deshalb rechnete Walcher sie nicht zu den übrigen. Doch wie die in der folgenden Untergruppe vorgestellten Fragmente zeigen, handelt es sich auch hier um ein (zu einem anderen Ofen gehörendes) Stück dieser Werkstatt. - Ein weiteres, von der Forschung immer zu diesem Kreis attribuiertes Stück ist der Weinkühler mit Kundschaftern des Hamburger Museums. Der Stil der das Gefäß zierenden Gestalten stimmt mit dem der Kacheln überein (grüner Grund, braune und manganlilafarbige Gewänder, Bart und Haare schwarz, die Körperteile rosafarbig-weiß - wie auch bei dem vorigen Waldschrat -, die Stiefel schwarz, die Weintraube blauglasiert). Der obere Teil 
des 40,5 cm hohen Gefäßes, das ursprünglich in Oberösterreich (Kirchdorf) gefunden wurde, schließt mit derselben gedrehten Schnurverzierung ab (mit weiß-gelb-lilafarbiger Glasur) wie zum Beispiel die Ecke der David und Goliath-Kachel ${ }^{24}$ ( $A b b$. 33).

Erwähnt sei an dieser Stelle noch ein gesondertes Eckwappen, das vielleicht mit einem der Budaer Öfen in Zusammenhang gebracht werden kann. Auch dieses Stück fand ich in der nach 1490 angehäuften Abfallschicht (im Jahre 1952, auf der Sohle des am Palast verlaufenden Felsgrabens), und es wurde bei dieser Frage bislang kaum in Betracht gezogen: Wappenschild aus gut geschlämmter, gelbgebrannter Scherbe (die Oberfläche bräunlich), ohne Glasur (aber am unteren Rand mit grünem Glasurfleck), H: 13,8 $\mathrm{cm}, \mathrm{B}: 11,6 \mathrm{~cm}$, D: 0,6 cm. Darauf, plastisch ausgearbeitet, drei überkreuzte Pfeile, der mittlere abgeflacht und ohne Spitze $(A b b .34)$. Dies ist das Wappen von Bischof János Filipecz, der zwischen 1484 und 1490 Kanzler bei König Matthias war und während dieser Zeit zahlreiche diplomatische Missionen im Ausland erfüllte. ${ }^{25}$ Seine Person gibt jedoch keine jeden Zweifel ausschließende Datierung, da er auch nach Matthias' Tod noch eine Rolle spielte (so dass man ihn auch mit den später zu behandelnden Öfen in Zusammenhang bringen kann). Dass ich das Eckwappen dennoch in erster Linie an dieser Stelle erwähne, begründen die Spuren der beiden kleinen, runden, abgebrochenen Zapfen, die auf der Rückseite des Kachelblattes erkennbar sind. Die schräge Abschnittstelle der oben erwähnten Eckkachel von Tata (Abb. 61) war ebenfalls mit zwei runden Löchern versehen - zwecks Befestigung des Wappens. Diese seltene Lösung könnte bedeuten, dass das Stück an dieselbe Untergruppe zu binden ist. (In anderen Fällen begegnet man anderen Befestigungslösungen.) Das Wappen zumindest deutet auf die persönliche Vermittlung (eine Auslandsreise?) des Bischof-Kanzlers hin, die Frage ist nur, wann das geschah. Zieht man die

${ }^{24}$ Wilder Mann, Samml. Figdor: WALChER 1909, Abb. 80, 15. Jh. - Wilder Mann, Samml. Lanna: O. V. FALkE: Die Sammlung des Freiherrn Adalbert von Lanna. Prag. I. Berlin 1909, Nr. 595, „nach Walcher Werkstätte in Oberösterreich“. - Weinkühler mit Josua und Kaleb: Samml. Lanna, Nr. 616. Salzachtal, Anfang 16. Jh. H. KOHLHAUSEN: Geschichte des deutschen Kunsthandwerks. München 1995, 375-376, Farbtafel XII. Diese Darstellung kommt auch an einer Ofenkachel vor, und zwar zusammen mit der Malachias-Kachel an einem aus dem Schloss bei Aussee erworbenen Ofen. Was die Forschung bislang nicht erkennen konnte: hier befindet sich in der mittleren Reihe des oberen Teils auch die David und Goliath-Kachel. Über den Ofen: Walcher 1905, 243 und A. WALCHER v. MOLTHEIN: Beiträge zur Geschichte deutscher Keramik III. Alpenländische Kachelkunst. Altes Kunsthandwerk 1927, 20-22, Taf. 20. Der Weinkühler und die identische Kachel: Abb. 16-17; wegen des Vergleichs der Unterschiede ihrer Glasuren (hellblaue Zinnglasur bzw. bei der anderen dunkelgrüne Bleiglasur an der Weintraube) meinte er, dass der Weinkühler später entstanden sei als die Kachel. (Wie unser Material beweist, beruht die Datierung nach 1500 wegen der Verwendung von Zinnglasuren auf einem Irrtum.) - Leider ist nur aus seiner Beschreibung bekannt, dass es unter den (aus verschiedenen Werkstätten stammenden) Kacheln dieses Ofens auch einen ,... Jäger mit einem Hasen auf dem Rücken ..." gab - im Weiteren wird man sehen, dass diese Darstellung unter den aus Buda bekannten Kacheln der Werkstatt ebenfalls vorkam (Abb. 37). Ich persönlich binde noch zwei wei-tere Kacheln an diese Werkstatt: eine große Wappenkachel des Nürnberger Museums wegen ihres charakteristischen Stils und ihrer Farben (durchscheinendes Weiß, Grün und Gelb, am Rand auf gelbem Ast grüne Blätter), s. Franz 1969, Abb. 149, „Österreich, um 1500“, sowie von den unglasierten Kacheln des im Salzburger Museum stehenden Ofens (nicht in ursprünlicher Zusammenstellung) die Szene mit der Heiligen Familie (A. WALCHER: Bunte Hafnerkeramik der Renaissance ... Wien 1906, Fig. 91, „Anfang 16. Jh.“). Derselbe Stil, am Gewand Josefs und Mariens mit dem typischen Muster.

25 János Filipecz (Pruis), ab 1476 Bischof von Wardein. 1476 schickt man ihn als Gesandten nach Urbino, 1486 nach Neapel, 1487 an den französischen Königshof; $1487 / 88$ bei König Wladislaw II. Gesandter in Böhmen, dann in Schlesien und der Lausitz. Im Oktober 1489 sendet ihn Matthias nach Linz, um mit Maximilian über den Waffenstillstand zu verhandeln. Nach Matthias' Tod legt er sein Amt nieder, verschenkt sein Vermögen und tritt in ein ausländisches Franziskanerkloster ein, wird aber 1506/07 als Anhänger Wladislaws II. am Wiener Hof in der jagiellonisch-habsburgischen Heiratsangelegenheit aktiv. 1508 zum böhmischen Landtag entsandt, verstorben im Jahre 1509. (Bonfini unterstreicht seine Freigebigkeit anläßlich seiner Frankreichreise und seine Vorliebe für Prunk.) V. BUNYITAY: A váradi püspökség története [Geschichte des Bistums Wardein] 1. Nagyvárad 1883, 308-321. - In den achtziger Jahren ließ Filipecz für die Wardeiner Kirche eine reich verzierte liturgische KodexReihe anfertigen (vielleicht in Prag). Kódexek a középkori Magyarországon (Handschriften aus Ungarn im Mittelalter). Katalog. Budapest 1985, 143, 163. - Sein Wappen schmückt die Titelseite eines Pontifikale, dessen Miniaturen in den 1480er Jahren in Buda entstanden. 
Fundumstände in Betracht, hängt es wohl eher mit der Budaer Bautätigkeit und Palastausstattung unter Matthias und nicht unter König Wladislaw II. zusammen. ${ }^{26}$

Leider ist nur ein zeitgenössisches Dokument überliefert, das die Öfen des Palastes erwähnt. Es stammt aus der Feder des humanistischen Geschichtsschreibers Bonfini. Er schreibt, die Bautätigkeit König Matthias' lobend, im Zusammenhang mit den Speisesälen im Obergeschoss, dass ,... die Öfen in den Speisesälen gewölbte Kacheln bedecken und nicht nur mit der Schönheit ihrer Farben, sondern auch mit der Vielfalt der darauf befindlichen imaginären Tiergestalten gefallen““. ${ }^{27}$ Seine Beschreibung an konkrete Öfen zu binden, ist schwierig. Lediglich die auffällige Farblichkeit und das Vorkommen der fantastischen Tiere berechtigen zu der Vermutung, dass es Öfen der "Rauriser Gruppe“ waren, die seine Aufmerksamkeit anzogen. (Diesen Teil seines Buches schrieb Bonfini zwischen 1489 und 1492.)

\section{Untergruppe}

Die folgenden Ofenkacheln behandele ich im Rahmen der Einteilung deshalb gesondert, weil sie meiner Meinung nach nicht zu dem (den) vorigen Ofen (Öfen?) gehören, da sowohl die Maße der Kacheln, als auch die Form der Ränder (glatte Kehle, unverziert) widersprüchlich sind. In Bezug auf Technologie und Stil zeigen sie zwar keine bedeutenderen Unterschiede, aber es gibt einige Typen darunter, deren Originalpositiv ein anderer Meister verfertigt haben dürfte. Von einem anderen Ofen zeugt beispielsweise Typ 1, der zu einer Ecke des unteren Ofenkörpers gehörte; nicht nur seine Abmessungen sind anders, sondern auch die die Ecke schmückende gedrehte Schnur ist schmaler als auf der David und Goliath-Kachel.

${ }^{26}$ Dies bekräftigt auch der Umstand, dass er nach 1490 nur noch als einfacher Mönch reiste, während er bei seinen früheren Reisen Geschenke des Königs mitführte und mit reichen Gegengeschenken heimkehrte (vom französischen Hof z. B. Silbergefäße, federgeschmückte Kopfbedeckungen). Die Forschung vermutet, dass er dem König damals das eine frankoflämische Graduale der Corvina-Bibliothek mitgebracht hat. - Eine denkbare Möglichkeit wäre, dass der Ofen noch zur Zeit des Salzburger Erzbischofs Bernhard von Rohr entstand, der sich wegen seines Konflikts mit Friedrich III. (den er zum Abdanken zwingen wollte) unter Matthias' Schutz stellte und ihm sogar seine österreichischen Burgen überließ. Allerdings käme dafür nur der Zeitraum zwischen 1479 und November 1481 in Betracht (denn da hatte er sein Amt schon niedergelegt, das der zusammen mit seinen Schätzen aus Ungarn zu Friedrich geflüchtete Beckensloer übernahm). Die Urkunde des im Mai 1481 in Wien geschlossenen Waffenstillstandes wurde von János Filipecz unterzeichnet, in der man auch den Names des Salzburger Erzbischofs, als einem der Friedensunterhändler, noch lesen kann. (V. TELEKI: A Hunyadiak kora Magyarországon [Das Zeitalter der Hunyadis in Ungarn] 5. Pest 1866, 181.) - Dass (wie von PRODINGER 1972, 3 aufgeworfen) irgendeine ungarisch-österreichische Werkstattbeziehung zu Erzbischof Beckensloer bestanden haben soll, ist nur schwer vorstellbar, wenn man dessen offene Feindschaft kennt (Bonfini hielt ihn für einen der Verursacher des ausgebrochenen Krieges). - Über den spätesten Zeitpunkt der Lieferung des Ofens nach Ungarn können vielleicht die Ereignisses des Jahres 1489 Auskunft geben. Damals nahmen Matthias und der römische König, Herzog Maximilian, Verhandlungen auf (Letzterer war im Gegensatz zu seinem Vater der Initiator des Friedensschlusses). Im September 1489 sollte es in Linz zu einem persönlich Treffen kommen (das aber wegen Matthias' Krankheit nicht stattfand). Der Zeitgenosse Bonfini schreibt, dass man János Filipecz nach Linz entsandte, dem
Matthias reiche Geschenke für Maximilian mitgab („Ioannem Varadiensem episcopum oratorem misit, ut de pace tractaret ... Maximilianum ... in Lincio quadrigentos vini cados totidemque boves et duodena nummum milia dono misist.“ Dec. IV. Liber VIII.) (Berichte des päpstlichen Gesandten bzw. Gesandten des Hofes von Ferrara zwischen Juni und Oktober über die Verhandlungen, die Verlängerung der Waffenruhe sowie gegenseitige Heiratspläne [zwischen Maximilians Tochter und Herzog János Corvin bzw. Maximilians Sohn und der Schwester der Königin Beatrix]: V. FRAKNói: A Hunyadiak és a Jagellók kora [Das Zeitalter der Hunyadis und Jagiellonier]. Budapest 1896, 314315.) - Es wäre durchaus denkbar, dass man den Ofen (die Öfen?) als Erwiderung der Geschenke nach Ungarn schickte und Filipecz' Wappen ein Hinweis auf seine Vermittlerrolle ist.

${ }^{27}$ A. BONFINI: Rerum Hungaricarum Decades. (Francfurtii 1581) Decas IV. Liber VII. „Hypocausta in tricliniis mammatis tegulis obtecta, que non modo colorum pulchritudine, sed animalium confictorum varietate conspicua.“ - Mit ,hypocaustum" ist hier nicht die ursprüngliche antike Bedeutung des Wortes, sondern (wie auch in Konskriptionen des 16.-17. Jahrhunderts) der Ofen des heizbaren Raumes gemeint, und ,mammatis“ bedeutet im übertragenen Sinn „Wölbung, gebogene Fläche" - vermutlich wegen der Tiefenwirkung der Kacheln (eigene Übersetzung d. Verf.). - Leider verstand der Humanist kaum etwas von Realien. Selbst seine Architekturbeschreibungen sind nicht wirklich fachmännisch, außer wenn es sich um Werke der Renaissance handelt. - Reisende, die den Palast später besuchten, erwähnen die Öfen nicht mehr. Vielleicht hatten die Türken, die figurale Darstellungen verachteten, diese bis dahin schon abgeschlagen? (Und vielleicht fehlen deshalb auch die meisten Gesichter? Denn die Gesichter an den realtiv unversehrt erhalten gebliebenen Steinmetzarbeiten der Renaissance wurden absichtlich zerstört.) 

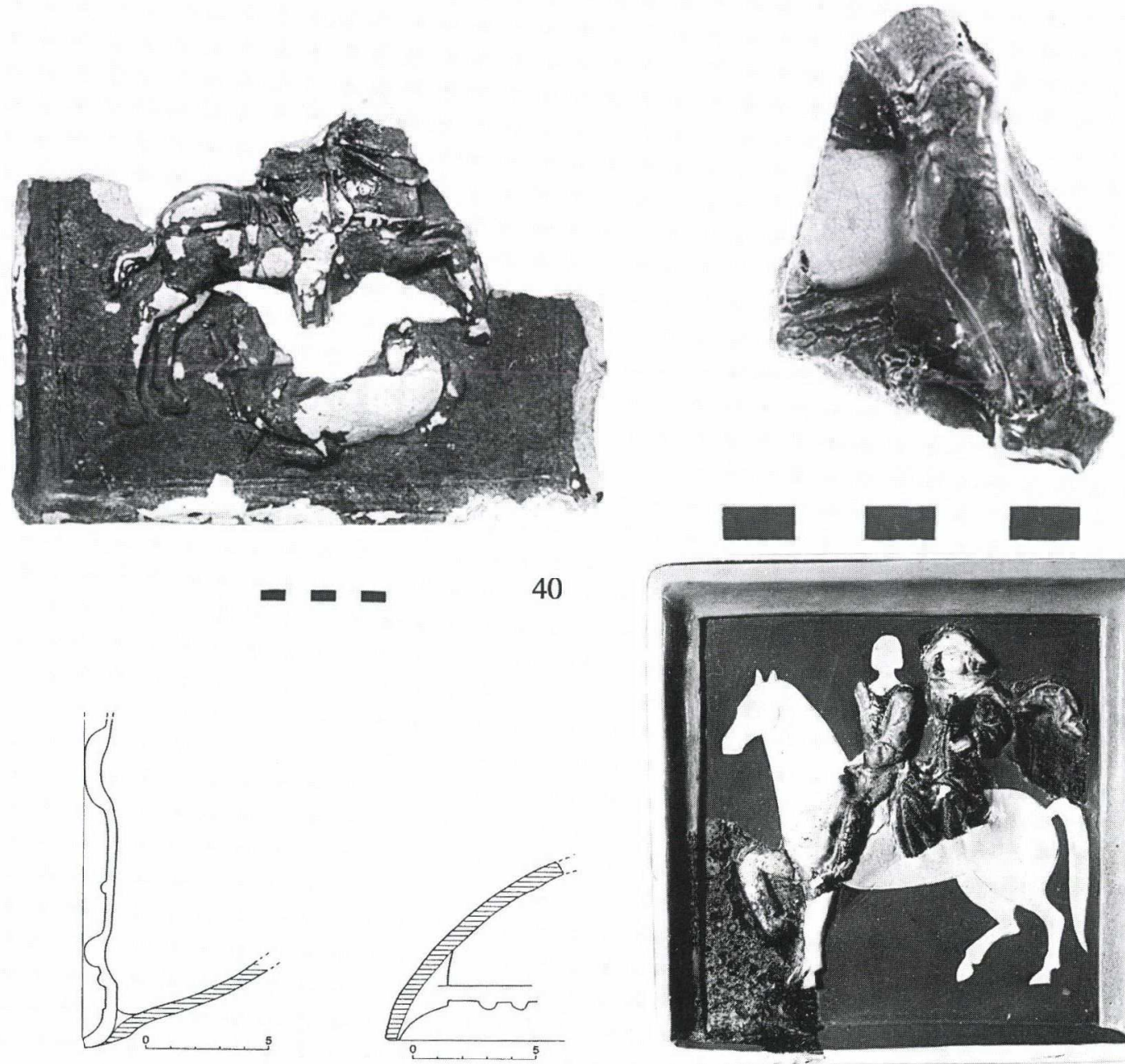

40

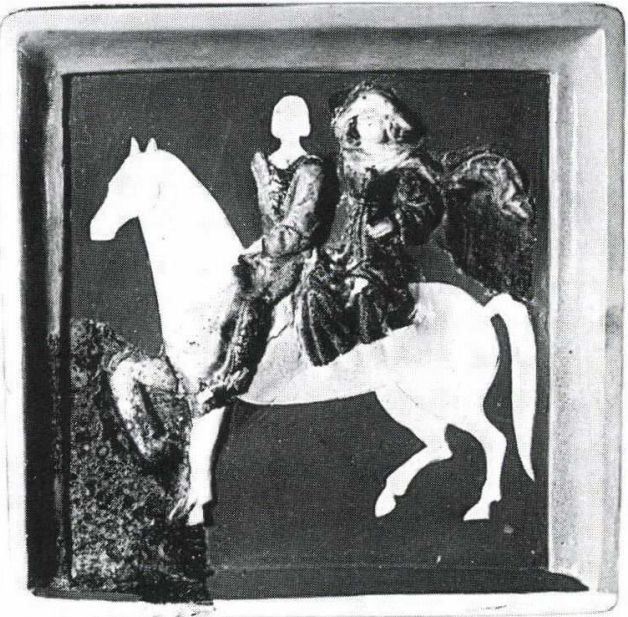

42

Abb. 40-42. 40: Hl. Georg, grünglasierte Kachel; 41: buntglasiertes Bruchstück identischen Typs; 42: reitendes Paar, buntglasierte Kachel
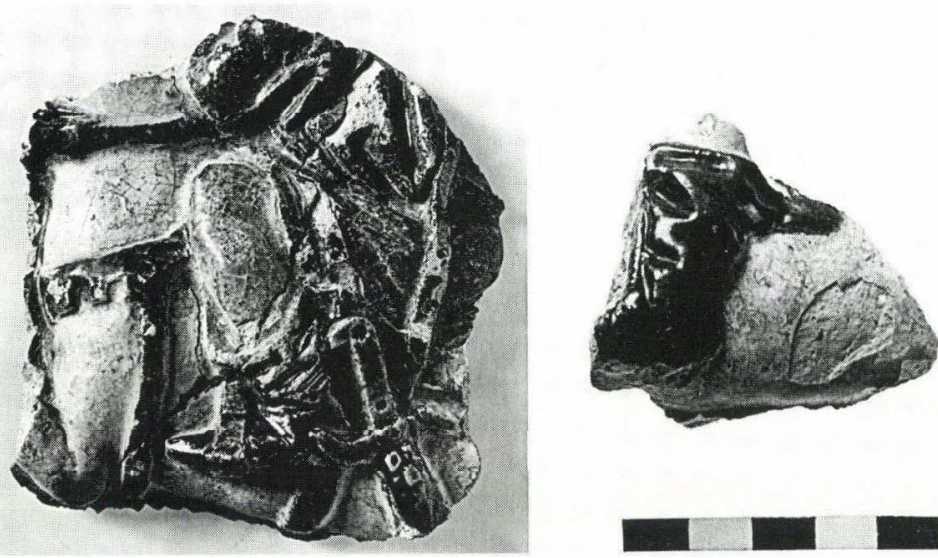

Abb. 43. Husar zu Pferde, Bruchstücke 

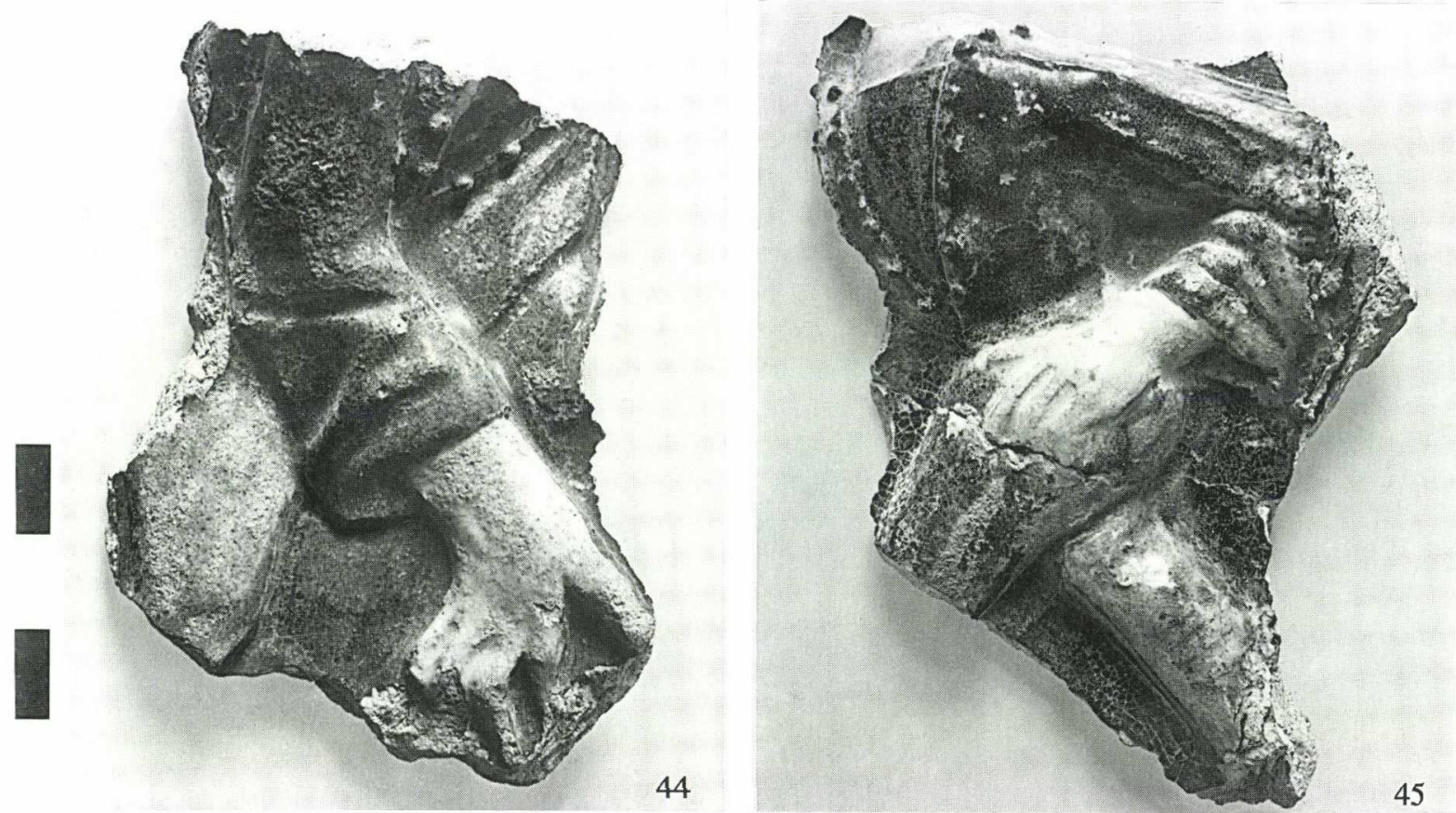

Abb. 44-45. Fragmente von buntglasierten figuralen Kacheln
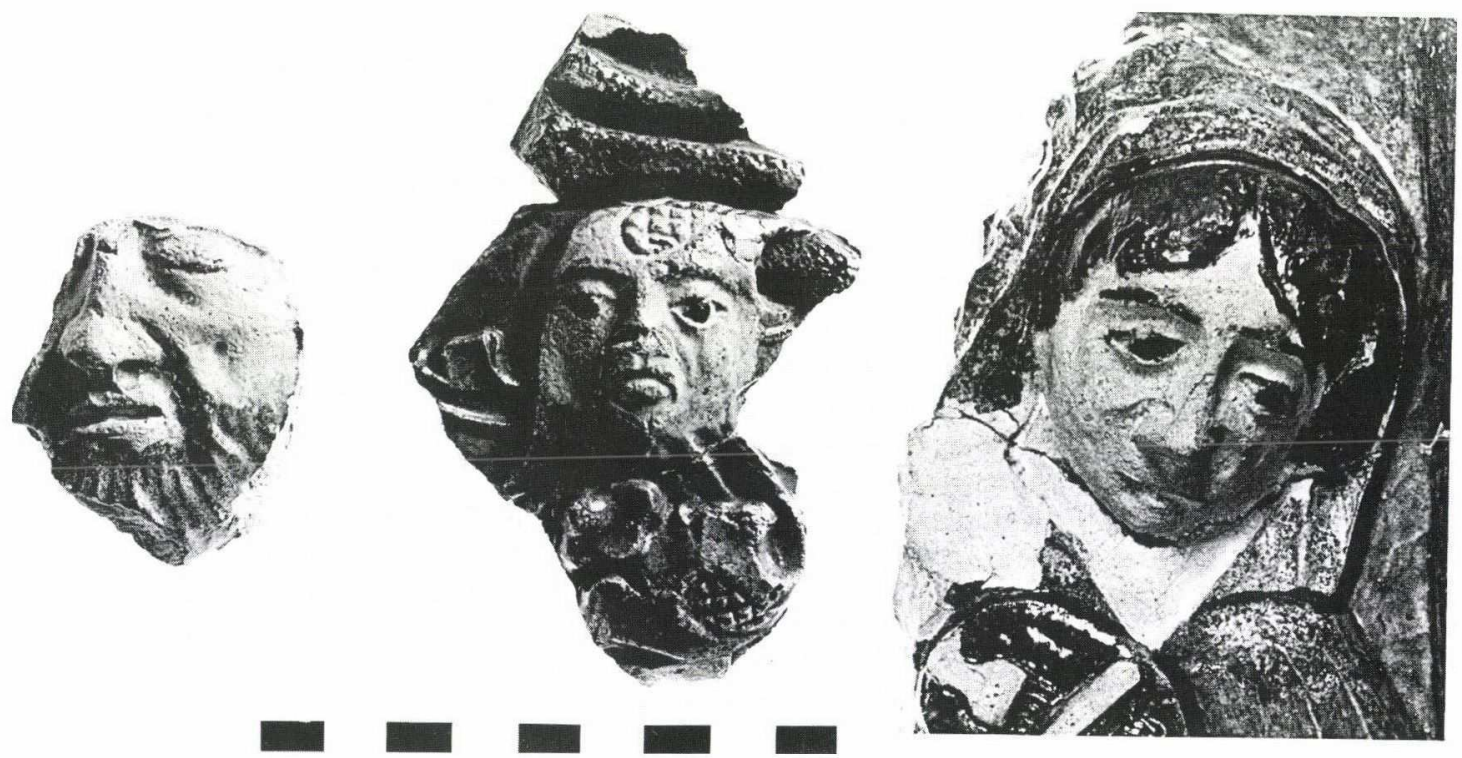

Abb. 46. Gesichter von buntglasierten Kacheln 

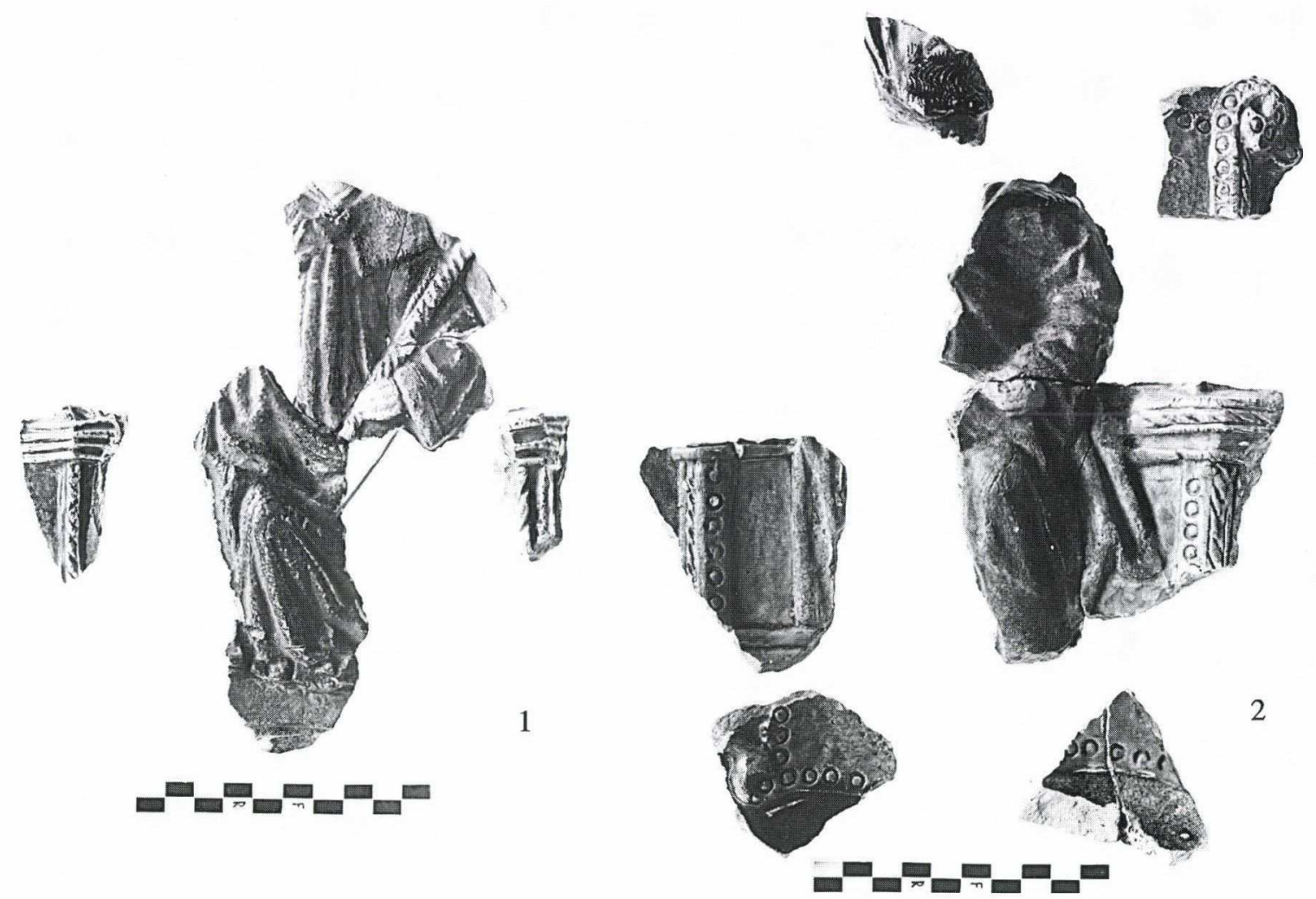

Abb. 47. Thronende Gestalten, Fragmente
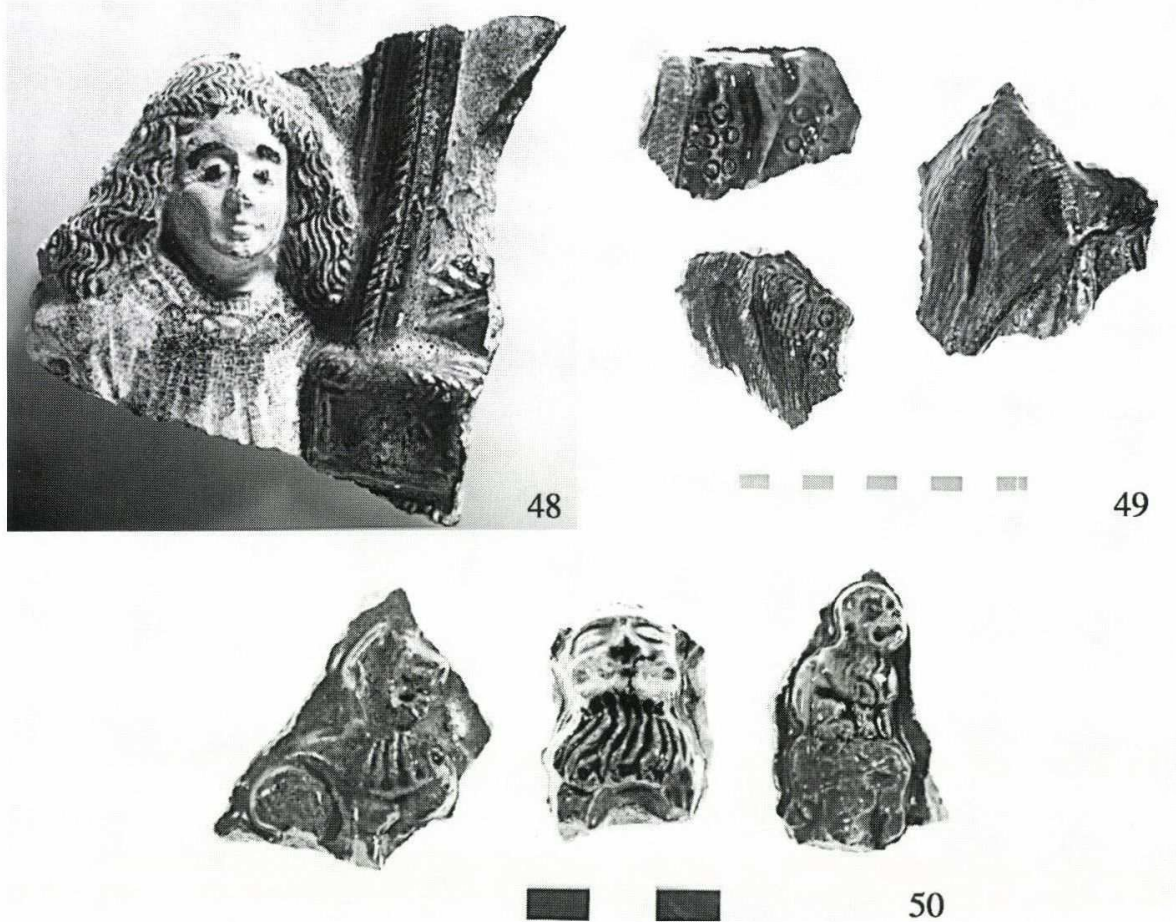

Abb. 48-50. 48: neben einem Thron stehende Gestalt; 49: Details der Kleidung; 50: kleine Löwenfiguren 
1. Jacob. Viereckige Kachel mit glattem, geschlossenem Vorderblatt. Dem Betrachter zugewandte Halbgestalt in einem Gewand mit dichtem Faltenwurf, auf dem Kopf eine seitlich herabhängende Mütze. In den Händen hält sie ein langes Spruchband, darauf in erhabenen Buchstaben die Inschrift: Jacob - pro p.... Weiße Scherbe, der rückseitige Halbzylinder aus rotgebrannter Scherbe. H: $28 \mathrm{~cm}, \mathrm{~B}: 27 \mathrm{~cm}$. Zwei Exemplare konnten ergänzt werden; beim ersten vor grünem Hintergrund lilabraunes Gewand und Mütze, Gesicht und Hände weiß, Spruchband mit gelber Glasur, der Rahmen gelb; beim zweiten zitronengelber Hintergrund und Rand, lilabraune Mütze, helles, bräunlichgrünes Gewand, das Spruchband weiß mit blauen Buchstaben (Abb. 36). - Der an das erste Exemplar gefügte Eckteil hat halbierte Abmessung, darauf ein stehender wilder Mann mit braunem Körper (zum größeren Teil ungewisse Rekonstruktion), weißes Gesicht, schwarzer Bart, Auge und Augenbraue blau. Die Ecke schmückt gelbe und grüne Schnurverzierung.

2. Jäger mit Hunden. Von diesem Typ kenne ich nur Fragmente. Die vollständige Komposition ist von einer grauen, unglasierten Kachel aus Österreich bekannt, bei der es sich allerdings um eine kleinere Kopie der Originalstücke handelt. ${ }^{28}$ Danach gibt die bewegte Komposition ein nach links schreitender, Horn blasender Jäger wieder, der in der linken Hand eine Lanze hält, von der ein daran befestigter Hase herabhängt; unten laufen drei Jagdhunde, der hintere Hund reckt sich nach dem Hasen. Unter den Fragmenten aus dem Budaer Palast blieben ein grünglasierter Kopf und von einem anderen Exemplar ein dunkelbrauner Hund auf braunem Grund erhalten ( $A b b$. 37). Aus dem Visegráder Palast wurde ein einfarbiges grünglasiertes Fragment mit einem gestiefelten rechten Bein und den Hunden publiziert. (Hier zieren das Gewandunterteil die von der vorangehenden Untergruppe bekannten winzigen Kreise.) H: 27,8 $\mathrm{cm}(A b b .37 .3)$.

3. Löwe. Von dem sich nach links aufbäumenden Löwen blieb nur der Kachelrand erhalten; die Enden der beiden Vorderbeine auf zitronengelbem Grund mit brauner Glasur. Nach der Musterung des Tierfells und der eingedrückten Oberflächenbehandlung der Zehen des oberen Beins dürfte diesen Typ derselbe Meister verfertigt haben, von dem auch zahlreiche Motive der 1. Untergruppe stammen. H: vermutlich $28 \mathrm{~cm}$; gelblichweiße Scherbe mit rötlichbraunem, zylindrischem Rückenteil ( $A b b .38$ ).

4. Verlobungsszene. Die rechte Seite der Kachel mit flachem Vorderblatt wurde gerade abgeschnitten, so dass nur die halbe Komposition erkennbar ist. (Vermutlich hat man sie am Ende einer an der Wand abschließenden Reihe als ergänzendes Halbstück verwendet, deshalb ist es keine richtige Ecke.) En face abgebildete, stehende Frauengestalt mit leicht nach rechts gewandtem Oberkörper, ihre rechte Hand ruht auf der Hüfte, mit der vorgestreckten Linken berührt sie die Finger ihres (fehlenden) Gegenübers. Der gekehlte Rahmen grün, der Hintergrund bräunlichgelb, das Gewand mit einfachem Faltenwurf lilafarbig, das im Ausschnitt sichtbare Hemd grün, Hände und Hals weißglasiert. Weiße Scherbe und rötlichbrauner, halbzylindrischer Rückenteil (mit einem Rest der oval ausgeschnittenen Feueröffnung). B: 14,5 cm (Abb. 39). - Die Haltung der Gestalt mit ausgestreckter Hand deutet darauf hin, dass sie zu einer Szene mit zwei Personen gehört hat, wie man im Spätmittelalter häufig die Verlobung darstellte. Die Darstellung entstand gewiss nach dem Vorbild eines Kupferstichs oder Holzschnitts. ${ }^{29}$

Die folgenden Kacheln geringerer Abmessung waren ebenfalls an einem anderen Teil des Ofens platziert - vielleicht in den unteren Reihen?

5. Reitendes Paar. Viereckige Kachel. Auf dem geschlossenen Vorderblatt nach links strebender Schimmel, auf seinem Rücken ein junger Mann (in blauem Gewand mit grünem Hemd), und hinter ihm sitzend, dem Betrachter zugewandt, eine Frau (das grüne Kleid in der Taille zusammengefasst, hinter ihrem Rücken flattert ein weißer Schleier). Der gekehlte Rahmen gelb. Das Vorderblatt weiße, der rück-

${ }^{28}$ Die unglasierte Kachel kam in Ebersdorf (N.Ö.) zum Vorschein, H: 22,5 cm (Museum Melk). Ihr Bild nach G. JARITZ: Die Kuenringer. Zwettl 1981, Nr. 803. - Darüber und über andere reduziert gebrannte österreichische Ofenkacheln detailliert: I. Holl in dem in Anm. 12 erwähnten Artikel. - Bei den jüngsten Grabungen in der Stadt Buda fand man das Paarstück dieser Kachel, wo der Jäger auf einem Pferd sitzt (unpubliziert).
${ }^{29}$ Wegen der genannten Mängel ist unser Stück leider nicht für einen genaueren Vergleich geeignet. Ähnliche Szene: Miniatur im Gratianuskodex (Druck, Venedig 1474); Rodericus Zamorensis: Spiegel des menschlichen Lebens, Eheschließung (Holzschnitt, Augsburg 1475). - Der alte Name der Verlobung war „Verspruch“, ung. „kézfogó“. 
seitige Halbzylinder bräunlichrote Scherbe. H: $24 \mathrm{~cm}$, B: $24 \mathrm{~cm}$ (Abb. 42). Zwei Fragmente lassen vermuten, dass es davon auch einfarbig grünglasierte Exemplare gab ( $A b b .53)$. - Eine im 15. Jahrhundert beliebte Darstellung. ${ }^{30}$

6. Hl. Georg. Viereckige Kachel mit geschlossenem Vorderblatt. Darauf ein nach rechts springendes Pferd, das der Hl. Georg in Rüstung reitet. Am Boden der Kachel windet sich der Drache, durchstoßen von einer - abgebrochenen - Lanze. Gelblichweiße Scherbe mit heller, gelblichgrüner Glasur; das Rückenteil ursprünglich ein scheibengedrehter, runder Rumpf. B: $24 \mathrm{~cm}(A b b .40) .{ }^{31}$ - Von diesem Typ ist auch ein Fragment mit buntglasierter Lösung vorhanden: weißer Pferdekörper auf grünem Grund, der Sattel dunkelbraun, das Bein des Ritters grünlichblau mit langhälsigem Sporn (Abb. 41).

Auf Grund der Fragmente von Buda und Visegrád dürften an diesen Öfen auch noch andere Reiterkompositionen beliebte Darstellungen gewesen sein (bei den Typen mit 24 und $28 \mathrm{~cm}$ ); siehe z. B. die Husaren-Darstellung auf $A b b$. 43, mit kurzschäftigen Stiefeln, der typischen hochgezogenen Beinhaltung und dem tief herabhängenden Säbel an der linken Seite (lilafarbenes Gewand, blaue Hose, schwarze Stiefel, das Pferdegeschirr grün).

Andere Fragmente mit figürlichen Darstellungen deuten darauf hin, dass es eine Vielfalt von buntglasierten Ofenkacheln - mit leider unbekannter Komposition - gegeben haben muss. Ein schreitender (tanzender?) Jüngling kommt in zwei Fällen vor. Charakteristisch ist ihre der Mode der zweiten Hälfte des Jahrhunderts folgende, eng anliegende Kleidung; hier hat man die farbliche Trennung mit unterschiedlichen Glasuren gekennzeichnet (das Gewandoberteil lilafarben-blau-gelb, die Strumpfhose lilafarben-blau-gelb; beim Paarstück lilafarbiges Oberteil, weiß-gelb-grün gestreiftes Hemd, blaue Strumpfhose). Bei beiden begleitet eine betonte Knopfreihe die Ränder des tiefen Halsausschnitts (Abb. 44-45). - Ein Männergesicht mit geschlossenen Augen und grünlichgrauem Bart (offenbar ein Gemisch von Bleiund Zinnglasur) könnte nach Abmessung und Stil als Paarstück der Jacob-Kachel gewesen sein (Abb. 46). Von ebenfalls größeren Kacheln dürften verschiedene Gewanddetails mit dichtem Faltenwurf stammen (feurigbraune Glasur auf grünem Grund bzw. über einem grünen Mantel lilafarbiger Pelz). Eine typische stilistische Lösung ist die Wahrnehmbarmachung der Fell- bzw. Pelztextur durch dichte, dünne Parallellinien, die auch die Plastik betonen (Abb. 49). - Die konsequente Andeutung der Gewandstoffe, ja überhaupt die Mannigfaltigkeit der Oberflächenbehandlung, weisen nach meiner Ansicht jenen Meister aus, der die Originalmatrizen für die David-, Weiberlist- und Jacob-Kacheln angefertigt hat; von seiner Hand zeugt auch der Stil der wenigen erhalten gebliebenen Gesichtsdarstellungen. Dagegen dürften die bedeutenderen Abweichungen aus dem Befolgen der Zeichnung der aus unterschiedlichen Quellen geschöpften Kompositionen resultieren.

Während die vorgenannten Fragmente keinen Aufschluss über die Form der Ofenkacheln geben, denen sie zuzuordnen sind, haben die Folgenden wahrscheinlich zu leicht vertieften Nischenkacheln gehört.

7. Thronender König (?). Fragment einer frontal dargestellten, sitzenden Gestalt in einem bräunlich schwarzen Umhang mit reichem Faltenwurf, die in ihrer Linken vermutlich ein Zepter hält. Gewandärmel und Kragen mit Pelz besetzt. H. des Fragments: $18 \mathrm{~cm}$ ( $A b b .47)$. Die plastische Darstellung ist auffallend flach. Dünne (D: 0,4-0,6 cm), hellgelbe Scherbe, wie auch das nächste Stück.

\footnotetext{
${ }^{30}$ Miniatur auf der Darstellung des „Monat August“ im Gebetbuch des Herzogs Berry, Anfang des Jahrhunderts, aber als Falknerszene; auf der Zeichnung der „Turnszene“ vom Meister des Hausbuchs mit sehr ähnlicher Lösung (die Kleidung des Mannes aber anders), um 1480; Rücklaken mit Jäger und Minne-Szenen, um 1480 (Wien, Kunsthistorisches Museum): R. JAQUES: Deutsche Textilkunst. Berlin 1942, Abb. 53. - Fragmente $(\mathrm{H}: 22 \mathrm{~cm})$ einer unglasierten Kopie dieses Kacheltyps fand ich in der Burg von Köszeg (Güns), und zwar in der Funde der zweiten Hälfte des 15. Jahrhunderts enthaltenden Schicht. Das bedeutet, man hat sie Ende des Jahrhunderts, spätestens aber
}

um 1500 weggeworfen. Demnach wurde das Original zu dieser Zeit bereits von einer ländlichen Werkstatt kopiert. I. HOLL: Kőszeg vára a középkorban (Die Burg Kôszeg - Güns - im Mittelalter). Budapest 1992, Abb. 149:1. Eine andere Kopie im Grazer Museum f. Volkskunde: K. STRAuss: Kacheln und Öfen der Steiermark. Graz 1940, Taf. XVIII:8, mit leicht umgeformten Details.

${ }^{31}$ Erstpublikation des Stückes: K. MeLIS: Szt. György alakos budai kályhacsempék [Budaer Ofenkacheln mit der Gestalt des HI. Georg]. In: E. FÜGEDI (red.): Múvelődéstörténeti tanulmányok a magyar középkorról. Budapest 1986, 261. 
8. Thronende Gestalt. Dies könnte das Paarstück der vorigen Kachel sein, aber hier blieben unter den Fragmenten auch Teile des Throns erhalten; gelbglasiert, mit gekerbten bzw. von kleinen Kreisen gesäumten Rändern. Hellilafarbener Umhang mit reichem Faltenwurf und schwarzem Umschlag. Plastisch schön ausgearbeitet. (Ob der auf dem Foto abgebildete weiße Kopf mit schwarzem Bart hierzu gehört, ist zweifelhaft. Er wurde nur wegen seiner Materials und der Maße beigestellt. - Abb. 47.2)

Auf Grund eines weiteren Bruchstücks kann verifiziert werden, dass in solchen Thronszenen auch mehrere Personen auftraten. Hier blieb ein Detail von einer auf der rechten Seite des Throns (und niedriger als dieser) stehenden Männergestalt erhalten: in lilafarbigem Gewand, mit der für das Jahrhundertende typischen, schulterlangen, gewellten Haartracht in Gelb (Abb. 48). - Welcher Kachel (Kacheln) diese Fragmente zuzuordnen sind, weiß ich zwar nicht, denke in Anbetracht ihres Charakters aber daran, dass auch die drei kleinen sitzenden Löwenfiguren zu derartigen Kacheln gehört haben ( $A b b$. 50). Es kommt nämlich vor, dass seitlich auf der Armlehne des Throns oder weiter oben kleine Löwen- oder andere Tierplastiken dargestellt wurden. ${ }^{32}$ Solche sind auf unseren Fragmenten vor grünem Hintergrund zu sehen (mit gelbem bzw. gelblichbraunem Körper; bei einer Maul und Augen mit weißer Zinnglasur; unter der einen Detail eines blauen, stilisierten Blattes).

Die Kacheln einer weiteren thematischen Gruppe zieren verschiedene Blumenmotive. Leider konnte nur eine davon ergänzt werden (und auch sie nur mangelhaft): 9. Rosenhecke mit Vogel. Zylindrisch gearbeitet, auf drei Seiten mit breitem, gekehltem Rahmen. Nach rechts und links aufwärts gebogene breitere Äste, an denen Blätter mit gekräuseltem Rand (grün) und kleine Rosen (lilafarben) hängen. Unter den dazu gehörigen Fragmenten befand sich auch das Stück eines Vogels mit hellblauem Federkleid (er war vermutlich in der Mitte oder oben platziert). Die Scherbe gelblich weiß, der Hintergrund gelbglasiert. H: $30 \mathrm{~cm}, \mathrm{~B}: 24 \mathrm{~cm}, \mathrm{~T}: 7 \mathrm{~cm}(A b b .51)$. - Andere Fragmente hatte man auf gelbem Grund nicht mit einem grünen, sondern dunkelbraunen Baumstamm und Zweigen mit grünen, gelappten Blättern verziert; in manchen Fällen war der Stamm auch schwarz bzw. weiß (Abb. 52.2). Ein weiteres Exemplar schmückten braune Zweige mit blaulilafarbigen Distelblüten. (Das Paarstück der Kachel - ein Fragment mit grünem Grund und gezacktem, lilafarbigem Blatt - beweist, dass man durch die unterschiedliche farbliche Gestaltung identischer Typen auch bei diesen nach größerer Mannigfaltigkeit strebte - $A b b$. 52.1.) Die nächste Kachel zeigte, nach den Fragmenten zu urteilen, auf grünem Grund gewundene Ranken und bohnenförmige Früchte mit gelber Glasur; auch hiervon gab es ein gegensätzliches Stück mit grüner Glasur auf gelbem Grund. Damit sind schon mindestens fünf verschiedene Motive nachweisbar ( $A b b$. 52).

In der zweiten Hälfte des 15. Jahrhunderts können derartige Kompositionen blumengemusterter Kacheln größtenteils auf die fantasiereichen Darstellungen der verbreiteten Kupferstiche zurückgeführt werden, obwohl man sich hier wegen der plastischen Ausführung auch mit einfacheren, aber übersichtlicheren Lösungen begnügte. Ihre Beliebtheit entsprang dem Erstarken der die Naturschönheiten erkennenden Betrachtungsweise; ähnlichen begegnet man an anderen kunstgewerblichen Gegenständen ebenfalls. An Kacheln waren sie auch im Elsass und im westlichen Deutschland verbreitet. ${ }^{33}$

32 Auf Meister Franckes Bild: Geißelung Christi (Hamburg 1424) sitzt auf den Armlehnen von Pilatus' Thron je ein kleiner Löwe. Verschiedene kleine Tiere stellt der Meister der Spielkarten auf der Armlehne des Throns der Königsgestalten des Kartenspiels bzw. weiter oben dar. Auch am Salzburger Ofen sieht man neben dem sitzenden Kaiser Maximilian auf dem Thron eine kleine Löwenfigur.

${ }^{33}$ Von Ranken und Blumen umgebene Tierdarstellungen (Vogel, Hunde usw.) waren an den elsässischen und rheinländischen Ofenkacheln in der zweiten Hälfte des 15. Jahrhunderts beliebt - im Allgemeinen ebenfalls an nischenförmig gestalteten Stücken. Auf anderweitige Beispiele dieser Mode (Kupferstich, Textil, Wandmalerei) wies ich bereits im Zusammenhang mit einem der Budaer Exemplare hin (Kranich oder Reiher jagende Hunde): I. HOLL: Középkori kályhacsempék Magyarországon
(Mittelalterliche Ofenkacheln in Ungarn) IV. ArchÉrt 117 (1990) 88-89, Abb. 39-40. - Elsass: J.-P. MinNE: La céramique de poêle de l'Alsace médiévále. Strasbourg 1977, Nr. 109-116 (Vogel unter einem Rosenstrauch, mit Weinranken, zwischen blühenden Zweigen; Strassburg und Burg Ottrott). Diese sowie die thronende Könige darstellenden Kacheln (Nr. 163-170) stimmen trotz der identischen Thematik nicht mit den Budaer Stücken überein. - Köln: I. UNGER: Kölner Ofenkacheln. Köln 1988, Nr. 51, Kachel mit Distelranken, Ende 15. Jh.: Nr. 58, papageienartiger Vogel im Blütenstrauch, um 1500. Bern: ROTH-KAUFMANN 1994, Nr. 317, Vogel mit Astranken, erste Hälfte 15. Jh. (Im hiesigen sehr reichen Fundmaterial gibt es nur diesen einen Typ.) - Ennstal (?): WALCHER 1909, Abb. 102, Hirsch und Hund mit Rosenhecke, 15. Jh. 

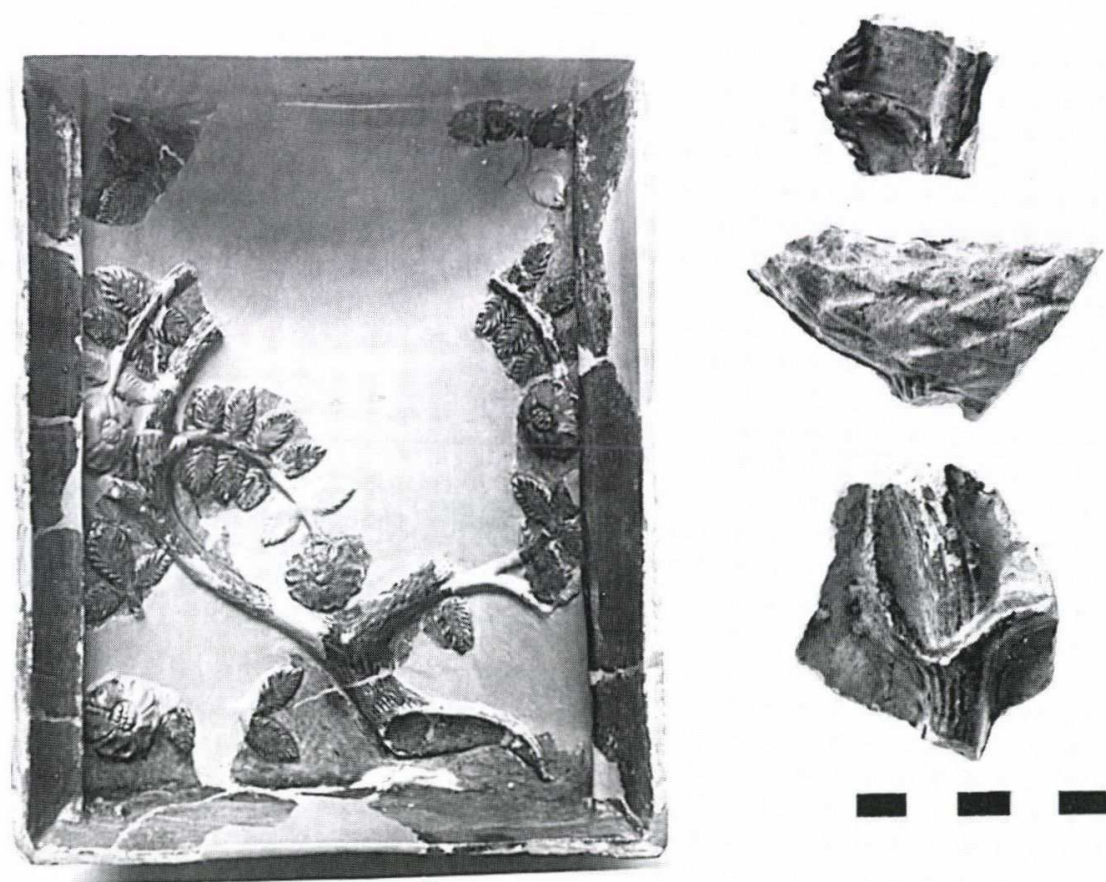

Abb. 51. Buntglasierte Ofenkachel mit Rosenhecke und blauem Vogel

Bei zahlreichen weiteren buntglasierten Fragmenten kann man heute nicht mehr entscheiden, zu welcher Gruppe (welchem Ofen) sie gehörten: verschiedenfarbige Spruchbandfragmente (gelb, weiß, blau auf weißem Grund), ein Gesichtsfragment mit langem, welligem, gelbem Haar oder ein Wildschweinkörper (braun, dunkelbraun, die vordere Hälfte mit bräunlichgrüner Farbe vermischt, auf dem Rücken mit weißem Streifen). Das plastisch ausgearbeitete Detail einer Krone (weiß, gelb, braun) zeigt in seinem Charakter die Form der österreichischen Herzogskronen ${ }^{34}$ (Abb. 54). Allerdings gehörte diese Krone nicht zu einem Kopf, sondern schwebte frei (vielleicht über einem Wappen?). An dieser Stelle sei auf die buntglasierten Wappenfragmente verwiesen, von welchen drei auf das schon erwähnte Bündnis mit Bayern hindeuten (im gevierten Schild ein schwarzes Feld, darin goldgelber Löwe, blauweiße Rauten). Eines der Fragmente (schwarze Adlerschwinge in gelbem Feld) könnte das Wappen Oberschlesiens sein, und ein Stierkopf (mit blauen Hörnern) in einem braunen Feld ein Fragment vom Wappen der Niederlausitz. Letztere legen den Bezug zu Matthias und zu König Wladislaw II. gleichermaßen nahe. Die gelben Adler im blauen Feld sind offenbar Fragmente vom niederösterreichischen (bzw. dem sog. altösterreichischen) Wappen. Da König Matthias dieses Wappen nach seinen österreichischen Eroberungen niemals benutzt hat, kann es nicht mit seiner Person in Verbindung stehen. Ein kleines Fagment zeigt eine blau gekleidete Gestalt mit einem Detail des jagiellonischen Wappens (in braunem Feld weißer Adler mit Krone) in der Hand; es deutet also auf Wladislaw II. hin (Abb. 55). Die beiden letztgenannten Fälle avisieren wahrscheinlich schon den Zeitraum nach 1490 - obwohl natürlich die Möglichkeit besteht, dass das Jagiellonenwappen lediglich ein Hinweis auf das bereits 1478 abgeschlossene Bündnis mit Wladislaw II. sein soll, während es sich bei der Verwendung des altösterreichischen Wappens um einen Irrtum des die ungarländischen Heraldiklösungen nicht kennenden österreichischen Meisters handelt. - Bedauerlicherweise sind von dem Typ keine vollständigen Kacheln bekannt, die eventuell Licht in ihre Anwendung bringen könnten.

34 „Erzherzogshut mit Zackenkranz und Bügel“: Herzog Rudolf IV. von Österreich, Bildnis um 1365, Wien. (Propyläen Kunstgeschichte Bd. 6. Berlin 1972, Abb. 289.) 


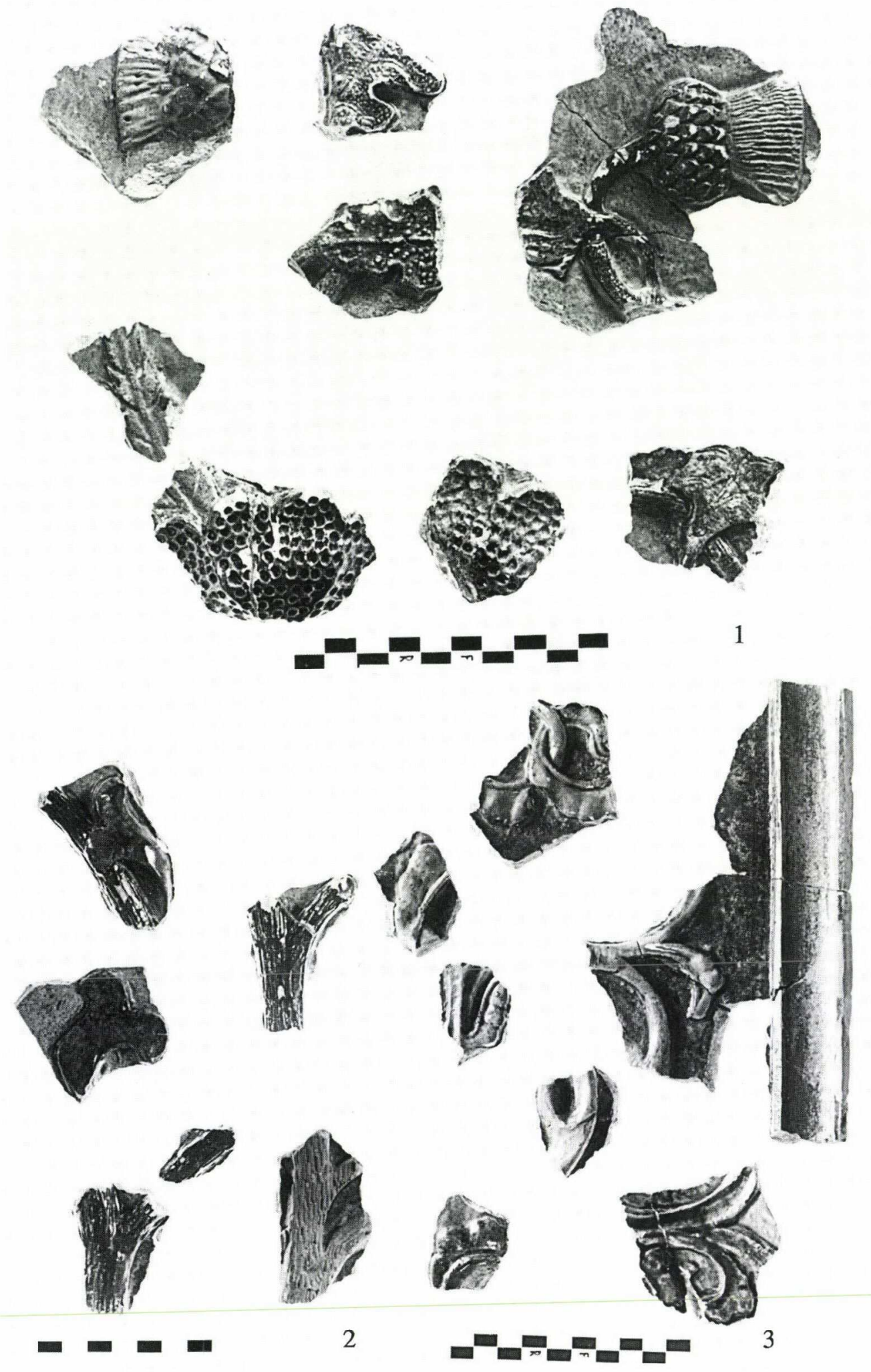

Abb. 52. Buntglasierte Kacheln. 1: Blumen; 2: Baumstamm und Blätter; 3: Ranken mit bohnenförmigen Früchten 

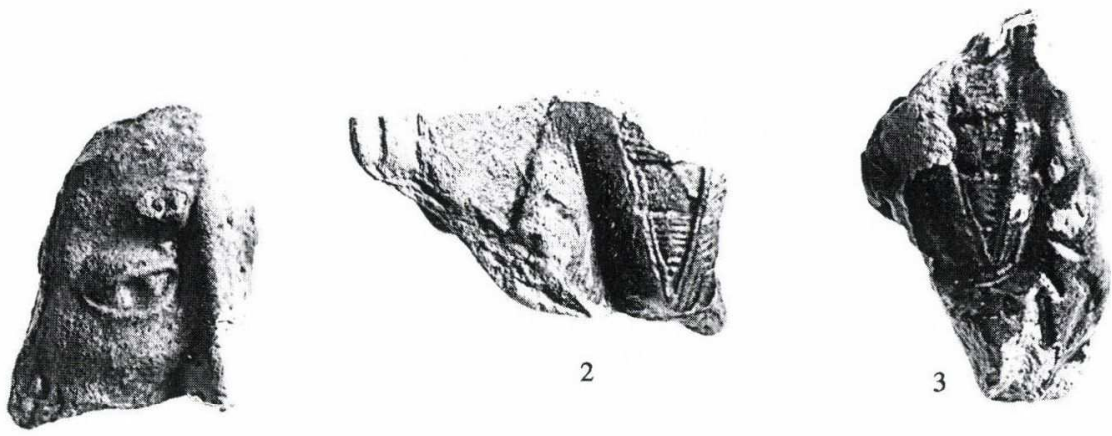

1

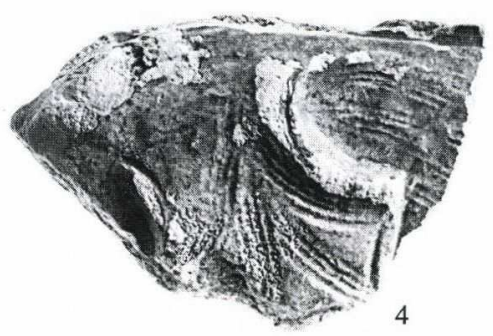

Abb. 53. Grünglasierte Kachelfragmente (2-3: Details von der Kachel mit reitendem Paar)

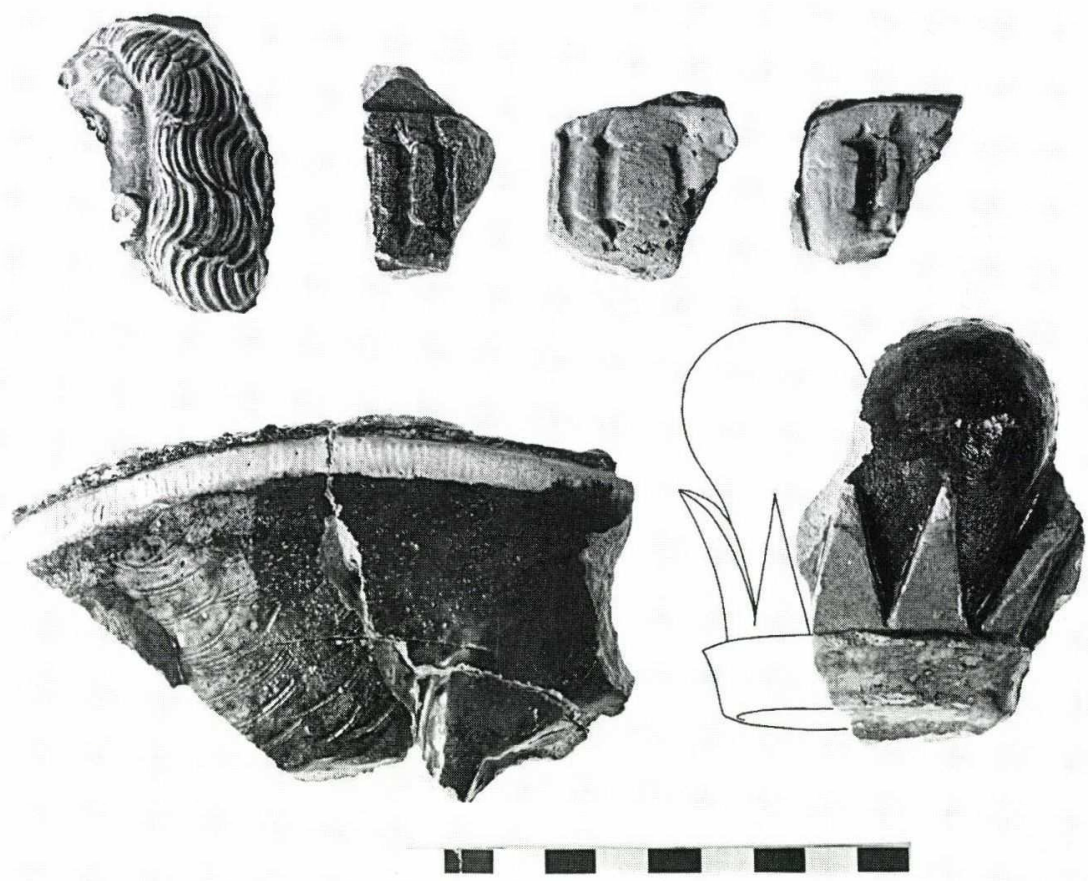

Abb. 54. Buntglasierte Kachelfragmente, Ende 15. Jh. 


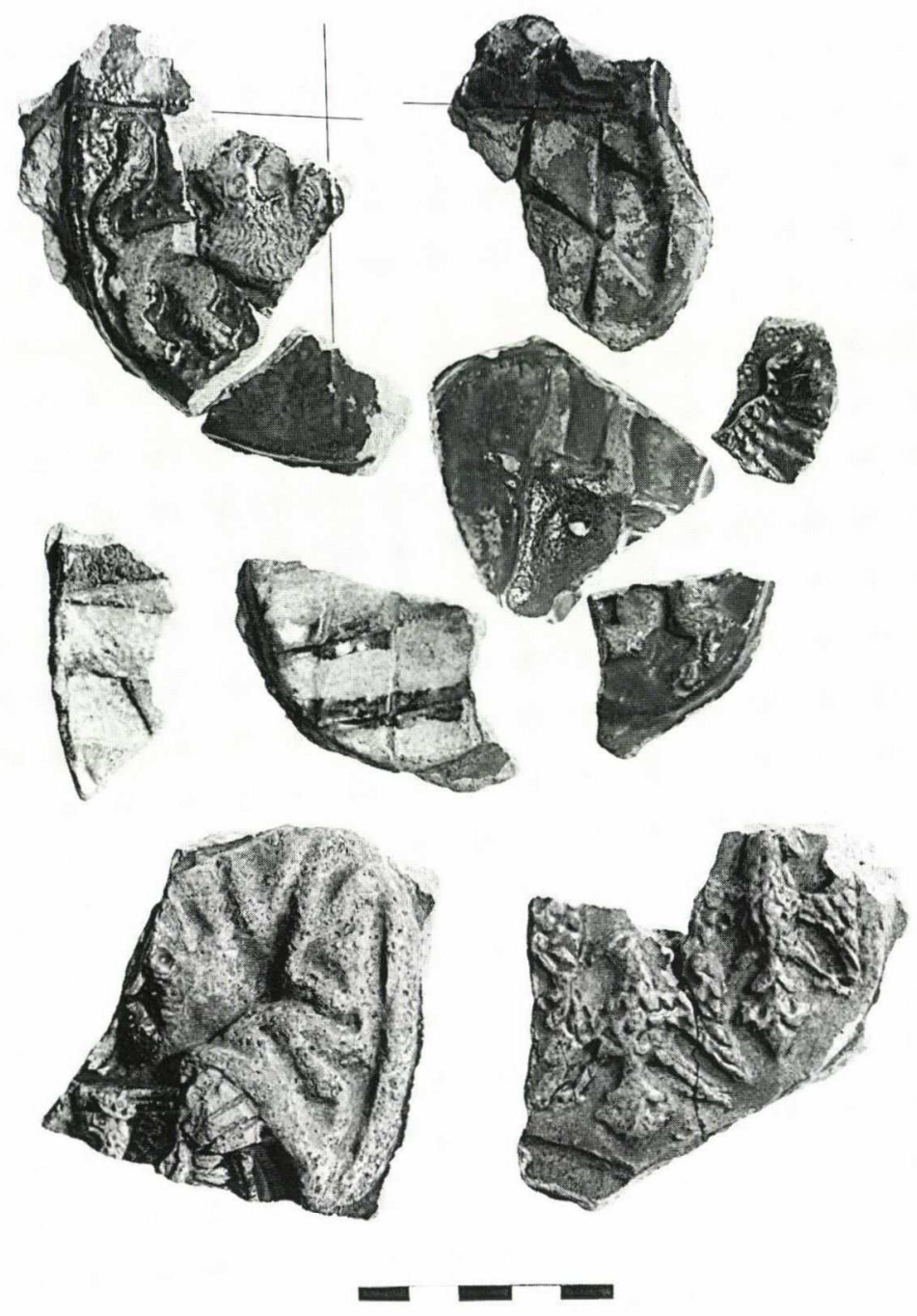

Abb. 55. Wappenfragmente von buntglasierten Kacheln

$\mathrm{Zu}$ einem anderen polychromglasierten Ofen dürfte ein anderes, von einer Eckkachel abgebrochenes Wappen gehört haben, auf dem eine schön ausgearbeitete, plastische Rose in einem Punktreihenrahmen zu sehen ist; die äußeren Blütenblätter dunkelblau, die inneren mit weißer Zinnglasur, in der Mitte eine gelbe Narbe. Zwischen den Blütenblättern verzweigen sich in vier Richtungen kleine grüne Blättchen. Auf der Rückseite des stark gekrümmten Wappenschildes sieht man, dass es an einer dreieckförmig abgeschnitten Kachelecke befestigt war. H: $13 \mathrm{~cm}, \mathrm{~B}: 12 \mathrm{~cm}$, D: 0,5-1 cm; gelblich weiße Scherbe (Abb. 35). Eine zweifelsfrei auf die dieses Wappen benutzende Person hindeutende Angabe ist mir leider nicht bekannt.

\section{Verbreitung}

Bedeutungsvoll im Hinblick auf die Verbreitung der Ofenkacheln der Rauriser Gruppe in Ungarn ist das - wenn auch zahlenmäßig bescheidene - Fundmaterial, das zwischen 1934 und 1938 bei den Bauforschungen und Freilegungen des Erzbischofspalastes in der Burg von Esztergom (Gran) zum Vorschein 
kam. ${ }^{35}$ Obwohl davon nur zwei Kacheln restauriert werden konnten, sind gerade dies vom Gesichtspunkt des Stils der Gruppe entscheidende Stücke.

1. Biblischer König. Viereckige Nischenkachel. Nach rechts gewandte bärtige Halbgestalt, die einer Blüte mit fleischigen Blättern entwächst; in der linken Hand ein Zepter, auf dem Kopf eine Turbankrone. Dahinter beidseitig und oben gewundenes Spruchband, aber ohne Inschrift. Auf drei Seiten gekehlter Rand, der oben ehemals einen bogigen Abschluss hatte und sich darüber (einem weiteren Fragment zufolge) in durchbrochenen Bögen fortsetzte, aus denen jeweils eine weibliche Halbgestalt herausschaute. Farben: grüner Hintergrund, Gewand gelb, Gewandärmel blau, Krone und Gürtel blau, schwarzer Bart, weißes Gesicht, gelber Rand. Hellgelbe, gut geschlämmte Scherbe. Höhe der Kachel, ohne die obere Bekrönung: $29 \mathrm{~cm}, \mathrm{~B}: 23,2 \mathrm{~cm}$, T: 6,5-7 cm (Abb. 56).

2. Hofnarr. Rechteckige Nischenkachel, zu einer rechtsseitigen Ecke gehörend. Aus den Blättern einer Blume herauswachsende, nach rechts gewandte Halbgestalt, zurückgelehnter bärtiger Kopf mit Mütze und dem typischen geschlitzten Kragen. Farben: grüner Hintergrund, blaugelbe Blüte, Gewand lilafarbig, Kapuze und Kragen hellblau, Mütze gelb, Gesicht und Hände weiß, schwarzer Vollbart. Rechts am gekehlten Rand der Kachel verläuft eine aus zwei Ästen gedrehte, blaue und bräunlichgelbe Verzierung (Abb. 56).

Beide Stücke zeigen die für die 1. Untergruppe typische plastische Gestaltung (Gewänder, Hände, Gesichter) und Oberflächenbehandlung; auch die Farbtöne der Glasur stimmen überein. Gleichzeitig deuten die Maße und Verwendung der Bekrönung darauf hin, dass es sich hier um einen Ofen anderer Zusammensetzung handeln muss.

3. Durchbrochenes Bekrönungsfragment. Entspricht dem 1. Typ, gehörte aber zu einem anderen Kachelexemplar. Aus den Bögen blicken weibliche Halbgestalten in Kleidern mit Kragen und vor der Brust zusammengelegten Händen. Zwischen den beiden Bögen ist unten ein verblasster Löwenkopfabschluss erkennbar. Gelb mit grüner Bleiglasur, Gesicht und Hände weiß. B: 23,5 cm (Abb. 57).

Von den übrigen Kacheln blieben nur kleine Bruchstücke erhalten: bärtiger Kopf (H: 6,5 cm), mit Pelz gesäumter Mantel, ein der Halbgestalt auf der linken Seite der Giebelkachel ähnelndes Detail (gelb mit weißer und hellilafarbener Glasur), unteres Teil von einer nach innen vertieften Kachel mit dichten Gewandfalten (grün, weiß, blau und blasslilafarben), Hintergrunddekoration mit gotischer Fiale ( $A b b .58$ ); an einer Kachelecke Detail von einem sich auf ein Gesims stützenden Arm (grün, blau, lilafarben, H: 10 $\mathrm{cm}$ ), eine bläulichweiße Hand (das Gewand gelb, hellblau, blasslilafarben); ein lilafarbiges Tierbein auf grünem Grund mit dem typischen eingeritzten Hintergrundmuster (Abb. 59). - Wenngleich nur Fragmente, lassen diese Stücke doch erahnen, aus wievielen verschiedenartigen, bis ins kleinste Detail ausgearbeiteten und farbenfrohen Kacheln der Ofen im Esztergomer Palast bestand.

Durch einen glücklichen Umstand weiß man in diesem Fall sogar, wie der unterste Teil des Ofens beschaffen war:

4. Sitzende Löwen. Mehrere Fragmente belegen, dass der Ofen von großen, handgeformten, sitzenden Löwen getragen wurde: hinteres Teil des Tierkörpers (innen hohl) mit dem linken Hinterbein, H: 14 $\mathrm{cm}$, sowie Fragmente der Vorderbeine, das größere $24 \mathrm{~cm}$ hoch. Gelbliche Scherbe, grobkörniger als bei den Kacheln, mit goldgelber und grüner Glasur $(A b b .60)$. Ursprünglich dürften die Löwen mindestens 40 $50 \mathrm{~cm}$ hoch gewesen sein. ${ }^{36}$

Die ungarischen Könige nutzten ihren unterhalb der Visegráder Burg am Donauufer gelegenen Palast schon seit dem 14. Jahrhundert. Ein besonders beliebter Aufenthaltsort war er für König Matthias,

\footnotetext{
${ }^{35}$ Die genauen Fundumstände des archäologischen Fundgutes sind unbekannt; die Kacheln kamen wahrscheinlich in der Verfüllung zum Vorschein, die man nach der Zerstörung des Palastes im 17. Jahrhundert vornahm. - Die Funde habe ich 1949, noch als Student, im Auftrag von Professor Tibor Gerevich, der die Bauforschungen leitete, inventarisiert und fotografiert. Dem folgte, auf meine Bitte hin, die Restaurierung des 1. Typs.
}

\begin{abstract}
${ }^{36}$ Hinsichtlich ihrer Maße sind auch die fünf unteren Löwenfiguren am Ofen der Hohensalzburg ähnlich. Dort handelt es sich jedoch um stehende Tiere, die stämmig wirkten, während sie in Esztergom sitzen. - Aus der zweiten Hälfte des 16. Jahrhunderts blieben einige vollständige Öfen erhalten, die von sitzenden Löwen getragen werden (Tirol, Salzburg und Süddeutschland; s. FRANZ 1969, Abb. 314, 320, 335, 345), aber schon anderen Stils.
\end{abstract}



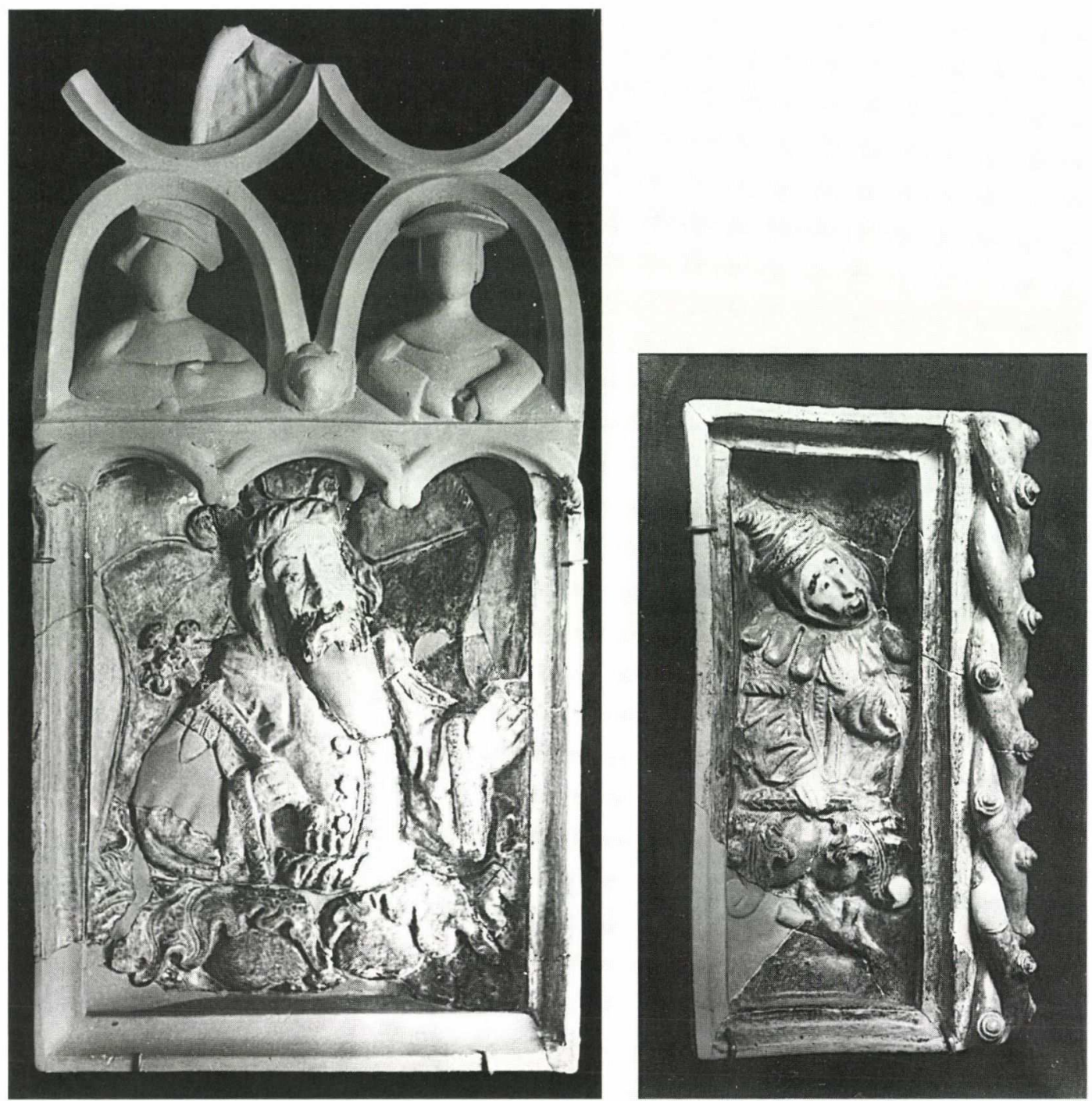

Abb. 56. Buntglasierte Kacheln: biblischer König und Hofnarr - FO: Esztergom, Burg bzw. Bischofspalast (Museum Esztergom)

der im Jahre 1484 begann, ihn von Grund auf umbauen zu lassen. Für den im Ergebnis des Umbaus entstandenen ausgedehnten Palast mit mehreren Gebäuden wurden unter anderem neue, repräsentative Öfen benötigt: Die Hofwerkstätte setzte hier gleich mehrere Öfen (mit der Wappenserie des Königs und seiner Verbündeten), den letzten nach 1488. ${ }^{37}$ Mit dem bayerischen Bündnis des Königs hängt es zusammen, dass man hierher zwischen 1487 und 1490 auch einen Regensburger Ofen lieferte. Daher kann es nicht verwundern, dass in den Visegráder Palast auch ein buntglasierter Ofen aus Österreich gelangte, von dem bislang leider nur wenige Fragmente bekannt sind. ${ }^{38}$ Identifizieren lassen sich unter den Kacheln der schon er-

${ }^{37}$ Letztes Stück der Wappenreihe ist das des Augsburger Bischofs Johann von Wardenberg; um Unterstützung für ihn suchte die Gesandtschaft des Bayernherrschers 1488 bei Matthias nach: I. HOLL: Középkori kályhacsempék Magyarországon VII. A lovagalakos kályha címertartó csempéjének új példánya múhelykérdések (Mittelalterliche Ofenkacheln in Ungarn VII.
Ein neues Eckkachelexemplar des Ofens mit Ritterfiguren Werkstattsfragen). BudRég 33 (1999) 314-323, Abb. 6.

${ }^{38}$ E. Kocsis-T. SABJÁN: A visegrádi palota kályhái és kályhacsempe leletei (The stoves and stove tiles of the Visegrád royal palace). Visegrád 1998, 40-41, Abb. 157-166. Aus den Grabungen der Jahre 1950-1992. 

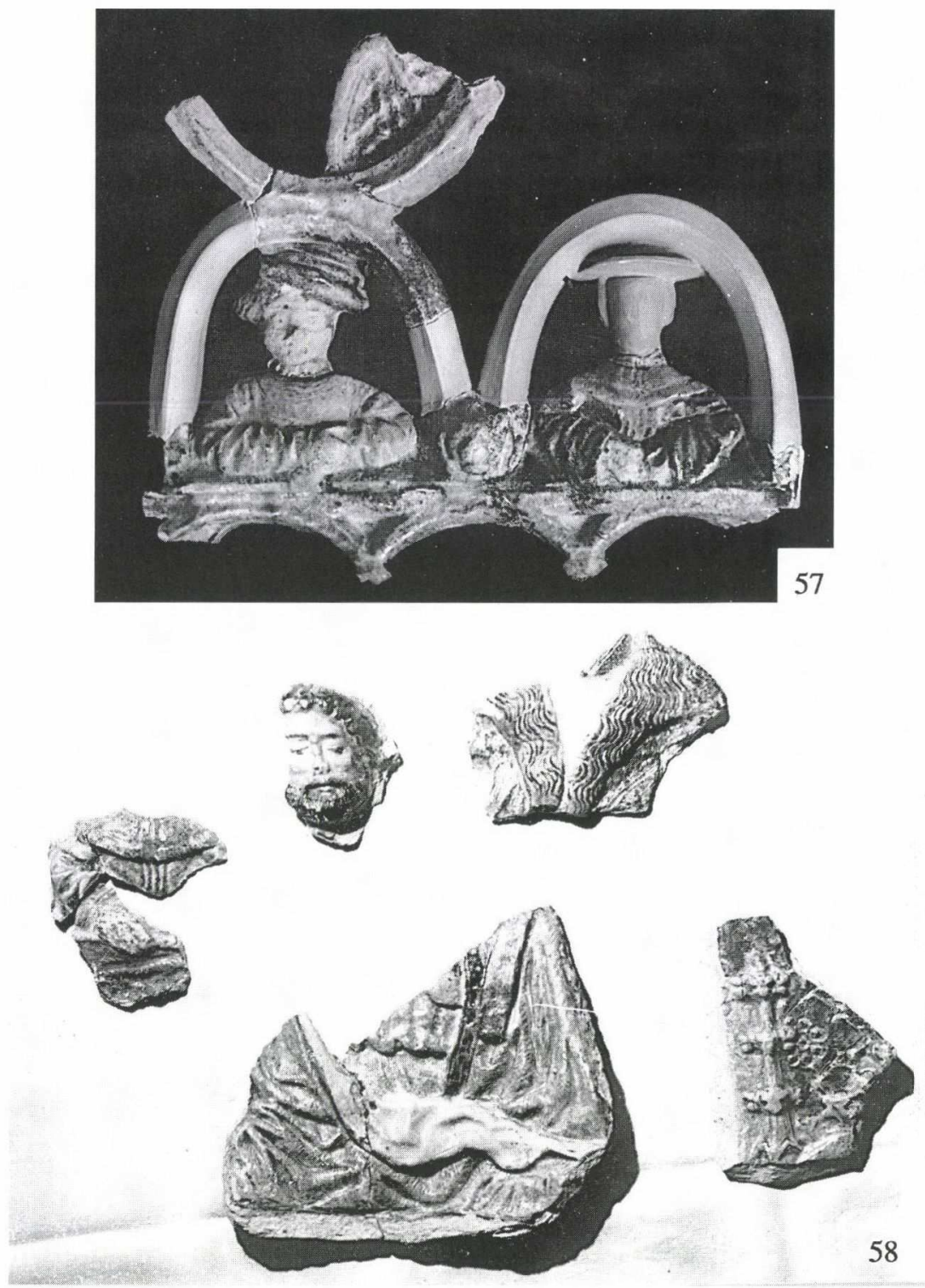

Abb. 57. Gesimsbekrönung - FO: Esztergom, Burg

Abb. 58. Bruchstücke von buntglasierten Kacheln - FO: Esztergom, Burg

wähnte „Jäger mit Hunden“ und das Fragment mit dem Hl. Georg. Darüber hinaus deuten wenigstens 15 weitere buntglasierte Fragmente auf Kacheln mit unterschiedlichem figuralem und Pflanzendekor hin. Sie alle zeigen in ihrem Charakter den Stil und die Farbnuancen der 1. und 2. Untergruppe. - Bis jetzt ist auf Grund des Fundmaterials noch nicht zu entscheiden, ob hier mehrere polychrom glasierte Öfen standen oder nur einer, zu dem man aber verschiedene Kacheltypen verwendet hat. Auch sie gingen im Zeitalter der Türkenherrschaft unter.

Eine dritte der Burgen, in denen sich der Königshof bekanntlich aufhielt, ist Tata. Laut Schriftangaben suchte König Matthias seine Burg von 1472 bis Ende Januar 1490 jeden Sommer und im letzten Jahrzehnt sogar in den Wintermonaten auf. Dies ist meiner Meinung nach der Grund, weshalb er hier neben einem Exemplar des zuvor erwähnten Regensburger Ofens auch einen Ofen aus der Werkstatt der „Rauriser Gruppe“ aufstellen ließ. 

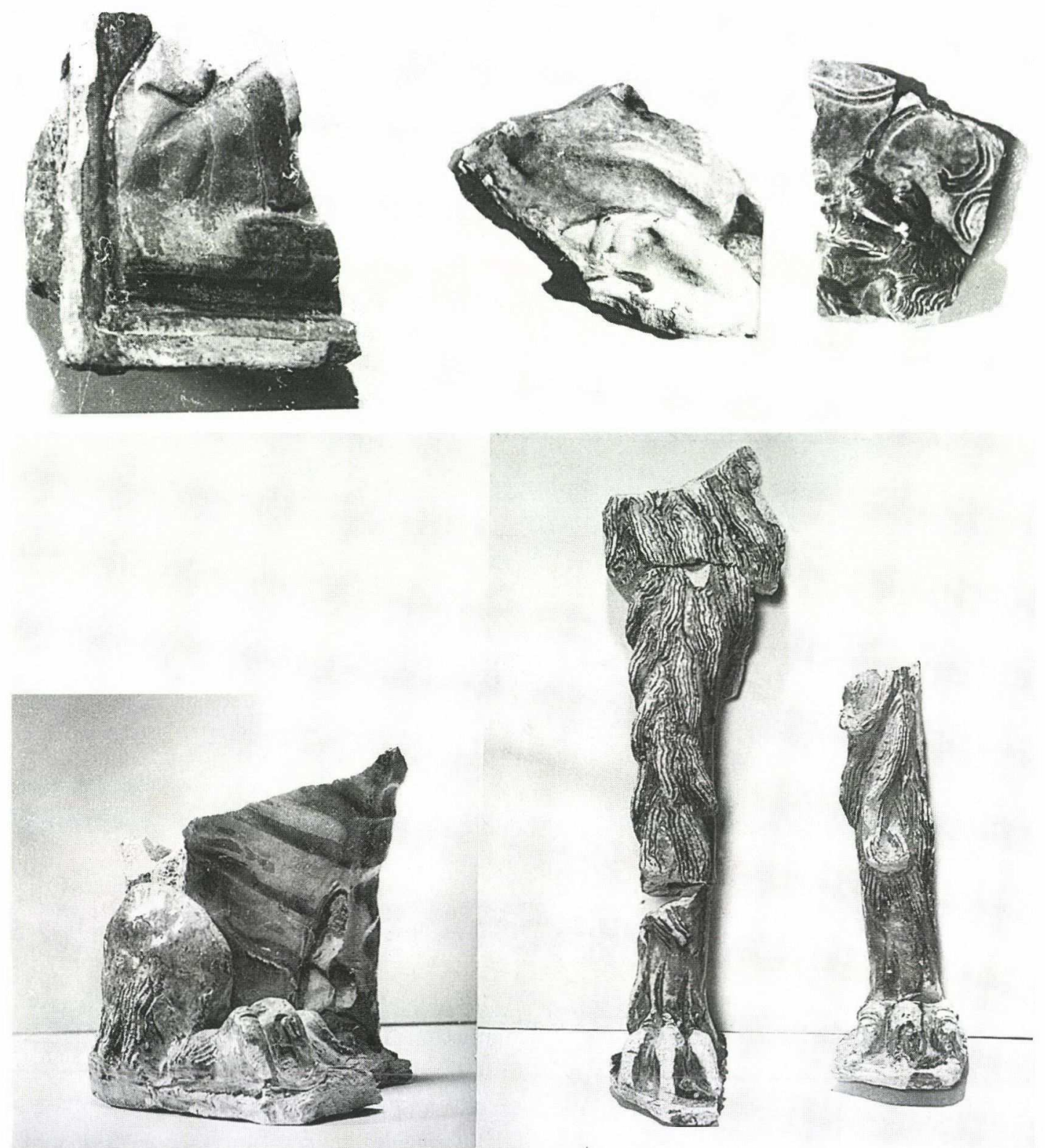

Abb. 59. Bruchstücke von buntglasierten Kacheln - FO: Esztergom, Burg

Abb. 60. Fragmente der den Ofen tragenden sitzenden Löwen - FO: Esztergom, Burg

Aus den zum Vorschein gelangten Fragmenten konnten bisher nur zwei Kacheln rekonstruiert werden: Das weiter oben beschriebene Exemplar mit dem Motiv „Lebensbaum des Paradieses“ - hier aber auf der linken Seite der nischenförmig gestalteten Eckkachel, umrahmt von der um einen Ast geschlungenen Blattranke. (Da diese Kachel größer ist, füllt die für eine kleinere entworfene Dekoration die nischenartig gewölbte Fläche seitlich und unten nicht ganz aus. $\left.{ }^{39}\right) \mathrm{H}: 30,7 \mathrm{~cm}(A b b .61)$. Auf irgendeine figurale

${ }^{39}$ Nur das Bild: S. B. SzATMÁRI (in Anm. 10 zit. Bericht), Abb. 8. Ihre Beschreibung zusammen mit der nächsten Kachel, aber ohne Abbildung: Matthias Corvinus und die Renaissance in Ungarn. Schallaburg Katalog. Wien 1982, Nr. 367-368. 


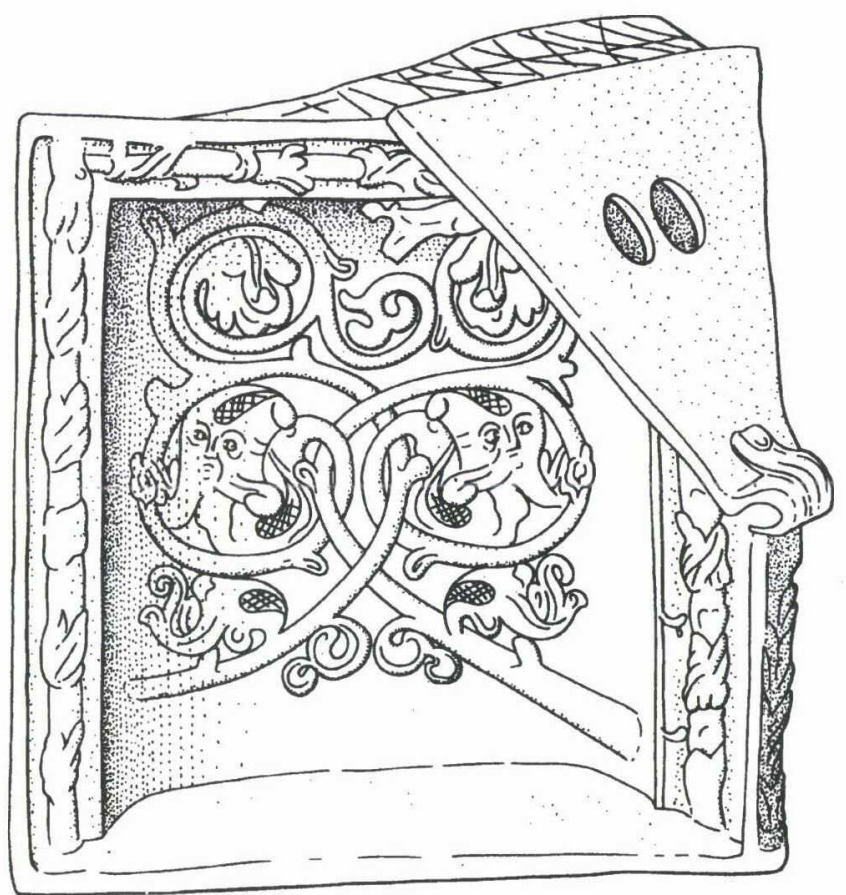

Abb. 61. Eckkachel - FO: Tata, Burg (nach S. B. Szatmári)
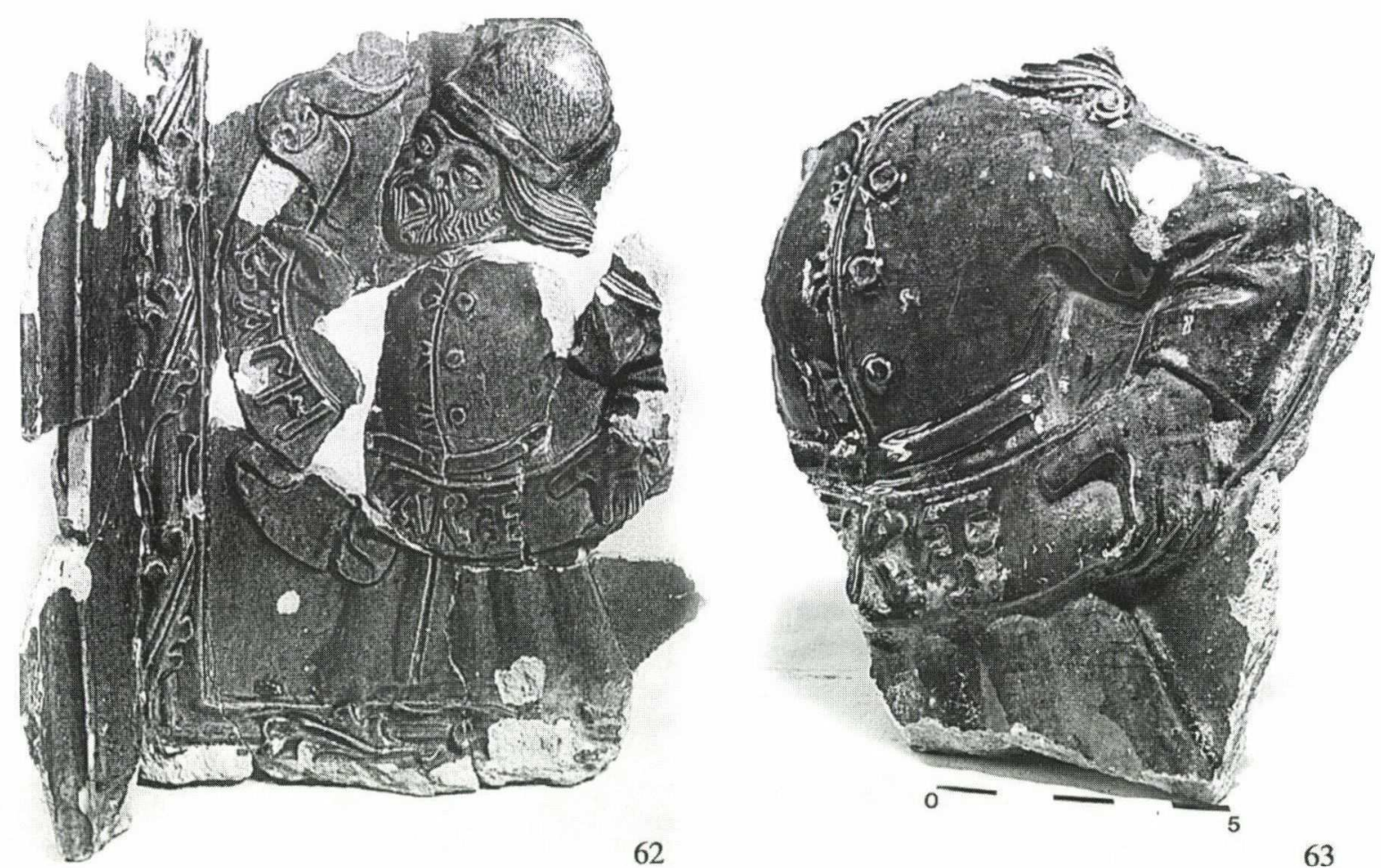

Abb. 62. Grünglasierte Kachel mit Brustbild des Propheten Zacharias - FO: Bratislava, Burg, Slowakei (nach Egyházy-JurovskáFüryová)

Abb. 63. Bruchstück der Zacharias-Kachel - FO: Eger, Burg 
Darstellung deutet lediglich ein weißglasiertes Spruchbanddetail am Fragment der rechtsseitigen Kachel hin. - Die äußeren Ecken der Kacheln hatte man schräg abgeschnitten und dort ein glattes, dreieckiges Tonblatt mit zwei Löchern angeklebt - die Befestigungsstelle des Wappens.

Auch die zweite Kachel zeigt das Paradiesbaum-Motiv, allerdings in einfacher, viereckiger Form und mit grüner Glasur. Maße: $25 \times 25 \mathrm{~cm}$.

Von den anderen Kacheln wurden nur Abbildungen dreier Fragmente publiziert: Fragmente von zwei Kachelexemplaren mit Prophetengestalt (eines grün-, das andere polychromglasiert): bärtiger Kopf, in der rechten Hand ein Spruchband haltend (ZA...). Das dritte buntglasierte Fragment zeigt einen liegenden Hund und ein Bein mit langem, schnabelspitzigem Schuh. - Dass es weitere Fragmente dieser noch nicht aufgearbeiteten Gruppe des Fundmaterials gibt, ist ihrer kurzen Erwähnung zu entnehmen: auch hier künden biblische Propheten, Heilige, eine Königsgestalt und Tiere von dem reichen Motivschatz. ${ }^{40}$ - Der Ofen dürfte zusammen mit den übrigen während der türkischen Belagerung im Jahre 1529 zerstört worden sein.

Die Preßburger Königsburg gehörte zwar ebenfalls zu den königlichen Besitztümern, kann aber nicht zu den Aufenthaltsorten des Königs gerechnet werden, da ihm hierfür ein Stadtpalais zur Verfügung stand. ${ }^{41}$ Die in der Burg zum Vorschein gelangten, in dieses Zeitalter datierbaren Ofenkacheln sind also Zeugen der Anwesenheit bzw. Fürsorge des königlichen Burghauptmanns. Das bei den Grabungen freigelegte Material wurde noch nicht detailliert aufgearbeitet, bekannt sind lediglich zwei Exemplare:42

1. Prophet Zacharias. Viereckige Kachel mit geschlossenem Vorderblatt; warme, grasgrüne Glasur. Den Innenrand des breiten, nach innen vertieften Rahmens begleiten lange, um einen Stab geschlungene Blätter. En face abgebildete Halbgestalt in einem geschnürt-geknöpften Wams, auf dem nach links gewandten bärtigen Kopf eine kegelartig aufragende Mütze; in den Händen hält sie ein Band mit der Inschrift: ZACHARE. Höhe des Fragments: $30 \mathrm{~cm}$, B: $25 \mathrm{~cm}$ (ursprüngliche Abmessung vermutlich ca. $34 \times 30 \mathrm{~cm}) .(A b b .62)$

Von dem anderen Exemplar gibt es wenigere Fragmente. Es war das Paarstück der vorigen Kachel, mit einer anderen Gestalt. Von der Inschrift ist nur der Buchstabe „a“ erhalten.

Die Preßburger Kacheln sind zweifellos Stücke aus der Werkstatt der Rauriser Gruppe. ${ }^{43}$ Das beweisen die von Buda wohlbekannte Rahmenverzierung sowie der Umstand, dass auch in Visegrád (das Wams grün, der Gürtel mit gelblich brauner Glasur) ${ }^{44}$ und Tata (ein grün- und ein polychromglasiertes Fragment) ${ }^{45}$ übereinstimmende buntglasierte Fragmente von Zacharias-Kacheln dieser Werkstatt erhalten blieben. - Von den Kacheln der rückwärtigen unteren Seite des Salzburger Ofens hat Walcher (und auch die neuere Literatur) leider nur das „MALACHIAS“-Bild publiziert; die übrigen Motive zählt nur Prodinger auf, aber ohne Abbildungen. Obwohl hier demzufolge verschiedene Apostel und Heilige

${ }^{40}$ Text des Vortrages von 1976: S. SZATMÁRI-BIRÓ: Städtisches Leben ... am Beispiel ... Tata. In: Das Leben der Stadt des Spätmittelalters. Veröffentlichungen d. I. f. Mittelalterliche Realienkunde, Nr. 2. Wien 1980, 45-46, Abb. 35-36 (,... Köpfe von Aposteln und Königen; ... geharnischte Ritterfigur des Hl. Georg ...; Die Figuren halten ... Spruchbänder ...; bunte pelzbesetzte Mäntel; ... ein springender Hirsch, ein laufender Hund; ... Bibel haltende Hand eines Priesters im Chorhemd und der Schnallenschuh einer auf dem Ofen stehenden Skulptur ..."). Nach ihrer Auffassung ähneln die Funde den Kacheln des Salzburger Ofens; hauptsächlich den an der rückwärtigen Seite unten platzierten Kacheln, die auf identische Vorbilder hindeuten. Sie übernimmt die von VOIT und später FRANZ, 55 vertretene Meinung: Umzug der Töpfer einer Budaer Werkstätte nach Wien und deren Einfluss auf Salzburg, wie sie auch PRODINGER, 4 äußert. - Die Kacheln von Tata wurden ihrzufolge aus den Negativen der Budaer Werkstatt vor Ort hergestellt. - Die Funde grub man 1967 in der Verfüllung des Kellers der Burg aus.

${ }^{41}$ Das Stadtpalais mit Garten stand im 15. Jahrhundert an der Ecke der Ventur-Gasse. Hier hatte 1440/41 schon Königin Elisa- bet gewohnt, und Matthias und Beatrix benutzten es aller zweidrei Jahre für einen kurzen Aufenthalt. J. BALOGH: A múvészet Mátyás király udvarában [Die Kunst am Hofe König Matthias'] I. Budapest 1966, 174-176. - Von hier sind noch keine Funde bekannt.

${ }^{42}$ B. EgYhÁZY-JUROVSKÁ-K. FÜrYOVÁ: Stredoveké kachlice. Bratislava 1993. Katalog Nr. 10, Nr. 9. - Grabung von A. Fiala 1989/91; A. FIALA-A. SEmANKO: Bratislava hrad. 1992, Manuskript. - In der Burgausstellung habe ich 1993 noch zahlreiche weitere grünglasierte Fragmente gesehen, die ohne Zweifel den Stil der 1. Untergruppe mit dem eingeritzten, gemusterten Hintergrund zeigen.

${ }^{43}$ Der Katalog ordnet sie der Werkstatt Besztercebánya (Banská Bystrica, Slow.) zu, deren allbekannte Kacheln jedoch einen anderen Stil vertreten.

${ }^{44}$ E. KoCSIS-T. SABJÁN (in Anm. 38 zit. Bericht), Zeichnung 162 (die Verfasserin verweist bereits auf die Preßburger).

${ }^{45}$ S. B. SZATMÁRI (in Anm. 10 zit. Bericht), Abb. 6-7. 


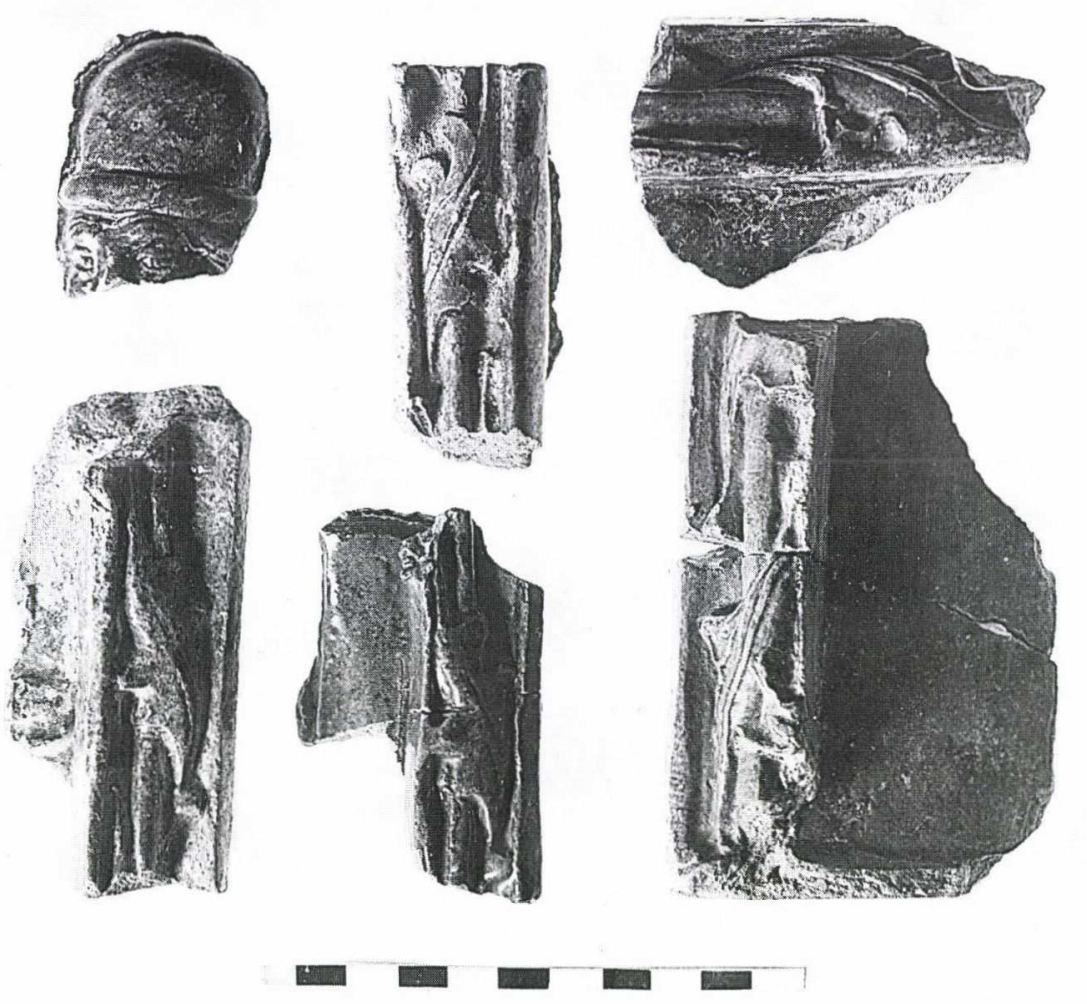

Abb. 64. Fragmente von grünglasierten, aus roter Scherbe gefertigten Kacheln (Buda, königl. Palast)

mit Spruchband in den Händen abgebildet sein müssen, ${ }^{46}$ kann ich sie jedoch mit unseren Fragmenten nicht vergleichen.

Buntglasierte Fragmente kamen auch noch an einem siebten Ort vom Gebiet des mittelalterlichen Ungarn zum Vorschein; leider dermaßen kleine Stücke, dass man sie nicht mehr mit den bekannten Typen abstimmen kann. ${ }^{47}$ Ihr Fundort ist die Burg der Erzbischöfe von Kalocsa auf der östlichen Seite der Donau, unweit von Bács (Bac, Serb.). Die sechs publizierten Fragmente lassen sich auf Grund der minutiös ausgearbeiteten Details hierzu attribuieren. Eigentümer der Burg war zwischen 1480 und 1501 der bekannte Humanist und Mäzen, Erzbischof Péter Váradi, im Zeitraum 1479-1484 Kanzler und Vertrauter des Königs. Ab dem Sommer des Jahres 1484 bis zu Matthias' Tod hielt er sich jedoch nicht in seiner Burg auf, da dieser ihn wegen irgendeines unbekannten Vergehens eingekerkert hatte. Seine Freiheit erlangte er erst nach dem Tode des Königs wieder. In den neunziger Jahren ließ der Burgherr hier bauen und empfing auch mehrmals König Wladislaw II. als Gast. ${ }^{48}$ Der hiesige prachtvolle Ofen dürfte also wahrscheinlich schon in dieser Zeit geliefert worden sein.

Auf weitere herausragende Kirchenmänner hohen Ranges - die ebenfalls mit dem Königshof in Verbindung standen - deutet ein an den Bischofspalast der Burg von Eger (Erlau) zu bindendes Fragment hin. Beim Sichten des sehr reichen, aber fragmentierten und großenteils unaufgearbeiteten Ofenkachel-

${ }^{46}$ Nach Prodinger 1972, 2:1. Reihe: 1-2, 2. Reihe: 2-6, 3. Reihe: 5-6 (letztere sind die Malachias-Kacheln, die übrigen andere Apostel und Heilige), 4. Reihe: 3-4 (Hl. Johannes, Hl. Jacobus) - insgesamt also 11 St.

${ }^{47}$ Aus der Grabung 1958/59: S. NADJ: Tvrdjava Bac (Die mittelalterliche Burg Bac). RVM 10 (1961) 89-115, Tab. IX:4,
Tab. X:1, 3-4, 7-8 (ein Fragment mit der gemalten Inschrift kaiser).

${ }^{48}$ V. FRAKNói: Váradi Péter érsek élete [Biographie des Erzbischofs Peter von Wardein]. Budapest 1884; Századok (1883) 842; zwischen 1494 und 1500 . 
materials, ${ }^{49}$ das von den älteren Ausgrabungen in der Burg stammt (1925-1938), fiel mir ein grünglasiertes Stück in die Hände, das angesichts des Preßburger Exemplars heute bereits dieser Gruppe zugeordnet werden kann:

Das Fragment einer den Propheten Zacharias abbildenden Kachel mit dem Brustteil der Gestalt, ihrer linken Hand und einem Detail des Spruchbandes (...RE) beweist die Existenz eines hiesigen Ofens (B: $10 \mathrm{~cm} ; A b b .63)$. Seine weiteren Kacheln sind leider nicht bekannt.

Wie aus dem Obengesagten hervorgeht, lässt sich die genaue Aufstellungszeit der buntglasierten Öfen noch nicht bestimmen. In den Palästen von Buda und Visegrád bzw. in der Burg von Tata könnte auf Grund der bayerischen Wappen ${ }^{50}$ der Zeitraum zwischen 1470 und 1490, insbesondere das letzte Jahrzehnt, in Betracht kommen (bzw. im Falle eines der Budaer Öfen eventuell danach). Der erzbischöfliche Ofen in der Burg zu Bács dürfte zwischen 1491 und 1500 gesetzt worden sein. Zum Ofen des Esztergomer Erzbischofs fehlt bislang jeglicher Anhaltspunkt, ${ }^{51}$ und auch im Falle der Erzbischöfe von Eger ist unklar, ob die Angaben über die 1493 reparierten ,großen Öfen“ oder über die beiden 1503 gesetzten „großen Öfen deutschen Geschmacks" zutreffend sind. ${ }^{52}$

Meiner Meinung nach hat die Halleiner (Salzburger?) Werkstatt über einen längeren Zeitraum gearbeitet. ${ }^{53}$ Der Reichtum ihres Musterschatzes war das Ergebnis beständiger Erweiterung, die auch von der Anpassung an die Ansprüche der verschiedensten Käufer beeinflusst wurde. Ein kleinerer Teil der Dekorationen setzte die alte Hafnerpraxis fort, doch auch die Übernahme von zahlreichen neuartigen - sakralen ebenso wie weltlichen - Themen erfolgte, mit Darstellungen, die in anderen Zweigen des Kunst-

${ }^{49}$ Die hier zum Vorschein gelangten Ofenkacheln gehörten zu verschiedenen Öfen aus dem 15.-17. Jahrhundert. Von diesen und den gleichgearteten Funden der neuen Grabungen (aus dem 15. Jh., von der Mitte des 16. Jh. und aus dem 17. Jh.) wurde bislang nur ein kleiner Teil aufgearbeitet. Siehe I. HoLL: Renaissance-Öfen. (Mittelalterliche Ofenkacheln in Ungarn V.) ActaArchHung 45 (1993) 247-299, mit weiterer Literatur. - Von den früheren Öfen blieben leider nur einige Bruchstücke erhalten.

${ }^{50}$ Unter den Fragmenten aus Tata kommt ebenfalls ein bayerisch-pfälzisches Wappen aus der für die Gruppe typischen weichen, weißen Scherbe und mit grüner Glasur vor, das ich hierzu attribuiere.

${ }^{51}$ Über die vier Jahrgänge zwischen 1487 und 1491 der modenesischen Rechnungsbücher des Esztergomer Erzbischofs Ippolito d'Este (1487-1497) liegt in kunsthistorisch-architektonischer Hinsicht eine detaillierte Auswertung vor (nur das des Jahres 1488 ist unvollständig): P. VoIT: I codici modenesi de Ippolito d'Este e le construzioni edili a Esztergom. ActaHistArt 5 (1958) 283-315. In diesen ist weder vom Aufstellen, noch von der Reparatur eines wertvolleren Ofens die Rede; erwähnt werden lediglich billige, schwarz bemalte, einfache Kachelöfen (Oktober 1489: ,... ditto per pignate per stufa piccola, danari cinquante"), sowie die vorangehende Reparatur des Ofens in Ippolitos Zimmer (,,... Giorgio Kaza per conzatura dele stufe del Reverendissimo - din 50."). P. VOIT: Magyar kerámikatörténeti tanulmányok [Studien zur Geschichte der ungarischen Keramik] I. MúvÉrt 1954, 113-116 und Anm. 11-13. Auch unter den 1491 durchgeführten Arbeiten für die hier einziehende Witwe Beatrix kommt das Aufstellen eines neuen Ofens nicht vor. - Sollte der prächtige Esztergomer Ofen demnach erst vor dem Herbst des Jahres 1487 oder nach 1491 hierher gelangt sein? Vielleicht des- halb datierte VorT ihn „um 1490“. (S. Anm. 1 in seinem populären Buch des Jahres 1963.)

${ }^{52}$ In Eger käme Bischof Orbán Dóczy (1486-1492) in Betracht, denn im Palast seines Nachfolgers, Bischof Tamás Bakócz (1493-1497), hat man 1493 bereits dessen „große Öfen" ausgebessert („Item Fornaces domini in domibus domini magnas feci reformare denuo pro den VIc XXV."). Die Rechnungsbücher des diesen hier ablösenden Bischofs Hippolit (1498-1520) berichten im Jahre 1503 darüber, dass zwei neue Öfen gesetzt wurden („Item solvit uni magistro, qui fecit duas magnas fornaces modo alemanico in castro et erant necesse propter vetustatem aliarum florenos viginti tres.“). M. DÉTSHY: Munkások és mesterek ... 1493 és 1596 között [Arbeiter und Meister ... zwischen 1493 und 1596] II. EMÉ 2 (1964) 155.

${ }^{53}$ Auch der Vergleich der Budaer Fragmente deutet darauf hin, dass die Kacheln nicht während eines einzigen Arbeitsvorganges entstanden: Im Falle verschiedener Typen sind beispielsweise in den Farbunterschieden der grünen Glasur beträchtliche Abweichungen erkennbar, ebenso wie die schon erwähnten Abweichungen des Scherbenmaterials. Bei einzelnen ist die Dekoration infolge der Abnutzung des Negativs verblasst. In ähnlicher Weise kann man das z. B. bei den blattverzierten Kachelrändern sehen, deren zahlreiche Varianten (bei den grünglasierten mindesten fünf verschiedene) sich jedoch ebenfalls mit mehrjähriger Arbeit erklären lassen. Die Unterschiede in ihrem Stil bekunden auch in diesem Fall das Schaffen mehrerer Meister. Auf jeweils unterschiedliche Handhabung deutet hin, dass bei einzelnen Kacheln das dünne Keramikblatt mit der Hand geglättet wurde, um der Plastik des Negativs zu folgen (wodurch die Rückseite eine gewellte Oberfläche bekam), während man das Keramikblatt bei anderen, der Stelle der erhabenen Plastik folgend, verdickt hat, so dass die Rückseite glatt ist. 
gewerbes schon früher beliebt, vom Töpferhandwerk bis dahin aber noch nicht entdeckt worden waren. Dies und die ausgezeichnete Technologie dürften dazu beigetragen haben, dass sich der Ruf der Werkstatt verbreitete. In Ungarn gelangten ihre Öfen zuerst an die Schauplätze des Königshofes und auf dessen Einfluss dann in die Paläste der auch die königliche Repräsentation und Bautätigkeit nachahmenden Prälaten.

\section{Kopien}

Schon ab der zweiten Hälfte des 14. Jahrhunderts kam es häufig vor, dass eine andere Werkstatt von ein oder zwei Kacheln der in den Palästen des Königshofes aufgestellten Öfen wenig später Kopien anfertigte, die ihr bei der Arbeit behilflich sein bzw. ihren Musterschatz erweitern sollten. ${ }^{54}$ Wie oben erwähnt, ist das im Falle der Rauriser Gruppe auch in Österreich nachweisbar. Dass es hier in Ungarn ebenfalls geschah, darauf deutet bisher nur ein Fragment hin: das Kopffragment von einer Kopie der Zacharias-Kachel (Abb. 64). Beweis für die Kopie sind die etwas kleineren Abmessungen im Vergleich zum Original (um etwa $20 \%$, B: $4 \mathrm{~cm}$ ); zudem wurde sie nicht aus der üblichen weißen oder gelben, sondern aus bräunlichroter Scherbe hergestellt, und unter der dunkelgrünen Glasur liegt eine dünne gelblich weiße Engobeschicht. Diese Lösung steht mit zahlreichen in die zweite Hälfte und an das Ende des 15. Jahrhunderts zu datierenden Ofenkacheln im Einklang, die wahrscheinlich in einer der Budaer Werkstätten entstanden. An anderen, ähnlich grün- und olivgrün glasierten Fragmenten (ebenfalls aus roter und brauner Scherbe) kann man die typischen Rauriser Rahmenverzierungen sehen, von denen bislang vier Varianten bekannt sind (welches Motiv die Kacheln zierte, zu denen sie gehörten, ist leider unklar - $A b b$. 64). Es gibt darunter auch Fragmente von einem Exemplar, das nicht die gewohnte halbkreisförmige Innenausformung zeigt, sondern wo die Seiten rechtwinklig an das flache, verzierte innere Blatt anschlossen. Diese Art seltenere Form lässt sich bei den Hofwerkstätten an den von der Mitte bis in die achtziger Jahre des 15. Jahrhunderts hergestellten Kacheln belegen..$^{55}$ Ein Teil der erwähnten Randverzierungen ähnelt zwar den Rauriser Typen, stimmt aber nicht völlig mit ihnen überein. Anscheinend hat der das Positiv anfertigende Meister diese nur nachgeahmt, bei einigen dagegen das kopierte Negativ umgearbeitet.

\section{EIN OFEN VOM „SALZBURGER TYP“ IN BUDA}

Anhand der vorab beschriebenen Ofenkacheln kann man sehen, dass die in Buda, Visegrád und Tata - sowie in den Palästen der Erzbischöfe und Bischöfe - aufgestellten Öfen nicht mit dem 1501 entstandenen Salzburger Ofen identisch waren. Bei diesem hat man zwar an der rückwärtigen, also kaum sichtbaren Seite auch Kacheln des „Rauriser Typs“ verwendet, doch deren Motive waren urpsrünglich für andere Öfen vorgesehen. Sie sind also, auch nach meinem Dafürhalten, an einen älteren, noch Ende des 15. Jahrhunderts tätigen Meister der Werkstatt zu binden.

Im Laufe der wiederholten erneuten Untersuchung der Funde aus dem Budaer Palast gelang es jedoch, einige Fragmente abzusondern, ${ }^{56}$ die zweifelsfrei schon einer späteren Gruppe angehören. Als

${ }^{54}$ I. HOLL: Neutronenaktivierungsanalyse mittelalterlicher Ofenkacheln II. Beobachtungen zur Fertigungstechnik, Vervielfältigung, Ton- und Engobeauswahl. ActaArchHung 47 (1995) 275-277, Abb. 9-12.

${ }^{55}$ Solcher Art sind die König Matthias darstellenden buntglasierten Kacheln: I. HOLL-M. BALLA: Neutronenaktivierungsanalyse mittelalterlicher Ofenkacheln. ActaArchHung 46 (1994) 384, Abb. 2, sowie die in dieser Form hergestellten Typen der Kacheln des Ofens mit Matthias' Wappenreihe: J. TAMÁsI: A nagyvázsonyi Kinizsi-vár doboz alakú csempékbő́l rakott kályhája (Der aus schachtelförmigen Kacheln aufgesetzte Ofen der Burg von Nagyvázsony). VMMK 18 (1986) Abb. 15.
${ }^{56}$ Die geringe Zahl der Fragmente beweist keineswegs, dass diese nicht zu einem separaten Ofen gehört haben könnten. Auch im Falle anderer Öfen kommt es vor, dass von dem Budaer Exemplar kaum Bruchstücke erhalten blieben. Beispiele dafür sind ein Ofen vom „Typ Pomáz“ vom Ende des 14. Jahrhunderts (Fragmente von 4 Kacheln), der früheste sigismundzeitliche Ofen (1 Kachel und einige kleine Bruchstücke), der „norddeutsche Ofen“ (1 Kachel) sowie ein böhmischer Ofen aus der Zeit um 1500 (Fragmente von 3 Kacheln). S. I. HoLL: Középkori kályhacsempék Magyarországon (Mittelalterliche Ofen-kacheln in Ungarn) IV. ArchÉrt 117 (1990) Abb. 17; Holl 1983, Abb. 47; I. HolL: Spätgotische Ofenkacheln. ActaArchHung 50 (1998) Abb. 59-62. 


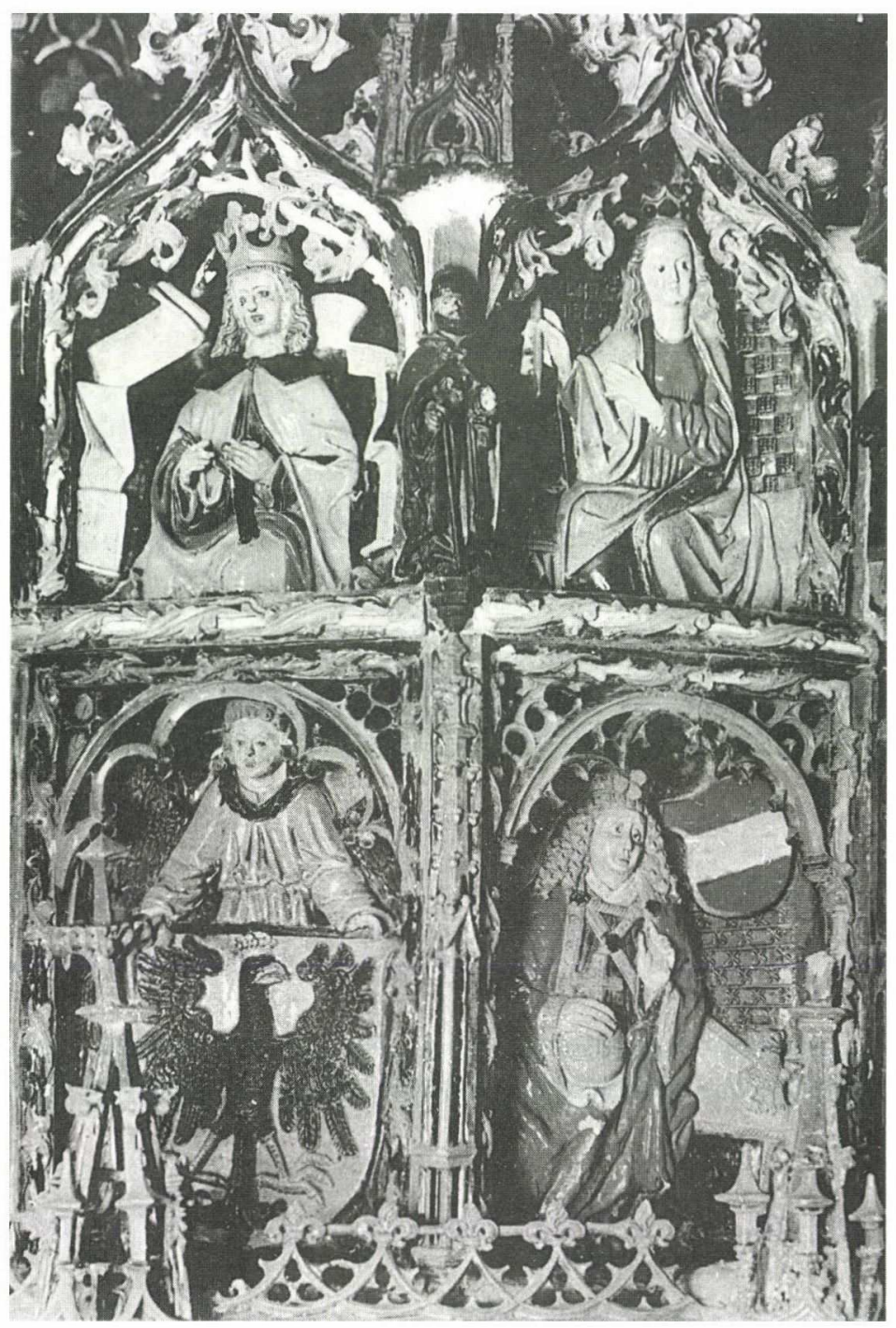

Abb. 65. Kachelofen, Festung Hohensalzburg, Ausschnitt vom oberen Teil, Dat. 1501 (nach Prodinger)

Grundlage zu ihrer Bestimmung dienten jene Kacheln, welche in Salzburg die Tätigkeit des späteren Meisters charakterisieren. Das ist in erster Linie die von den früheren abweichende, höhere Kenntnisse der Plastik zeigende Ausarbeitung in Verbindung mit dem stark hervortretenden Relief (das sich am Salzburger Ofen in einigen Fällen völlig von der Grundfläche abhebt). Eine in technologischer Hinsicht reifere Lösung stellt auch die Anwendung neuer Glasurfarben ${ }^{57}$ dar, wie z. B. das flammende Dunkelblau (bei den

\begin{abstract}
${ }^{57}$ In den zahlreichen Publikationen des Salzburger Ofens hat man die Aufzählung der angewandeten Farben in der Regel leider weggelassen, oder sie ist unvollständig. Nur PRODINGER, 2 fasst sie zusammen (und erwähnt zum ersten Mal auch das rote „Orange“). Die häufig publizierten Farbabbildungen eignen sich meist nicht zur Beobachtung der Details, lediglich PRODINGER 1972, Abb. 6 sowie einzelne farbige Detailaufnahmen bei F. BLÜMEL: Deutsche Öfen. München 1965, 17 lassen sich verwenden. - Unverständlich ist, dass WALCHER 1905 - die erste
\end{abstract}

detaillierte Aufarbeitung - nur die Farben Blau, Gelb, drei verschiedene Grün, Braun, Lila und alle als Bleiglasur aufzählt (das Weiß und das Rot fehlen!). Erst später, bei der Behandlung des Ofens von Aussee, rechnet er auch das Hellblau zu den Zinnglasuren. In einer anderen Zusammenfassung (Bunte Hafnerkeramik der Renaissance ... Wien 1906, 60) gibt er eine detailliertere Farbaufstellung: Blau in zwei, Grün in drei und Gelb in drei Tönen sowie Braun und Schwarz. 


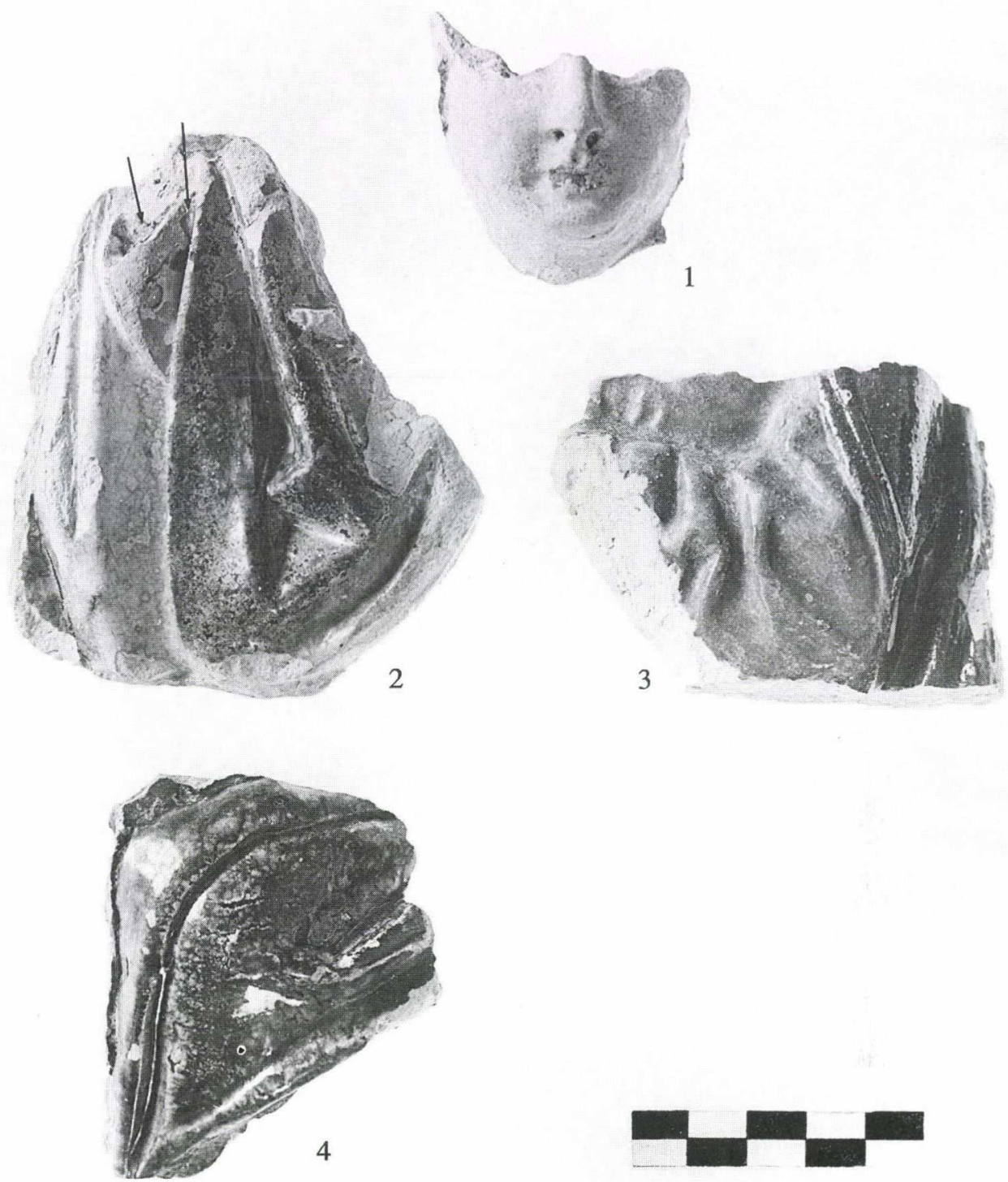

Abb. 66. Fragmente von Kacheln mit der HI. Ursula - FO: Buda, Palast ( $\rightarrow$ kobaltblaue Glasur-Überreste)

Früheren nur Blassblau) und das Tomatenrot. Andererseits kombinierte man die verschiedenen Farben mit größerer Mannigfaltigkeit nebeneinander; nicht nur im Falle der Kleidung (wie mitunter auch früher schon), sondern auch an den rein dekorativen Zwecken dienenden Kacheln und dünnen Leistenkacheln. Bei letzteren ist das Aststück unter der rankenden Blattreihe abwechselnd weiß, rot, hellblau oder schwarz (bei manchen Exemplaren kommen sogar auf einer Kachel Blätter mit zwei verschiedenen Farbtönen vor: gelb und rot).

Von zwei der Salzburger Kacheltypen konnten unter den Fragmenten aus dem Budaer Palast Paarstücke identifiziert werden:

1. Hl. Ursula. Bruchstück von den Falten des Mantels unter der rechten Hand (die in Salzburg als typisches Attribut einen Pfeil hält) mit grüner und weißer Glasur. Das an der Hand hervorschauende Gewanddetail war ursprünglich dunkelblau, die Glasur blätterte aber ab (Abb. 66.2). Detail des linken Armes mit grünlichblauer Glasur, seitlich der Mantelsaum mit dunkelbrauner Glasur ( $A b b$. 66.3). Detail 

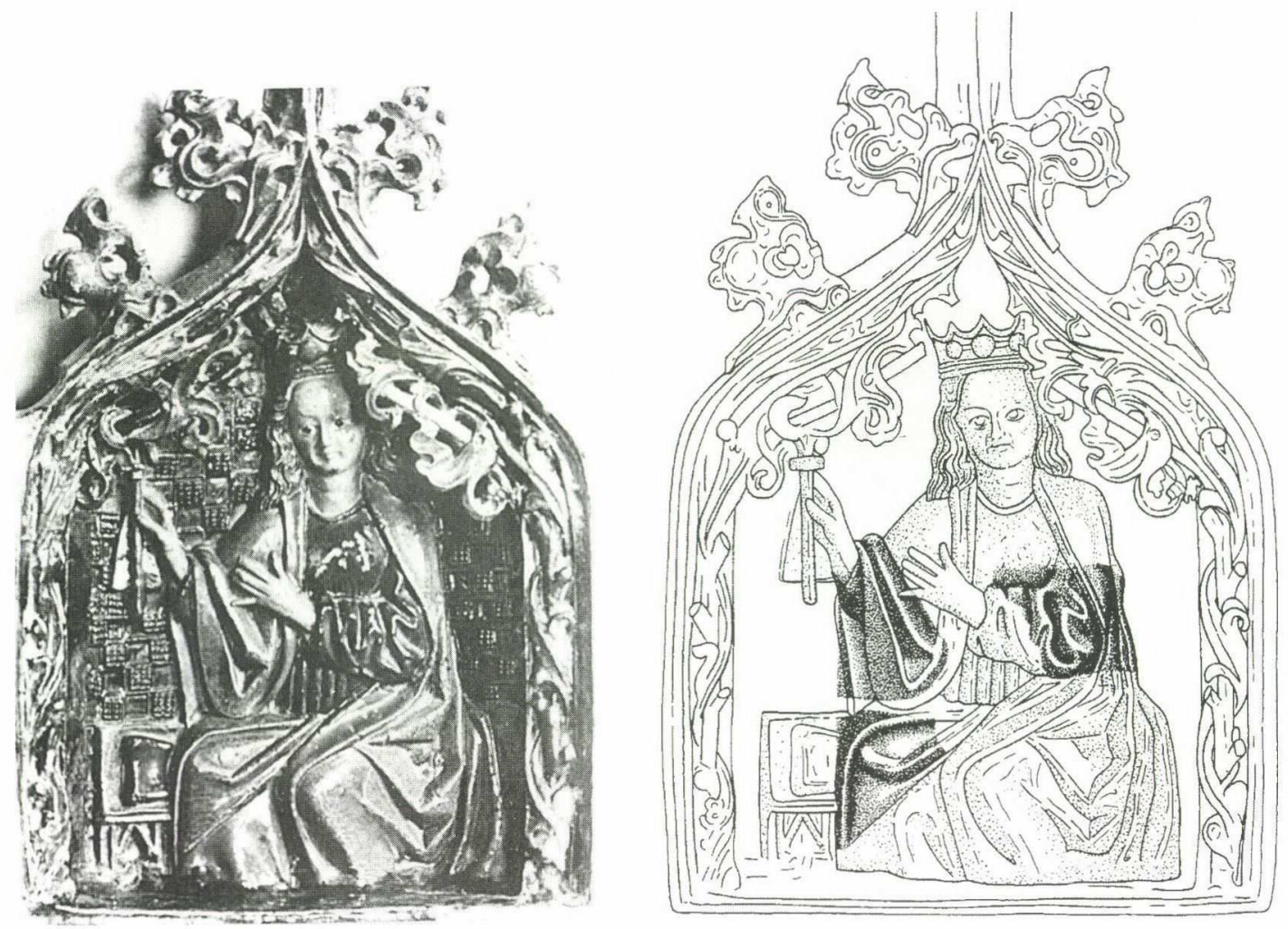

Abb. 67. Giebelkachel mit Hl. Ursula, Hohensalzburg (nach Franz) und die Bruchstücke aus Buda

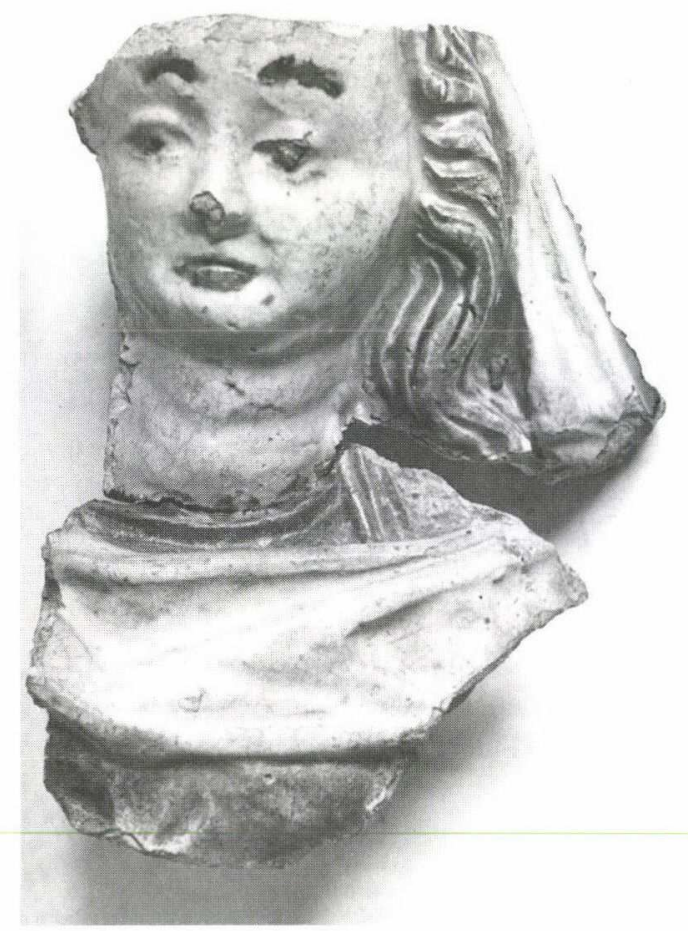

Abb. 68. Kopffragment einer weiblichen Heiligen von einer Giebelkachel - FO: Buda, königl. Palast 


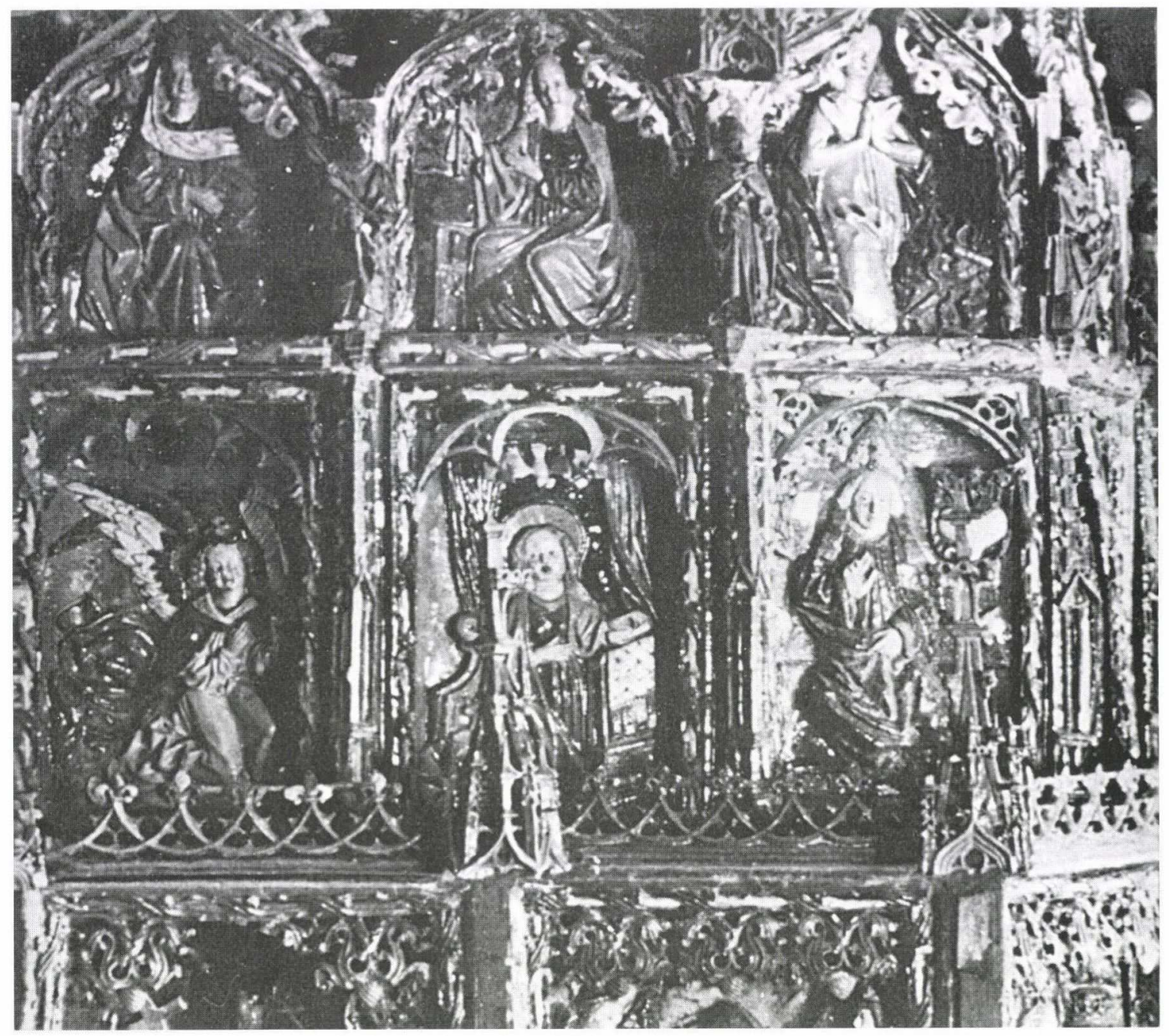

Abb. 69. Ofen, Hohensalzburg, Ausschnitt, obere Kachelreihe - linke Seite des Oberbaues (nach Franz)

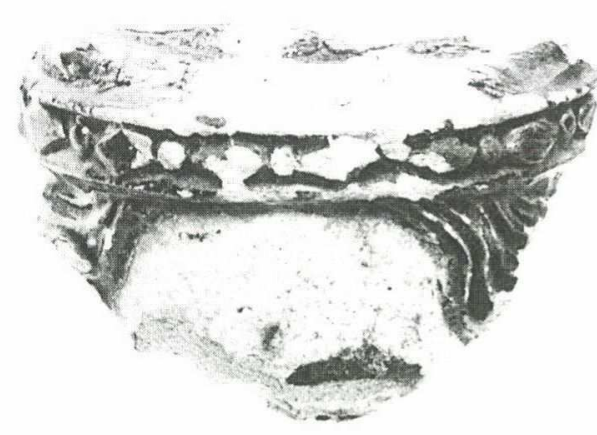

70

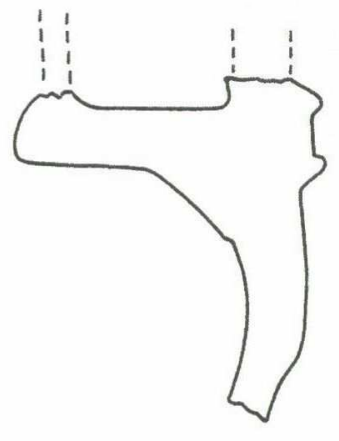

3
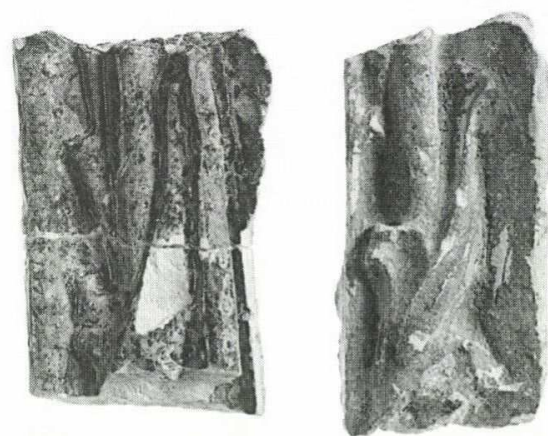

71

Abb. 70. Bruchstück von einem bekrönten Kopf, buntglasiert (Buda, königl. Palast) Abb. 71. Fragmente grünglasierter Kachelrahmen (Buda, königl. Palast) 

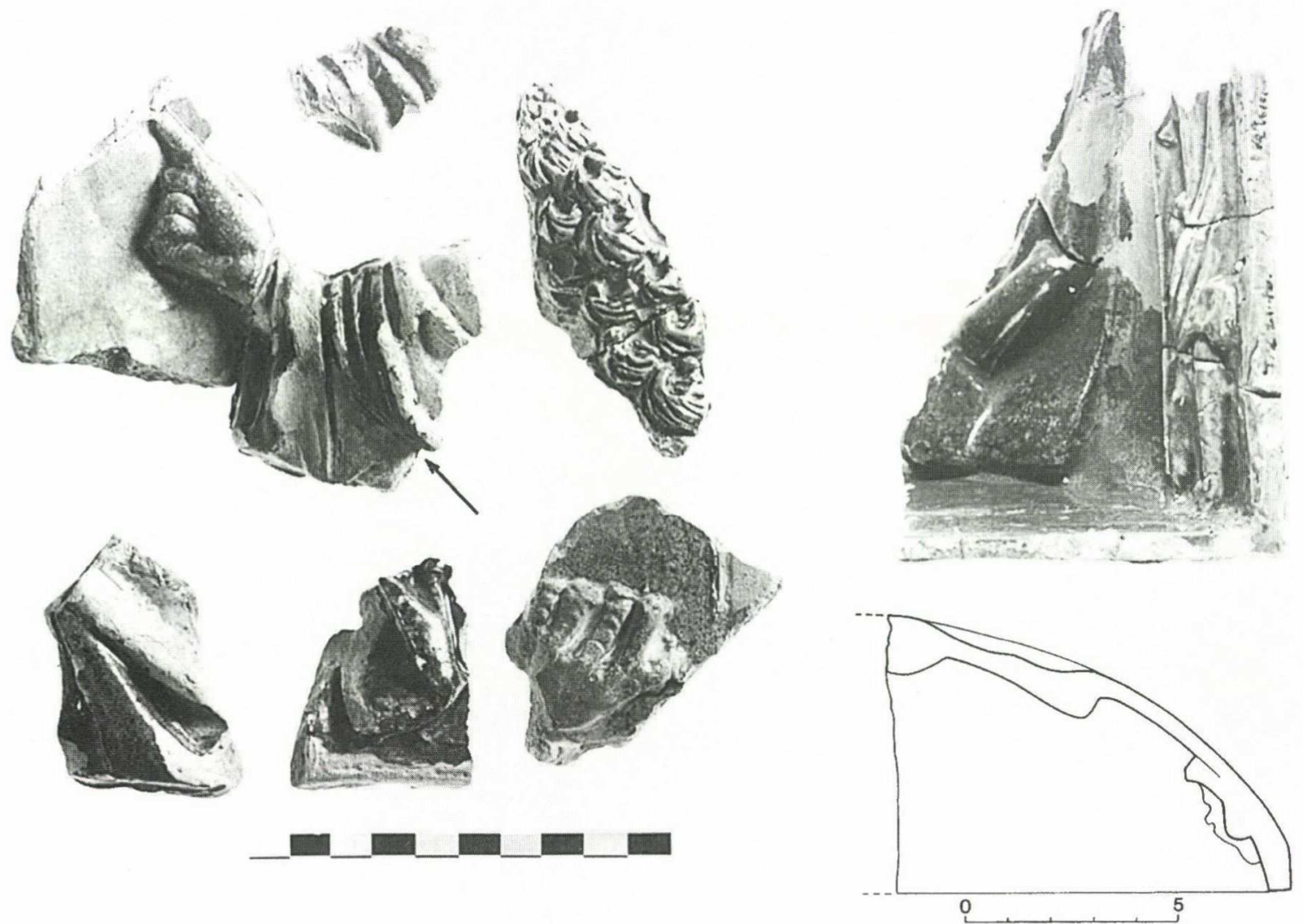

Abb. 72. Buntglasierte Kachelfragmente vom Ofen des Typs Salzburg ( $\rightarrow$ kobaltblaue Glasur-Überreste) (Buda, königl. Palast)

des das rechte Knie bedeckenden Mantels mit heller, gelblichbrauner Glasur (Abb. 66.4). Alle Fragmente aus gelblichweißer, gut geschlämmter Scherbe, die beim ersten und dritten Stück jedoch, ins Negativ eingeglättet, stellenweise dünner wird, während sie beim zweiten Stück dick ist $(0,7-1,3 \mathrm{~cm})$. Wie die Farbunterschiede der verwendeten Glasuren bezeugen, stammen die Fragmente in unserem Fall von drei verschiedenen, aber zu ein und demselben Typ gehörenden Kacheln. Bei einer war der Mantel grün (die umgeschlagene Innenseite weiß), bei der anderen dunkelbraun und bei der dritten hellbraun glasiert. Das überascht deshalb nicht, weil in der obersten Kacheireihe des Salzburger Ofens - wo sich diese sitzend dargestellten weiblichen Heiligen befinden $(A b b .65)$ - gleich zwei Exemplare der Hl. Ursula zu sehen sind: einmal an der Vorderseite ${ }^{58}$ (über der Kachel Kaiser Maximilians, $A b b$. 65), zum anderen auf der linken Seite (über der Maria der Verkündigungsszene; $A b b .69$ ).

2. Bruchstück mit einer weiblichen Heiligen. Von der sitzenden Gestalt kann man das Gesicht (weiß, Auge und Augenbraue schwarz), ein Detail des gelben, gewellten Haares sowie den über Kopf und Brust gelegten weißen Schleier erkennen; gelbes Gewand, Detail des Mantels am Hals lilafarbig. Die plastische Ausführung ist ebenso kunstvoll wie bei den figuralen Exemplaren von Salzburg. (H: 10,5 cm, D: 0,5 cm; $A b b .68)$. Auch hier tritt das vollständige Stück unter den Giebelkacheln der obersten Reihe des Ofens auf, und zwar auf dessen breiterer linker Seite, links neben der zweiten Hl. Ursula (Abb. 69). Wie es scheint, waren die Farben des Budaer Exemplars in diesem Fall identisch.

58 Nach Prodinger 1972, Abb. 6 sind deren Farben: der Mantel gelb, innen dunkelblau, das Kleid rot, Gesicht und Hände weiß, der Hintergrund grün, mit Schachbrettmuster.
Randverzierung: schwarz, rot, gelb. Am anderen Exemplar kann man die Farben nicht gut erkennen: der Mantel gelb, das Gewand hier aber anders (braun oder blau?). 


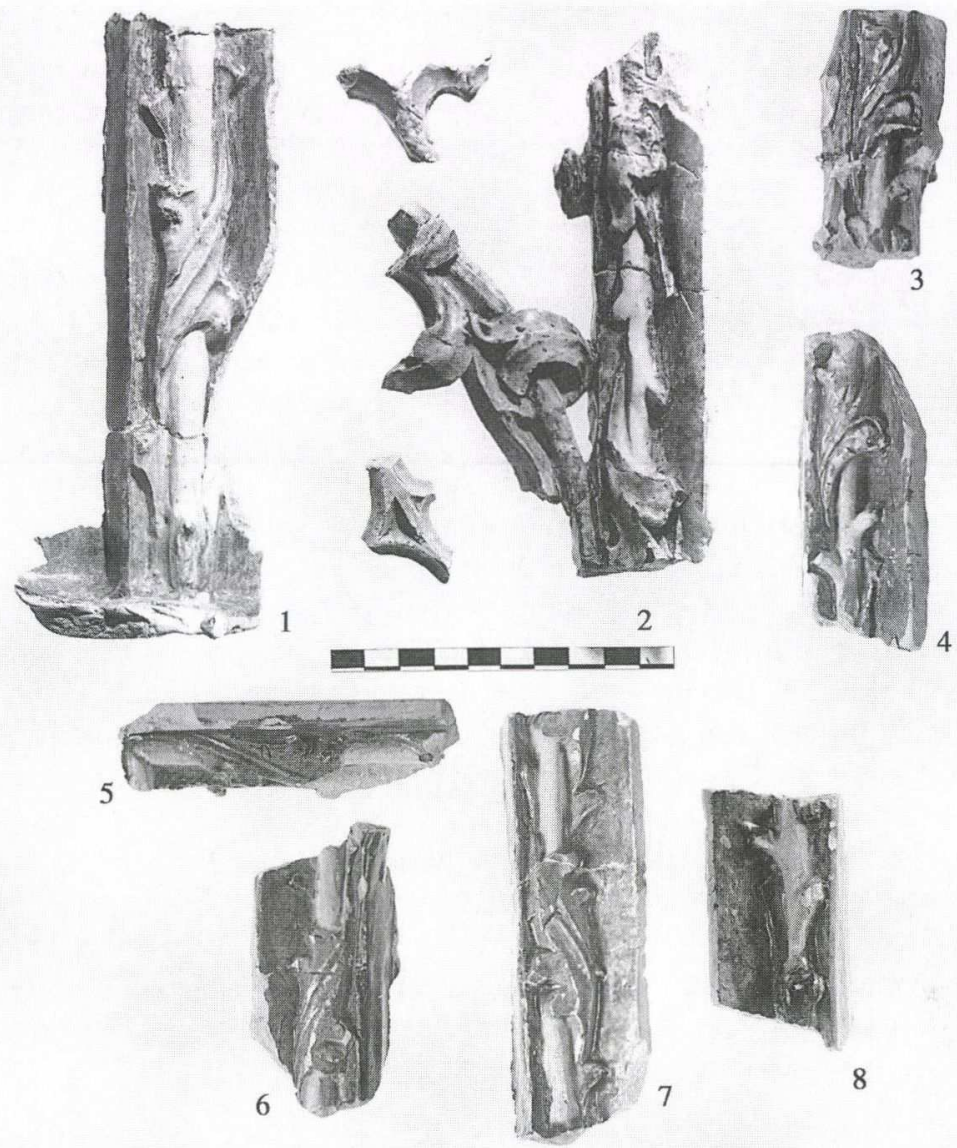

Abb. 73. Rahmenverzierungen von Ofenkacheln (mit grüner, gelber, weißer und lilafarbener Glasur) (Buda, königl. Palast)
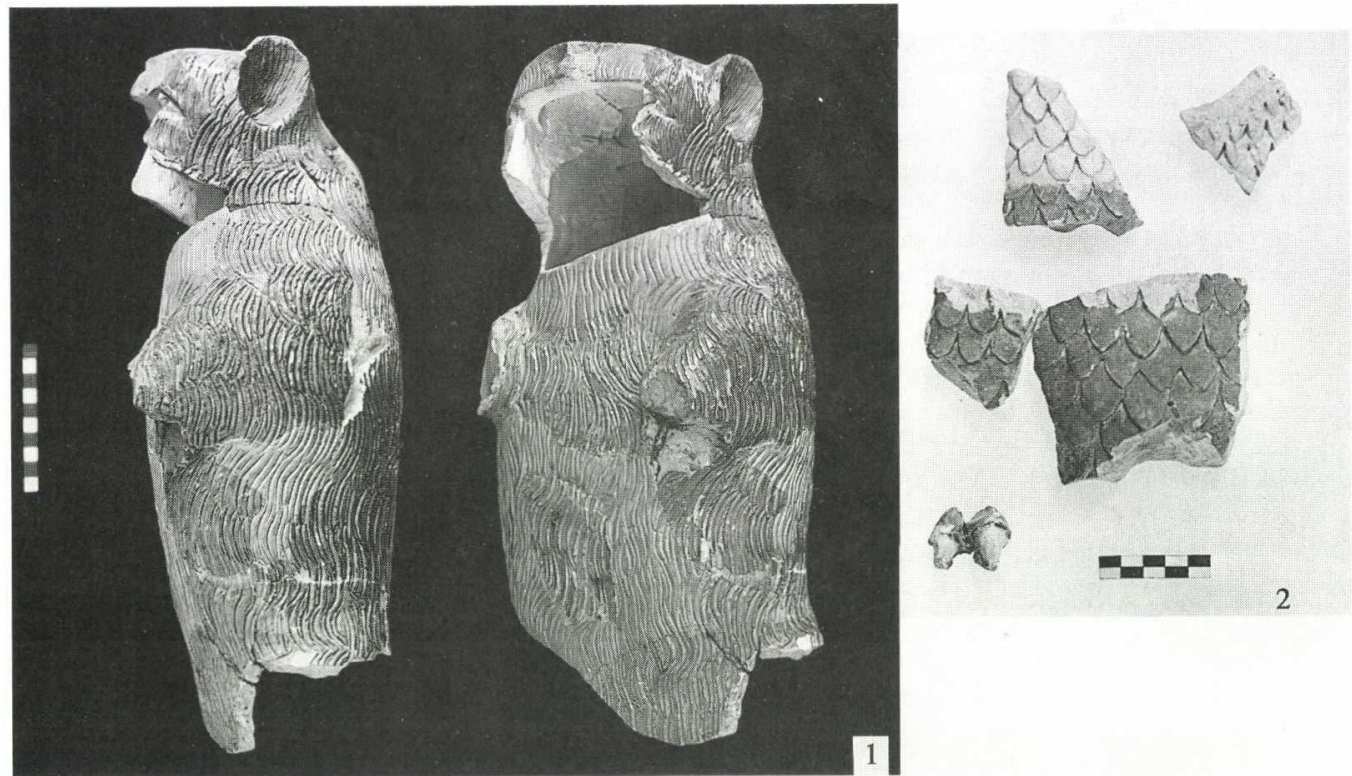

Abb. 74. Fragmente der den Ofen tragenden Tierfiguren. 1: Bär; 2: Adler (mit weißer, blauer und lilafarbener Glasur) (Buda, königl. Palast) 
Die übrigen Bruchstücke eignen sich leider nicht zur genauen Bestimmung. Zwei Kopffragmente (Abb. 66.1, 70), das eine mit dem unteren Rand der Krone, könnten von jeder beliebigen Kachel dieses Typs stammen. Das bräunlichgelb glasierte Detail einer ringellockigen Frisur ist mit seiner ausgeprägten Plastik typisch für den Meister des Salzburger Ofens (ähnlich dem Haar Kaiser Maximilians in der mittleren Reihe). Auch zwei grünweiß bzw. hellbraun glasierte Gewandfaltenreste (Relieftiefe: 0,8-1,1 cm) sowie eine Hand mit blassblauer Glasur (?) vom Rand einer Kachel (Abb. 72) lassen sich hierzu attribuieren. Vermutlich zu einem der Heiligen in der oberen Reihe gehört eine sehr schön ausgearbeitete, nach links weisende Hand (auf gelbem Grund dunkelblaues Gewand ${ }^{59}$, Glasur abgeplatzt, sowie grün und weiß; $A b b$. 72.). Ein kleines hellblaues Armfragment macht dadurch auf sich aufmerksam, dass es gelöst vom Hintergrund freiplastisch geformt wurde, was seltener auch in Salzburg vorkam.

Ein weiteres unserer Exemplare ist das Bruchstück der rechten unteren Ecke einer Nischenkachel: Detail der Gewandfalten mit bräunlichlilafarbiger Glasur (Relieftiefe: 1,4 cm); Hintergrund lebhaft gelblichgrün; am Rand auf gelbem Grund mit gelbem Blatt; sicher Detail einer sitzenden Gestalt von einer der oberen Kachelreihen des Ofens (H: $12 \mathrm{~cm}, A b b .72)$.

Im Zusammenhang mit der 1. Rauriser Untergruppe habe ich bereits auf die Anwendung der vielen verschiedenen Rahmenverzierungen hingewiesen. Beim Salzburger Ofen findet man zahlenmäßig zwar etwas weniger, doch das gleichen ihr Farbreichtum und ihre Mannigfaltigkeit wieder aus. Unter den Budaer Exemplaren ähnelt der am Rahmen der vorgenannten Kachel befindliche Typ (an zwei Seiten des um den Ast rankenden Blattes jeweils ein kleiner Lappen) jenem Typ, dem man an den Rändern der Salzburger „Kachel mit Passionswappen“ begegnet. ${ }^{60}$ (S. noch das gleiche Motiv auf grünem Grund mit weißgelber Farbe: $A b b$. 73.1.) Eine andere Variation dieses Blatttyps ist gedrungenerer Form. Auch sie kommt in Buda vor grünem Hintergrund mit weiß-gelber Farbe vor. Unter den Fragmenten gibt es einen abgebrochenen Rest der durchbrochen gearbeiteten Verzierung vom oberen Teil der Kachel bzw. an einem Stück ist der überhängende Bogen mit den angeklebten Blättern (gelbes Blatt an lilafarbigem Stab) zu sehen (Abb. 73.2-4). Diese Lösung erscheint in Salzburg in der mittleren Reihe des oberen Ofenkörpers mit unterschiedlichen Verzierungen ( $A b b .69)$, in Buda ist sie aber anders.

${ }^{59}$ Auffällig ist, dass die dunkelblaue Kobaltglasur in beiden Fällen von der Scherbe abplatzte. Als würde die Oberfläche darunter eine matte, graubraune Engobeschicht bedecken? Wollte man damit etwa die bisher nicht verwendete Glasur besser binden oder ihren dunklen Ton gewährleisten? (Vermutlich wurde die gut deckende blassblaue Glasur gemischt mit Zinnglasur angewandt.) - Wie die kobaltblaue Glasur auf dreierlei verschiedene Weise verwendet werden kann, demonstrierte man zu einem früheren Zeitpunkt (zwischen 1460 und 1473?) in der Beziehungen zur Schweiz aufweisenden Werkstatt des Meisters des „Dreikönige-Ofens": an den plastischen Teilen gemischt mit weißer Zinnglasur (was einen blassblauen-grünlichblauen Ton ergab); auf den vertieften Flächen - wo sie sich nicht mit anderer Glasur vermischte - über weißer Engobe, so dass das Brokatmuster eine scharfe, weiß-dunkelblaue Farbe bekam; an den Gesimsen mit echter Majolikatechnik blaue Bemalung über dem Zinnglasurgrund (HoLL 1983, Abb. 12, 15-18). Es liegt auf der Hand, dass die entwickeltere Technik der schweizerischen (?) Werkstatt - vielleicht die erste nördlich der Alpen - keine direkte Beziehung zu den Meistern der Werkstatt Salzburg-Hallein bedeutet. Von Einfluss auf diese und andere Werkstätten (Wien?) aber dürfte sie gewesen sein.

Eine andere, technologisch bedeutsame Farbe ist das Rot. Lange Zeit konnten es die Töpfer nicht herstellen (einmal abgesehen von seinem Gebrauch im Altertum: an kretischen und ägyptischen Fayencen 1700-1300 v. Chr., sowie in China: an „dreifarbig“ glasierten Keramiken des 8. Jahrhunderts), weil sich die mit Kupfer- oder Eisenoxid erreichbare Farbe beim Brennen leicht veränderte. - Im Nahen Osten, in Iznik, verwandte man zu seiner Herstellung ab 1560 erstmals rote Engobe mit Eisenoxid (Bolus armena, Erde von Lemnos), bedeckt mit farbloser Glasur (also keine echte Glasurfarbe). Zur gleichen Zeit wird es in Italien erstmals angewandt. Zur Technologie s. I.-A. DAYTON: Minerals, Metals Glazing and Man. London 1978; M.-C. BEuRdeley: Chinese Ceramics. London 1974; A. LANE: Later Islamic Pottery. London 1957, 56-57. - Die Versuche der schweizerischen Töpfer zeigt die Ecke einer Berner Eckkachel (Halbfabrikat): über weißer Engobe mit orangeroter und schwarzer Bemalung (,2. H. 15. Jh." - weiter oben zit. Werk von RoTHKAUFMANN 1994, Anm. 33, Nr. 429). - Wie es in Salzburg gelang, diese Farbe (Tomatenrot?) herzustellen, müsste untersucht werden - auf jeden Fall eine bahnbrechende Lösung!

Seltener ist, wie man sie als Verzierung an Gefäßen des 10.-11. Jahrhunderts aus Konstantinopel verwendete (rote Engobebemalung unter gelber Glasur: „,red under-glaze slip“). In Süditalien erscheint sie im 13. Jahrhundert an Gefäßen und Tellern verschiedener Form (hier bereits in der Farbkombination braun-grün-rot und mit mannigfaltigen Mustern) - aber auch an diesen nur mit Bleiglasur. R. B. STEVENSON in: RedPainted and Glazed Pottery in Western Europe from the Eighth to the Twelfth Century. MedArch 13 (1969) 145; M. V. FONTANA in: La ceramica medievale di San Lorenzo Maggiore in Napoli. Napoli 1984. Vol. 1, 129-150.

${ }^{60}$ Franz 1969, Abb. 129. 

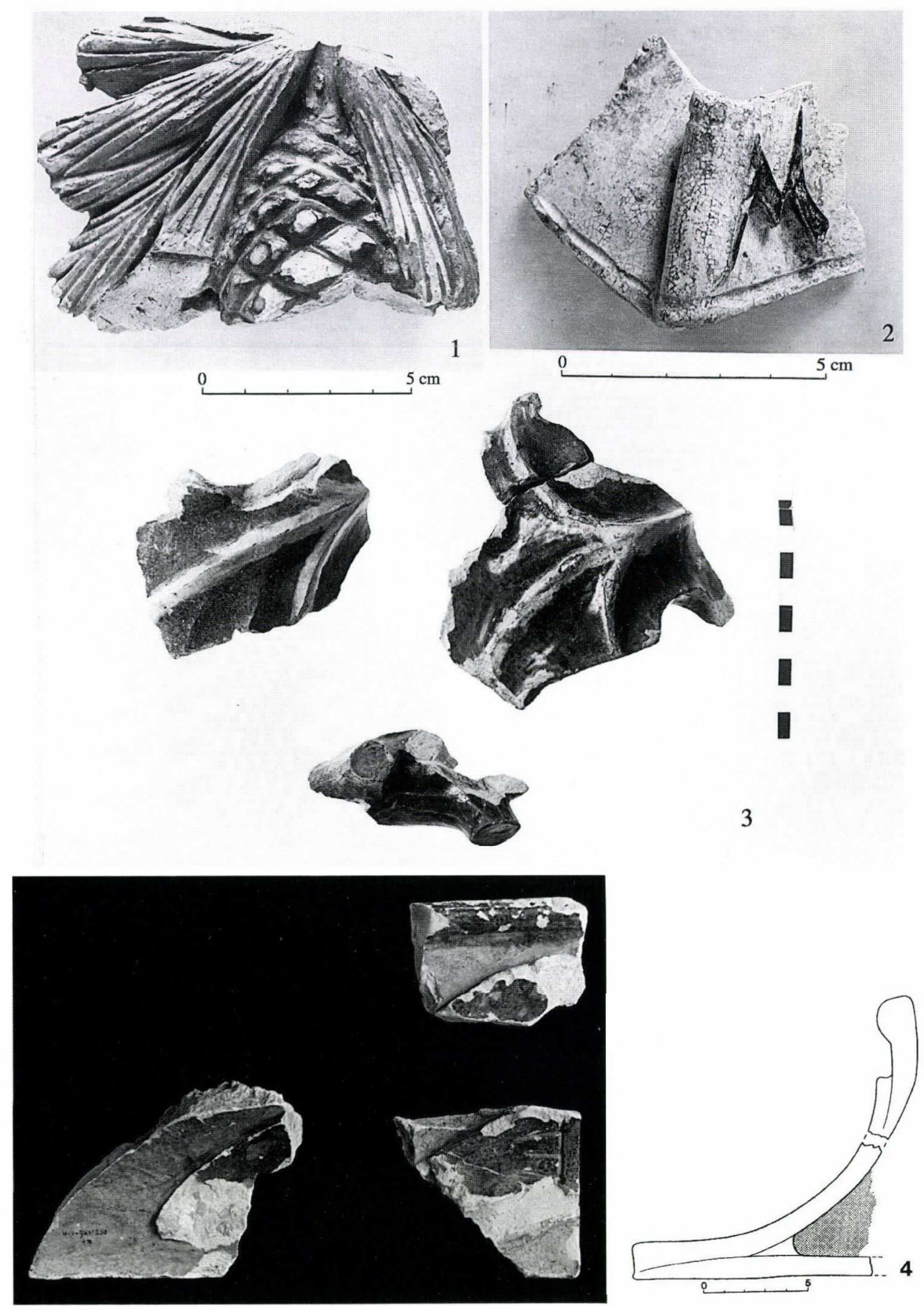

Abb. 75. Fragmente von Leistenkacheln (Buda, königl. Palast)

Eine dritte in Buda vertretene Blattform (beidseitig jeweils mit zwei kleinen Lappen) stimmt farblich ebenfalls mit den Vorgenannten überein (Abb. 73.5-7). Auch hiervon gibt es ein Bruchstück, das zum geraden oberen Abschluss einer Kachel gehört und die Reste der herabhängenden Durchbruchverzierung zeigt. Als Kachelrand konnte ich diese auf den vom Salzburger Ofen publizierten Abbildungen bis jetzt nicht entdecken, aber als waagerechte Leistenkachel findet man sie unter der obersten Kachelreihe 


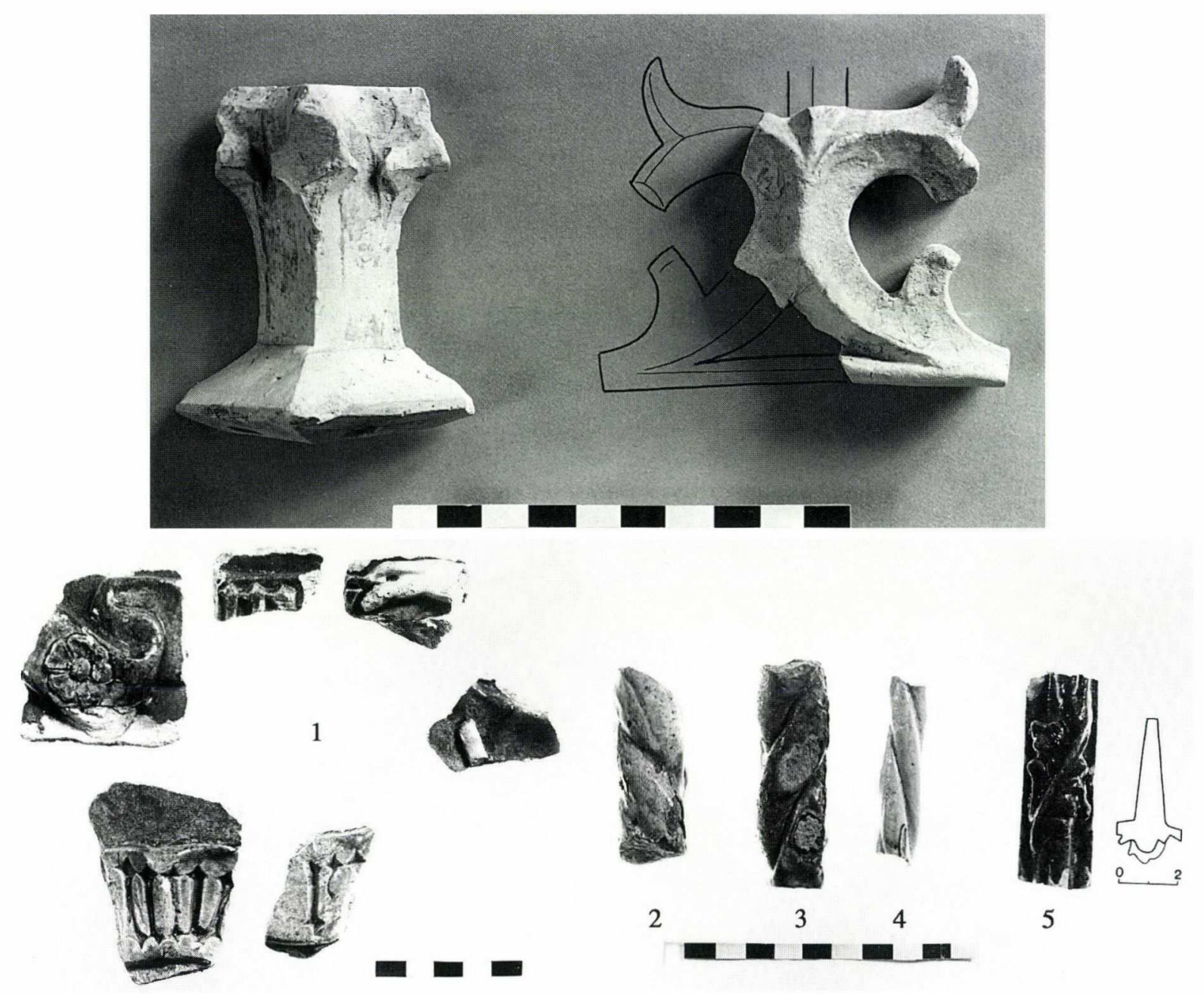

Abb. 76. Fragmente von Zierleisten (Buda, königl. Palast) Abb. 77. 1: Spruchbänder; 2: Eckverzierungen und Leistenkachel

(Abb. 65) und auch unter der oberen Kachelreihe am unteren Ofenkörper (abwechselnd zwischen zwei anderen). Übrigens tritt dieser Blatttyp in ähnlicher Form, doch mit anderen (kleineren) Maßen auch im Fall der Rauriser Gruppe auf, was ebenfalls bestätigt, dass es sich um eine identische, aber über längere Zeit tätige Werkstatt handelt.

Der erste Typ der Umrandung kommt auch an einfarbig grünglasierten Kacheln vor (Abb. 71$)$. Zu welchen Themen diese gehörten, weiß ich jedoch nicht.

\section{Fragen der Thematik, des Stils und der Zeitstellung}

Zum Kennenlernen des am Budaer Ofen angewandten Programms reichen unsere Fragmente nicht aus. Gewiss ist nur, dass sich an den obersten Giebelkacheln, in derselben Weise wie beim Salzburger Ofen, verschiedene weibliche Heilige aneinander reihten. Die Fragen, welche Themen weiter unten vertreten und ob diese der anderen Umgebung (weltlich, königlich) des Budaer Hofes angepasst waren, müssen vorerst offen bleiben. Ebenso wenig kenne ich den Zeitpunkt, an dem der hiesige Ofen aufgestellt wurde; allerdings dürfte er von dem des Salzburgers - das Jahr 1501 - nicht wesentlich abgewichen sein. 


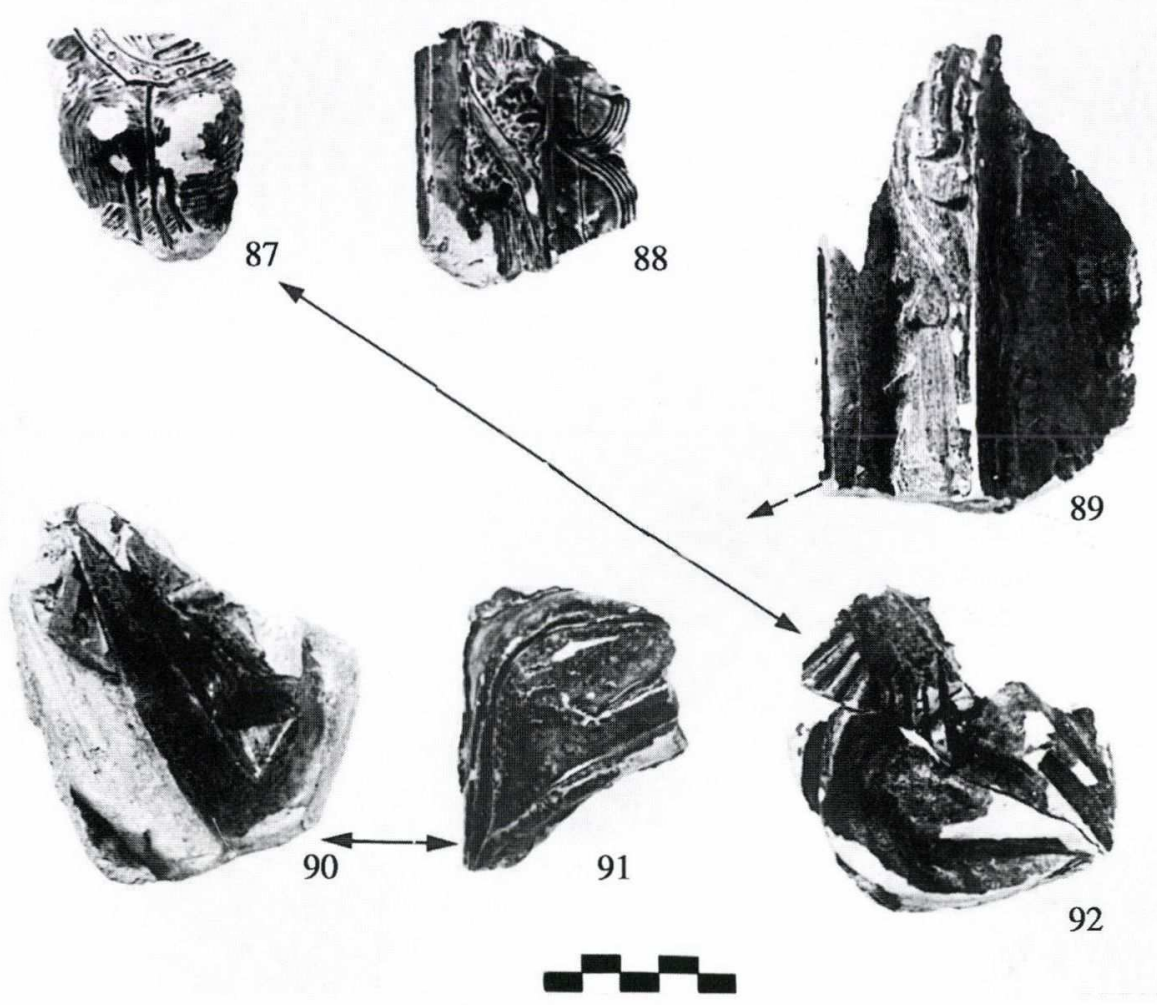

Abb. 78. Keramikproben - FO: Buda, königl. Palast

König Wladislaw II. setzte in der Anfangszeit nach Matthias' Tod die Bautätigkeit seines großen Vorgängers in Buda noch fort, wozu ihn wohl auch seine Heirat mit der französischen Prinzessin (1501-1506) angeregt haben mag. Damals könnte der Anspruch bestanden haben, einen neuen, repräsentativen Ofen aufzustellen - und diesen bei der gleichen Werkstatt zu bestellen, die schon die früheren Öfen geliefert hatte, lag auf der Hand. Das geschah vielleicht um 1502 (diese Jahreszahl stand an der Tür eines der Säle im Obergeschoss ${ }^{61}$ ).

Mit den Stilfragen des Salzburger Ofens hat sich die österreichische Forschung sehr eingehend beschäftigt. Sie stellte fest, dass der unmittelbare Einfluss der süddeutsch-österreichischen Plastik (Michael Pacher, $\uparrow 1498$; Hans Valkenauer) sowie als Vorbilder die wesentlich früheren Kupferstiche des Meisters E. S. nachzuweisen sind. Im Hinblick auf die die Technologie bestimmende Töpferwerkstatt akzeptierte sie die auf irrtümlichen Schlüssen beruhende Theorie von Voit übernehmend (königliche Werkstatt, BudaWien) - den Einfluss der Technologie und des Stils einer in Buda beheimateten Werkstätte. ${ }^{62}$ - Wie mit der vorliegenden Aufarbeitung bewiesen werden kann, sind die Wurzeln auf die Halleiner Werkstatt zurückzuführen. Hier wurde die auch früher schon modernste, neue Technologie weiterentwickelt bzw. die Anwendung dekorativer Details vervollkommnet. In dieser Hinsicht, so meine ich, hat die ungarländische Werkstatt der „Öfen mit Ritterfiguren“ nur eine indirekt inspirierende Rolle gespielt, ${ }^{63}$ vertrat sie doch

${ }^{61}$ L. Gerevich: The Art of Buda and Pest in the Middle Ages. Budapest 1971, 108, 116. - Die Jahreszahl wird in den Beschreibungen der im Zeitalter der Türkenherrschaft hier weilenden Reisenden an einem Türrahmen erwähnt; vermutlich ist sie ein Hinweis auf den Bau der zweiten Etage des westlichen Palasttraktes. - Dies war das letzte Aufflammen der hiesigen
Glanzzeit, eine kurze Fortsetzung der früheren königlichen Repräsentation.

62 WALCher 1905; Prodinger 1972; Franz 1969.

${ }^{63}$ Prodinger 1972, 2 hebt die Verwendung der kleinen Fialen hervor. Hier sind sie aber nur noch Dekoration, während sie früher als architektonische Elemente dienten. 
einen ganz anderen, früheren Stil - wobei ihr Einfluss in der zweiten Hälfte des 15. und im ersten Viertel des 16. Jahrhunderts gewiss mehrere mitteleuropäische Werkstätten inspiriert hat. Im Falle Salzburgs dagegen entwickelte man bereits Dekorationen völlig abweichenden Stils: die Verzierung mit rankenden Blättern in teils naturalistischerer, teils stilisierterer Auffassung. Stark gestreckte Blätter als Rahmendekor findet man beispielsweise am Schnitzwerk des Altarbildes von Fridrich Herlin aus dem Jahre 1472 oder an einem Kupferstich mit dem Bild der Hl. Katarina vom Meister der Weibermacht aus den 1450er Jahren, um nur zwei der zahlreichen Beispiele zu erwähnen. Die den oberen Teil der großen Salzburger Kacheln schmückenden Bögen - anstelle der gotischen Maßwerke mit naturalistischen Blatt- und Blumenranken durchflochten - wurzeln gleichfalls in dem neuen, in den siebziger und achtziger Jahren schon weitgehend verbreiteten Stil (zu dessen Verbreitung auch die Holzschnittillustrationen beitrugen); 1493/94 wurde er auch am Altar eines Ulmer Meisters verwendet (Blaubeuren). Die lokale Anwendung der gotischen Architektur- und Dekorationselemente (Fialen, reliefierte Bildfelder mit Kielbogenabschluss, um einen Ast rankende, stilisierte Blätter als Rahmen) in anderen Zweigen der Kunst ist jedoch schon 1443 an einem kunstgeschmiedeten Flügelretabel zu beobachten, auch hier als Einfluss der gotischen Altarkunst. ${ }^{64}$ Für einen Schreiner- bzw. Schnitzmeister, der der Werkstatt zu den Modellen ihrer Dekorationsdetails verhalf, mögen solche Arbeiten (Schnitzereien an Flügelaltären, Chorgestühl) alltägliche Routine gewesen sein womit die herausragende Stellung des den ganzen Ofen entwerfenden Meisters und seiner Werkstatt keineswegs geschmälert werden soll. Annehmbar erscheint die schon von A. Walcher geäußerte Vermutung, dass die große Eckfigur am Salzburger Ofen den Hafnermeister darstellt (leider befindet sich auf dem Spruchband hinter seinen Beinen keine Inschrift); sie zeigt einen jüngeren Mann. Vielleicht hat er den älteren Meister der Werkstatt abgelöst (bärtiger Kopf am früheren Ofen: Abb. 16), wobei er nicht nur die vorausgegangenen technologischen Neuerungen (und Negative) übernahm, sondern die Technologie auch weiterentwickelte (s. das Erscheinen der kobaltblauen, hauptsächlich aber der roten Farbe). Hier handelt es sich nicht einfach um technologisches Bahnbrechen, dem die Forschung bislang keine Beachtung schenkte: dies ist die bewusste Steigerung des Farbreichtums der einzelnen Kacheln. Hinzu kommt, dass man die rote Farbe nicht nur an kleineren Details, sondern auch auf größeren Flächen verwendete (z. B. am Mantel Kaiser Maximilians, am Gewand der Hl. Ursula, am Inneren des Mantels von Gottvater und Gottsohn in der Krönungsszene Mariä). Damit gelang es zum ersten Mal, die in der Tafel-bildmalerei beliebte kontrastreiche Farbwirkung an Ofenkacheln nachzuahmen! (Ganz zu schweigen von der Möglichkeit, nun auch Wappen in ihren Originalfarben wiedergeben zu können - s. das österreichische und das Salzburger Wappen.) All das ging mit der künstlerischen Steigerung der plastischen Ausführung im Stil der Plastik des ausgehenden Jahrhunderts einher. Nach meiner Meinung hat hier trotz der engen Werk-stattbeziehung ein Generationswechsel stattgefunden (der dazu beitrug, sich an der neuen Bautätigkeit des erzbischöflichen Auftraggebers zu orientieren), - denn die ältere Werkstatt folgte noch dem künstlerischen Stil der siebziger Jahre Süddeutschlands und des Salzburger Landes. ${ }^{65}$

\section{Keiner Gruppe zuweisbare buntglasierte Keramiken}

Abschließend möchte ich zu jenen Fragmenten kommen, die den aufgezählten Öfen bislang nicht mit Sicherheit zugeordnet werden konnten - aber auf jeden Fall in den Kreis des hier vorgestellten Materials gehören.

\footnotetext{
${ }^{64}$ Spätgotik in Salzburg. Salzburg 1976. Katalog Nr. 90, noch im Stil der reifen Gotik.

${ }^{65}$ Von der klassischen Auffassung einzelner Kacheln abgesehen hat diese Werkstatt den von den erwähnten süddeutschen Holzschnitten vermittelten, in den siebziger Jahren gebräuchlichen Stil angewandt: die Wiedergabe der Plastik mit vereinfachten, eckigen, gebrochenen Linien; andererseits ähnlich dem plas-
}

tischen Stil der zweitrangigen Meister der Kunst des Salzburger Landes. S. beispielsweise den Stil eines Holzreliefs mit der Anbetung der Könige: Gesichter, Hände, Gewandfalten. Abbildung: Spätgotik in Salzburg. Katalog Nr. 230. A. ROHMOSER: „Die Figuren derb, im Detail ein wenig primitiv gearbeitet." (ebenda, S. 134) - Ende der siebziger Jahre. 
Figurale Ofenfüße: 1. Fragment einer bärengestaltigen Keramikskulptur. Nur von Körper und Kopf blieb ein Teil erhalten, die Beine brachen ab. Am leicht abgeflachten Körper (Dm: 12,5 × 20,5 cm) ringsherum tief eingeritzte Ausarbeitung des Fells. Weiße Scherbe mit bräunlichgelber Bleiglasur (D: 1-1,5 cm, L: $41 \mathrm{~cm}$, innen hohl; $A b b .74)$. Das Stück wurde vor der Ostfassade des Budaer Palastes, in der Klärgrube Nr. III, zusammen mit Münzen des Zeitraums 1419-1617 gefunden. (An derselben Stelle lag das Exemplar von $A b b$. 43.1.)

2. Fragmente einer vogelgestaltigen Keramikplastik. Größere Stücke mit ausgearbeitetem Federkleid, in abwechselnden Streifen weiß, hellblau und lilafarben glasiert; ein kleineres Flügelfragment sowie die Vogelkrallen (gelb-weiß). Gut geschlämmte, mit Glimmersand gemagerte, weiße Scherbe; in Schnurbandtechnik verfertigt (D: 1,1-2,2 cm). Aus verschiedenen Zerstörungsschichten, 17. Jahrhundert (Abb. 74).

Da man im Falle des Esztergomer Ofens nachweisen kann, dass zu dem Ofen vom Rauriser Typ Füße in Löwengestalt gehört haben, ist es wahrscheinlich, dass es sich bei diesen Tieren (Bär, Adler?) um spätere Bestandteile handelt (sofern nicht verschiedene Tiere daran vorkamen?).

Ofengesimsdekorationen: Große, handgeformte Fragmente deuten darauf hin, dass das den Unterbau des Ofens abschließende Gesims ein um 6-7 cm herausragender Pflanzenschmuck zierte. An einem Stück umgeben den Tannzapfen (mit lilabrauner Glasur) blassgrüne Nadelblattbündel; weiße Scherbe, $12 \times 9 \mathrm{~cm}, \mathrm{D}: 2-4 \mathrm{~cm}(A b b .75 .1){ }^{66}$

Andere Fragmente sind Teile von großen, stilisierten Eichenblättern, außen mit blasslilafarbiger und weißer Zinnglasur, auf der Rückseite mit grüner Bleiglasur (demnach berührten sie das Gesims nur an kleinen Punkten). Gelblichweiße Scherbe, D: 1,7-2,5-3 cm (Abb. 75.3). Zu diesen gehörte vielleicht ein grüngelb glasiertes, fragmentiertes Aststück (D: $4 \mathrm{~cm}$, im Inneren mit durchgehendem Loch).

Das dritte Beispiel ist ein Detail von einem plastisch geformten Spruchband, mit weißer Zinnglasur und kobaltblau glasiertem M-Buchstaben (Abb. 75.2), das ebenfalls nicht zu einer Kachel, sondern vielleicht zur besonders hervorgehobenen Inschrift eines der Öfen gehört hat.

Fragmente blieben auch von einem großen, flach gewölbten Fußgesims erhalten. Oben beschließt es ein flaches Bandglied. Auf die gewölbte, gelbglasierte Oberfläche war irgendeine (grüne) Blattdekoration appliziert, die aber abbrach. Nach Abmessung und Stärke zu urteilen, könnte es das untere Sockelgesims des unteren Ofenkörpers gewesen sein. (Weiße Scherbe; einzelne Fragmente innen mit Mörtel ausgefüllt, der es an das stabile Ofenfundament band $-A b b$. 75.4.)

Bekannt ist weiters ein Fragment von einer durchbrochen gearbeiteten Zierleiste, die in Einzelstücken am oberen Teil irgendeines Ofens (eventuell in der Mitte des oberen Turmteils - wie in anderer Ausarbeitung in Salzburg - oder ganz oben) angebracht war (weiße Scherbe, ursprünglich mit blassblauer Kaltbemalung). Drei in Material und Bemalung übereinstimmende Fragmente dürften zu den herausragenden Kreuzblumen gehört haben, die aus mehreren übereinander gelegten Stücken angefertigt wurden (auf der Achse befindet sich eine durchgehende Bohrung, um sie zu befestigen; H: 7,5 cm - Abb. 76). - Die letzteren Stücke erwähne ich deshalb, weil sie in den Abfallgruben vor der Ostfassade des Palastes zum Vorschein kamen, wohin man auch andere Bruchstücke dieser buntglasierten Öfen geworfen hatte. ${ }^{67}$

Spruchbandfragmente: Stücke von zwei verschiedenen Kacheln. Auf dem ersten ein Ende des Bandes mit Rosette bzw. dem plastischen Minuskelbuchstaben und der das Band haltenden Hand (auf zinnobergrünem Grund ockerfarbige und weiße Glasur), auf dem zweiten scharf eingedrückte Buchstaben (auf gelblichgrünem Grund ockerfarbige Glasur); gelblichweiße Scherbe (Abb. 77).

${ }^{66} \mathrm{~J}$. BALOGH: A múvészet Mátyás király udvarában 1. Budapest 1966, 149 vergleicht das Fragment mit dem Majolika-Tondo von L. della Robbia (Bd. 2, Abb. 397-398). - In diesem Fall wäre das Stück noch in den sechziger Jahren entstanden und gehört nicht zum Material der vorliegenden Aufarbeitung. (Seine Provenienz könnte nur mit einer Scherbenanalyse bestimmt werden. - Im Budaer Palast kamen vor Ort hergestellte, unglasierte, runde Randfragmente aus roter Scherbe, in bemalt-vergoldeter Ausführung eine Girlande im Renaissancestil formend, vom Ende des Jahrhunderts zum Vorschein.)

${ }^{67}$ In der erwähnten Grube I (Anm. 6) und Grube II: Abb. 10, 51, 52 (unten), 53 (Fisch), 54 (Wildschwein), 77 (Spruchband), mit Münzen der Zeit zwischen 1544 und 1570. 
Kachelecke mit gedrehten Schnurverzierungen: mit weißer Zinnglasur bzw. gelbgrüner Bleiglasur (Abb. 77.2-4).

Bruchstücke dünner Leistenkacheln: Eine Lösung der bei den Rahmenmotiven der Kacheln erwähnten, um einen Stab oder Ast rankenden Blattverzierung, hier aber als dünnes, selbständiges Element (Abb. 77.5). Auf der Rückseite mit einem unglasierten Plattenglied zum Befestigen, das mit tiefen, schrägen Einkerbungen versehen war. Eines braun-, das andere grünglasiert. Solche Leisten (aber buntglasiert) platzierte man am Salzburger Ofen waagerecht bzw. senkrecht zwischen den Kacheln des Ofenunterbaus.

ANHANG

\section{Keramikanalyse}

Um die verschiedenen Ofenkacheln herstellenden Werkstätten des 15. Jahrhunderts absondern bzw. vergleichen zu können, begannen wir 1992, das Keramikmaterial mittels Neutronenaktivierungsanalyse zu untersuchen. ${ }^{68}$ Für die ersten Untersuchungsreihen wurden Kacheln mit rotgebrannter Scherbe ausgewählt, da diese die überwiegende Mehrzahl der Funde bildeten. 1995/96 stellten wir die nächsten Reihen mit Kacheln aus weiß- bzw. gelblichweiß gebranntem Material zusammen - hauptsächlich aus dem ersten Drittel sowie vom Ende des 15. Jahrhunderts (unter letzteren auch die nachweislich aus dem Ausland hierher gelieferten Stücke). Leider wurde diese Arbeit noch vor Beendigung abgebrochen, so dass nur wenige Ergebnisse vorliegen.

Die sechs hier vorgestellten Proben $(A b b .78)$ :

87: Grünglasierte, weiße Scherbe; Fragment einer Frauengestalt im typischen Rauriser Stil.

88: Grünglasierte, weiße Scherbe; Rauriser Rahmenverzierung.

89: Grünglasierte Kachel mit gelbem Rand aus der 1. Rauriser Untergruppe; gut geschlämmte, weiße Scherbe.

90: Fragment einer buntglasierten Kachel (Hl. Ursula); sehr gut geschlämmte, gelblichweiße Scherbe mit gelber, grüner, weißer, blauer Glasur.

91: Fragment einer buntglasierten Kachel (zweites Exemplar der Hl. Ursula); dieselbe Scherbe mit gelblichbrauner Glasur. abgeplatzt.

92: Fragment einer grünglasierten Kachel, Gewandfalten haltende weibliche Hand; weiche, gelblichweiße Scherbe, Glasur

Nach Analysierung dieser Scherben erfolgte der Vergleich mit einer anderen Kachelreihe des 15. Jahrhunderts. ${ }^{69}$ Auf Grund der Auswertungsgraphik konnte man die Kacheln in mindestens sieben Gruppen einteilen (was die verschiedenen Fundorte bzw. Zeitabschnitte erklären: Öfen vom ersten Drittel, von der Mitte und aus dem zweiten Drittel bzw. vom Ende des 15. Jahrhunderts). - Die hier behandelten Öfen sind nur durch die sechs aufgezählten Proben vertreten. Aus diesen lässt sich bereits jetzt der Rückschluss ziehen, dass sie im Vergleich zum gesamten Material eine völlig separate Gruppe darstellen: ihr Material ist mit dem der übrigen nicht verwandt. ${ }^{70}$ Nach ihrem Vergleich sind die Proben Nr. 87 und 92 als identisch zu betrachten. Das bedeutet eines der typischen Rauriser Stücke sowie ein anderes (welches in den Kreis der unter den grünglasierten Kacheln in geringerer Zahl vorkommenden Stücken mit entwickelterer Plastik gehört, siehe dazu Abb. 27-28). In naher Verwandtschaft zu diesen stehen auf Grund des Scherbenmaterials die Proben Nr. 90-91, d. h. die von zwei verschiedenen Exemplaren der Salzburger St. Ursula-Kacheln stammenden Fragmente. Etwas entferntere Ähnlichkeit mit den anderen zeigt die Nr. 89: das buntglasierte Rauriser Randstück. ${ }^{71}$ - Die Ofenkacheln der Salzburger und Rauriser Gruppe sind also auch im Hinblick auf ihr Rohmaterial eng miteinander verwandt, was die Vorstellung einer gemeinsamen Werkstatttradition auch von dieser Seite bekräftigt.

${ }^{68}$ I. HOLL-M. BALLA: Neutronenaktivierungsanalyse mittelalterlicher Ofenkacheln. ActaArchHung 46 (1994) 381-404; I. Holl (in Anm. 54 zit. Bericht).

${ }^{69}$ Bei dieser Gelegenheit analysierte Márta Balla 26 Kachelproben und verglich sie. Der größere Teil der Kacheln wurde unter den in Buda und Székesfehérvár zum Vorschein gelangten Funden - das ganze 15. Jahrhundert repräsentierend - ausgewählt. (Einige Proben, die weitere Vergleiche zu der hier behandelten Frage ermöglichen würden, blieben leider unberücksichtigt.) Auf die Veröffentlichung der entsprechenden Vergleichsgraphik verzichte ich an dieser Stelle deshalb, weil man sie nur mit der Beschreibung nicht hierher gehörender Kacheln auswerten könnte.
${ }^{70}$ Auf ähnliche Weise wichen bei früheren Materialuntersuchungen auch die drei von dem als Ofen eines schweizerischen Meisters bestimmten Ofen stammenden Proben auffallend von den Budaer Kacheln des 15. Jahrhunderts ab. Holl-BALLA, in Anm. 55, Abb. 13 (Kacheln des „Dreikönige-Ofens“).

${ }^{71}$ Die Scherbe der Probe Nr. 88 muss wegen der größeren Menge abweichender Spurenelemente gänzlich aus dem Vergleich ausgeklammert werden. Ähnliche schwer zu erklärende Anomalien kamen im Zuge der Analysen vereinzelt auch bei anderen Kacheln vor (obwohl diese von gut bestimmbaren Öfen stammen). 
Die in der Aufarbeitung angegebenen Bestimmungen der Farbtöne sind allgemein subjektiver Natur. Die von mir im Falle der Budaer Kacheln als goldgelb bzw. ockerfarbig bezeichnete Glasur entspricht auf der international gebräuchlichen PANTONEFarbskala den Tönen E 26-2 bzw. E 7-1 und E 12-1; das Grün ist in der Regel Chromoxidgrün: E 284-2 bzw. E 273 (s. Abb. 51-52). Sehr selten ist der Ton Zinnobergrün-hell E 281-3 (Abb. 77.1) und Kadmiumgelb E 6-1 (s. $A b b$. 54, Krone). Seltener kommen das Blassblau E 226-5, 227-5 und das dunklere Preußischblau E 205-2 vor ( $A b b$. 35). - An den Fragmenten vom Salzburger Typ wurde das Gelb E 26-2 und E 9-2 bzw. das Chromoxidgrün E 273-2 und E 293-1 verwendet ( $A b b$. 72, Arm und rechte Ecke der Kachel), an den farbigen Kachelrändern sind von diesen beiden Farben die Töne E 26-2 und E 273-3 vertreten ( $A b b$. 73). Das „Tomatenrot“ am Salzburger Ofen könnte (auf Grund des Fotos) der Ton E 62-2 sein.

\section{ZUSAMMENFASSUNG}

Im Königspalast von Buda - und in anderen Residenzen - standen bis zu den sechziger Jahren des 15. Jahrhunderts die früheren, für König Ladislaus V. gesetzten Öfen. Erst zwischen 1469 und 1473 gelangte ein mit bunten Zinn- und Bleiglasuren verzierter Ofen nach Buda, und zwar von einem Meister, der den süddeutsch-schweizerischen Stilkreis kannte (der „Dreikönige-Ofen“, vielleicht als Import). In den achtziger Jahren stellte eine königliche Werkstatt in Buda neue Öfen her, bei deren Kacheln man bereits die Technik der Mischglasur anwandte. Diesen dürften nach 1485 und auch später noch die Öfen der „Rauriser Gruppe“ aus der österreichischen Werkstatt gefolgt sein. Nach 1500 lieferte die Nachfolgerin dieser Werkstatt bereits für den Palast Wladislaws II. einen Ofen. ${ }^{72}$ Die letzteren Öfen sind keine Erzeugnisse der lokalen, für den Hof - und im Laufe des ganzen Jahrhunderts mit hoher Qualität - arbeitenden Werkstätten; sie belegen das Lebensniveau und den Geschmack des Budaer Hofes von der Abnehmerseite (wie es auch in zahlreichen anderen Kunstzweigen, im Falle der Architektur, Plastik oder Kodexmalerei, geschah). - Ich denke, dass meine Forschungen die Beurteilung der Werkstatt Salzburg-Hallein in ein ganz anderes Licht rücken: Mit einem Meister, der in den siebziger?-achtziger Jahren schon herausragende Kenntnisse besaß, der die neuen technischen Verfahren des Zeitalters kannte; mit einem spezifischen neuen Stil (wobei sich zur Vorbereitung der Positive vermutlich mehrere Schnitzmeister einschalteten). Er verfügte über einen ausgedehnteren Absatzmarkt, in Ungarn standen an sieben Orten Öfen von ihm. (Diese Art der Verbreitung ist im Falle der heimischen Aristokraten und Prälaten, die der höfischen Repräsentation nacheiferten, das ganze Jahrhundert hindurch nachweisbar.) - Den späteren neuen Ofen fertigte der das Wissen der vorhergehenden Werkstatt weiterentwickelnde Meister an, auf künstlerisch und technologisch höherer Stufe - von diesem gelangte, soweit mir bislang bekannt ist, nur ein Exemplar nach Ungarn.

In Ermangelung österreichischer und ungarländischer Schriftquellen besitzen diese Erklärungen ebenso nur annähernde Gültigkeit wie auch unsere Funde nur ein Bruchteil der einstigen Vollkommenheit sind. Aus demselben Grund muss auch die Frage der die Positive der Dekorationen vorbereitenden Meister bzw. Werkstätten offen bleiben. Dass hierbei mit mehreren, auf unterschiedlichem Niveau arbeitenden Meistern zu rechnen ist, steht außer Zweifel: Einer ersetzte die plastischen Mängel bei der der dekorativen Zeichnung untergeordneten Ausarbeitung durch Abwechslungsreichtum in der Oberflächendekoration bzw. übernahm seine Komposition von Kupferstichvorbildern; ein anderer folgte den Vorbildern mit einer weiterentwickelten Lösung. Für die spätere Werkstatt war bereits ein neuer Meister tätig, der über Kenntnisse der Plastik auf künstlerischem Niveau verfügte und in einem neuen Stil arbeitete, allerdings nur im Rahmen der Aufgaben einer einzigen Bestellung.

\section{LITERATUR}

FRANZ 1969

HOLL 1983

\footnotetext{
$=$ R. FRANZ: Der Kachelofen. Graz 1969, 57-61.

= I. HOLL: Középkori kályhacsempék Magyarországon (Mittelalterliche Ofenkacheln in Ungarn) III. ArchÉrt 110 (1983) 201-230.
}

\footnotetext{
${ }^{72}$ Die bislang an zahlreichen Fundorten (Buda, Sopron, Burg Ozora, Abtei Pécsvárad, Burg Somló) zum Vorschein gelangten buntglasierten Kacheln, vermutlich aus der Zeit Wladislaws II.,
}

werden hier nicht behandelt. Sie sind teilweise zwar verwandter Prägung, aber abweichender Lösung, und gehörten zu anderen Öfen; großenteils unpubliziert. 


\section{PRODINGER 1972}

ROTH-KAUFMANN 1994

WALCHER 1905

WALCHER 1909
I. HOLL

$=$ F. Prodinger: Der Ofen in der Goldenen Stube der Hohensalzburg. Alte und Moderne Kunst 17 (Mai 1972), Hefte 124/125, 1-5.

= E. ROTH-KAUFMANN: Spätmittelalterliche reliefierte Ofenkeramik in Bern. Bern 1994.

= A. WALChER V. Molthein: Der gotische Ofen auf der Veste Hohensalzburg. Kunst und Kunsthandwerk 8 (1905) 232-243.

= A. WAlcher V. Molthein: Die deutschen Keramiken der Sammlung Figdor. Kunst und Kunsthandwerk 12 (1909) 301-362. 